\title{
Identification of the function of the carboxy terminus of AFAP-110 in regulating AFAP-110's self-association, cell localization and the integrity of actin filaments
}

\section{Yong Qian}

West Virginia University

Follow this and additional works at: https://researchrepository.wvu.edu/etd

\section{Recommended Citation}

Qian, Yong, "Identification of the function of the carboxy terminus of AFAP-110 in regulating AFAP-110's self-association, cell localization and the integrity of actin filaments" (1999). Graduate Theses,

Dissertations, and Problem Reports. 3182.

https://researchrepository.wvu.edu/etd/3182

This Dissertation is protected by copyright and/or related rights. It has been brought to you by the The Research Repository @ WVU with permission from the rights-holder(s). You are free to use this Dissertation in any way that is permitted by the copyright and related rights legislation that applies to your use. For other uses you must obtain permission from the rights-holder(s) directly, unless additional rights are indicated by a Creative Commons license in the record and/ or on the work itself. This Dissertation has been accepted for inclusion in WVU Graduate Theses, Dissertations, and Problem Reports collection by an authorized administrator of The Research Repository @ WVU.

For more information, please contact researchrepository@mail.wvu.edu. 


\title{
Identification of the Function of the Carboxy Terminus of AFAP-110 in Regulating AFAP-110's Self-association, Cell Localization and the Integrity of Actin Filaments
}

\author{
Yong Qian
}

\author{
Dissertation submitted to the \\ School of Medicine \\ At West Virginia University \\ in partial fulfillment of the requirements \\ for the degree of
}

\author{
Doctor of philosophy \\ in \\ Biological science
}

Danel Flynn, Ph.D., Chair

Wei-Shau Hu, Ph.D.

Vinay Pathak, Ph.D.

James Sheil, Ph.D.

Jeannine Strobl, Ph.D.

Department of Microbiology and Immunology

Morgantown, West Virginia

1999

Key Words: Actin Filament Associated Protein, AFAP-110, Actin Filaments, Src, Leucine Zipper Motif, Actin Binding Domain. 


\begin{abstract}
Identification of the Functions of the Carboxy Terminus of AFAP-110 in Regulating AFAP-110's Self-association, Cell Localization and the Integrity of Actin Filaments
\end{abstract}

\title{
Yong Qian
}

The actin filament associated protein of $110 \mathrm{kDa}$ (AFAP-110) is a SH2/SH3 binding partner for Src. It has two SH2 binding motifs, one SH3 binding motif, one proline rich motif, two $\mathrm{PH}$ domains and one serine/threonine substrate region at its amino terminus and has been hypothesized to function as an adapter protein that mediate the effects of different signal proteins upon actin filaments. In this report, we demonstrated: 1) AFAP-110 has the ability to self-associate through carboxy terminal interactions. Analysis of the carboxy terminus of AFAP-110 reveals a leucine zipper motif. Expression of carboxy terminus as a fusion protein (GST-cterm) can affinity absorb AFAP-110 from cell lysates, and the integrity of leucine zipper motif in GST-cterm is required for the affinity absorption. FPLC confirm AFAP-110 exists in multimeric forms from monomer to tetramer in vivo; 2) $\mathrm{Src}^{527 \mathrm{~F}}$ transformation changes the profile of AFAP-110's self-association in vivo and abrogates the affinity absorption of AFAP-110 by GST-cterm in vitro, which is independent of tyrosine phosphorylation; 3)AFAP-110 directly binds to actin filaments through its carboxy terminus. Analysis of the carboxy terminus of AFAP-110 reveals that there are two homologies with consensus actin binding domains (ABD-1 and ABD-3) between amino acids 593-637. 4) AFAP-110 has an intrinsic ability to modulate the integrity of actin filaments and to induce the formation of lamellipodia and changes in cell shape, which may be regulated by the leucine zipper motif. Taken together, these results indicate that AFAP-110 may position itself upon actin filaments through the carboxy terminal region, and the leucine zipper motif may play a regulatory role in affecting the actin filament integrity and the formation of lamellipodia in response to different cellular signals that include Src.

In addition, we mapped two monoclonal antibody reactive epitopes within AFAP110. Mab 4C3 recognized an epitope within the SH3 binding motif of avian AFAP-110 and did not efficiently react with mammalian homologoes of AFAP-110. Mab antiAFAP-110 recognized an epitope within the carboxy terminus of AFAP-110, which is conserved across the species. These two monoclonal antibodies provided useful tools to study AFAP-110. 


\section{Table of contents}

Identification of the Function of the Carboxy Terminus of AFAP110 in Regulating AFAP-110's Self-association, Cell Localization and the Integrity of Actin Filaments ................................................ i

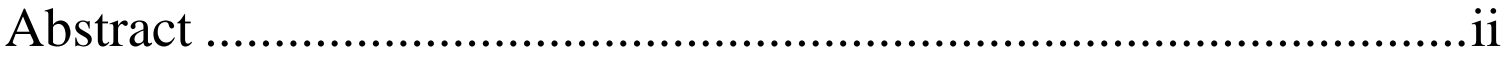

Acknowledgements .................................................................... vi

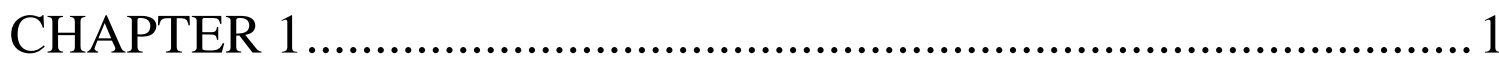

Introduction and Review of Literature.......................................... 1

I. Introduction ......................................................................................................................................2

II. Sre protein kinase ..........................................................................................................................

III. Types of actin binding protein .......................................................................................... 13

IV. AFAP-110 ....................................................................................................................... 16

V. Overall goals of this thesis................................................................................................2

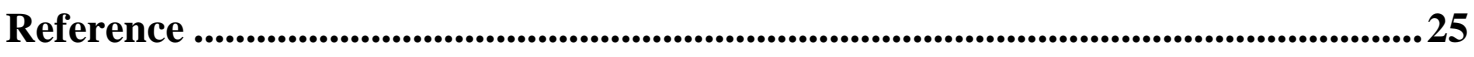

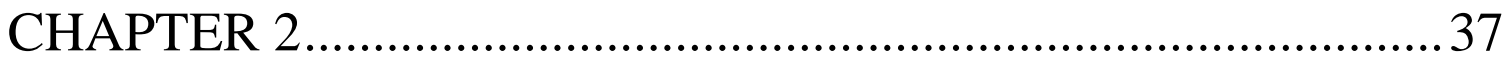

Monoclonal Antibodies Directed Against AFAP-110 Recognize

Species-specific and Conserved Epitopes........................................ 37

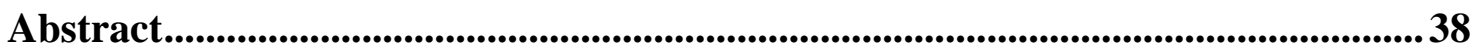

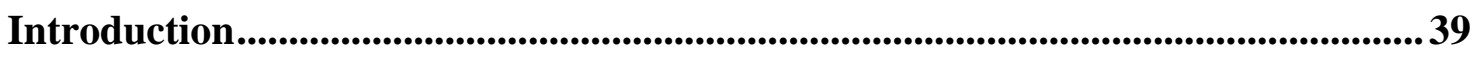

Materials and Methods......................................................................................................... 41

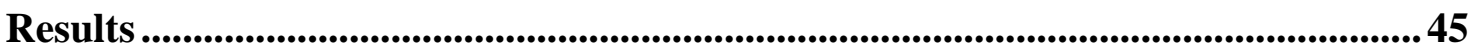

Discussion ....................................................................................................................................... 49 
Tables

Figures and Figure legends

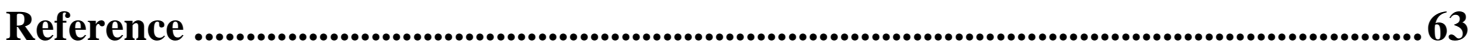

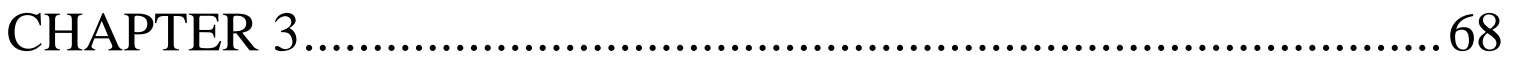

Src can regulate carboxy terminal interactions with AFAP-110, which influence self-association, cell localization and actin

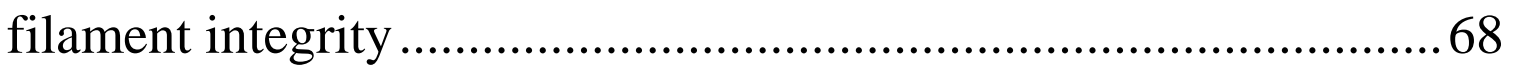

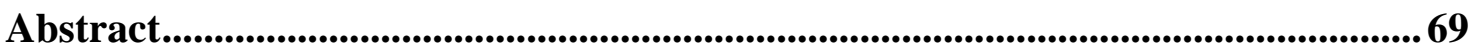

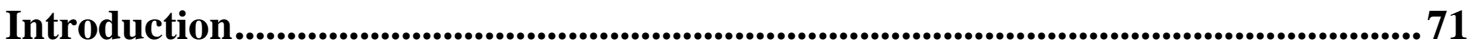

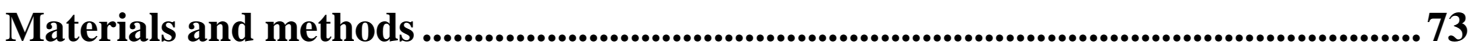

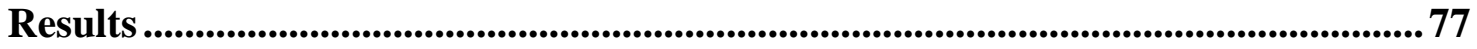

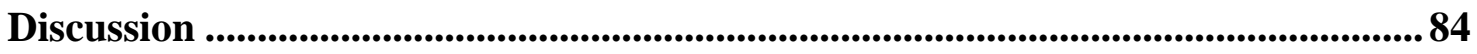

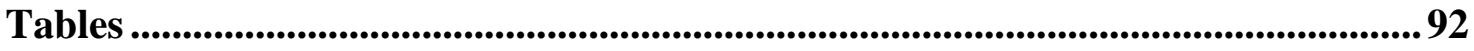

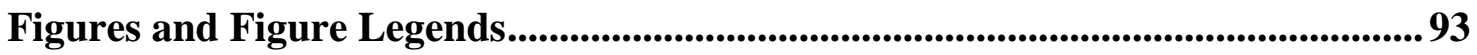

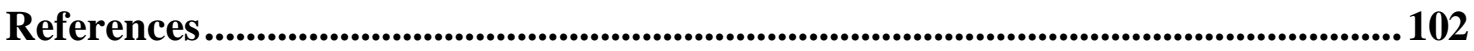

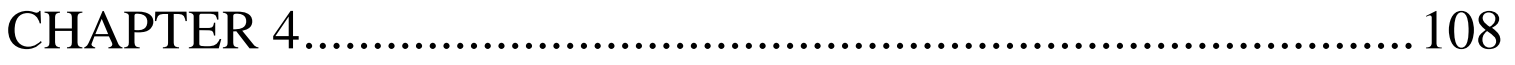

The carboxy terminus of AFAP-110 modulates interactions with actin filaments and regulates its ability to alter actin filament integrity and induce lamellipodia formation.............................. 108

Abstract ...................................................................................................................... 109

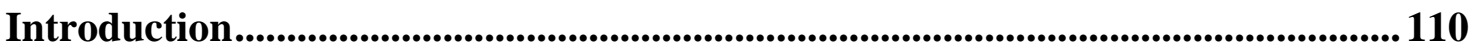

Materials and Methods................................................................................................. 112

Results ......................................................................................................................... 115 


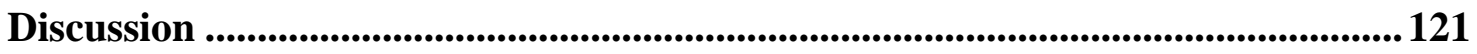

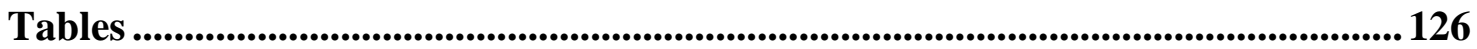

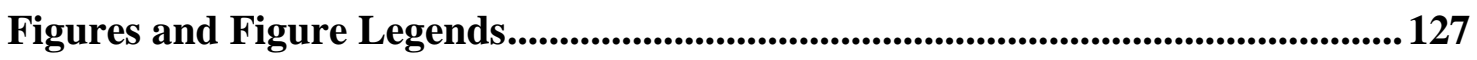

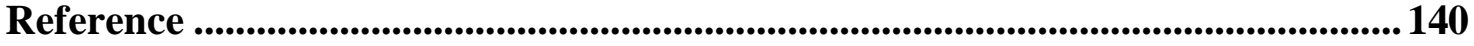

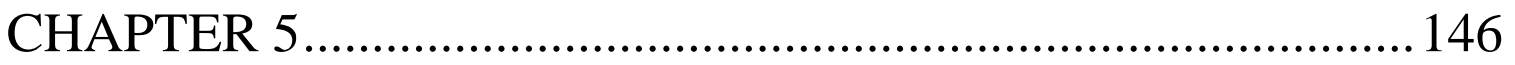

General Discussion................................................................. 146

Figures and Legends.................................................................................................................... 156

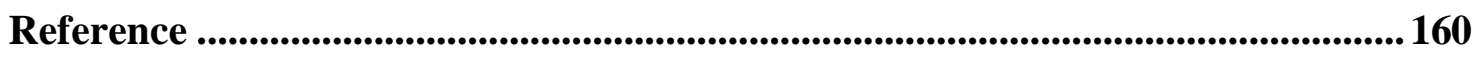

Curriculum Vitae ................................................................... 161 


\section{Acknowledgements}

I wish to express my great appreciation and indebtedness to my advisor, Dr. Daniel Flynn, for his whole-hearted support and great patience. It is his helpfulness, encouragement and scientific training that helped me to complete this thesis.

I would like to extend my appreciation and indebtedness to my committee members, Dr. Wei-Shau Hu, Dr. Vinay Pathak, Dr. James Sheil and Dr. Jeannine Strobl for their valuable discussion and advice.

I would like to thank all the laboratory colleagues of the Flynn Lab, Joe Baisdan, Thomas Brown, Lidia Cherezova, Anne Guappone and Justin Summy, and my close friends for their helpfulness and friendship.

Finally, I would especially like to thank my son Ruiqi Qian, my girlfriend, my parents, brother and sister for their understanding, sacrifice and support. 


\section{CHAPTER 1}

Introduction and Review of Literature 


\section{Introduction}

\section{Actin filaments}

Actin is one of the most abundant protein in eucaryotic cells. Each actin monomer (G-actin) has 375 amino acids and has a tightly bound ATP. The actin monomers are polymerized to form actin filaments (F-actin), and the polymerization of actin is associated with hydrolyzing ATP to ADP. Actin filaments form a polar structure and its plus (barbed) end is the fast growing end while its minus (pointed) end grows or elongates much slower. The basic structure of actin filaments is identical, and it is the actin binding proteins that create the diverse forms of actin filaments in eucaryotic cells. There are two major forms of actin filaments, in vivo: stable and labile actin filaments. The stable actin filaments form the core of microvilli, the contractile apparatus of muscle cells and main structural components for cell shape while the labile actin filaments are involving in many cell processes especially cell movement. (Albert et al, 1994).

In vivo, actin filaments are tightly regulated by actin binding proteins. They are under continuous cycles of polymerization and depolymerization, and undergo constant changes in cellular localization and organizations. They are involved in a wide variety of cellular processes, including the cell motility, cell shape changes during mitosis, cell contractile activities, cell-cell/cell-substrate interaction, mRNA localization, cell signal transduction and endocytosis (Schmidt and Hall, 1998). Information has emerged tremendously that there are a lot of clinical diseases that are directly related to the abnormalities of either expression or localization of actin filaments and actin binding 
proteins (Janmey and Chaponnier, 1995), especially in cardiomyopathies, the abnormalities of actin filaments and actin binding proteins have been identified to be the main cause for the diseases (Towbin, 1998).

\section{Rho-GTPase in the regulation of actin filaments}

Actin filaments function in the different cell processes through constant rearrangement and remodeling. The rearranged actin filaments form several discrete structures at the cell periphery for attachment to the substratum in response to extracellular signals. These discrete structures are focal adhesions, stress fibers, lamellipodia, filopodia and membrane ruffles (Hall, 1998; Thomas and Brugge, 1997). The formation of these structures can be regulated by Rho-like GTPases (Hall , 1994). Rho-like GTPases are the main regulatory proteins to link both extracellular and intracellualr signals to actin filaments (Schmidt and Hall, 1998). They can be divided into five groups in eucaryotic cells. All of them function as binary switches: GTP-Rho-like GTPases active form and GDP-Rho-like GTPases inactive form. The main Rho-like GTPase proteins that are involved in regulating actin filaments are Rho, Rac and CDC42 (Schmidt and Hall, 1998).

Rho regulates the formation of stress fiber and focal adhesion upon growth factor induction (Ridney and Hall, 1992). The stress fibers are the bundles of actin filaments associated with myosin and some other actin binding proteins. One of the main functions of stress fibers is contractility. The accumulation of stress fibers upon Rho stimulation is essential in small muscle cell contraction (Hirata et al, 1992). The focal adhesion is a structure by which cells attach to the extracellular matrix and is rich in stress fibers, 
intergrin and some actin binding proteins. Its' main function is to provide cells with adhesive points to extracellular matrix, as the name implies, and also to mediate cell signal transduction, migration and apoptosis (Taylor et al, 1998). Rho also has the ability to stimulate the polymerization of F-actin from new nucleation sites at the cell periphery, indicating Rho could have the ability to induce the formation of lamellipodia as well (Adam et al, 1996).

Rac is the second main Rho-like GTPase protein that regulates actin filaments. Rac is involved in regulating the formation of lamellipodia and membrane ruffles through stimulation of newly polymerized actin filaments adjacent to the plasma membrane in most cells stimulated by growth factors (Tapon and Hall, 1997; Mitchison and Gramer, 1996). The main function of both lamellipodia and membrane ruffle is to migrate cells in response to the cell signals. The lamellipodia are the cell membrane protrusions at the leading edge of migrating cell, which gives cells more adhesive contacts to the substratum. They are full of meshwork of actin filaments, and the polymerization of actin filaments is very active and dynamic within lamellipodia (Welch et al, 1997). The structure of membrane ruffles is similar to lamellipodia, with the difference being that the membrane protrusions of membrane ruffles are upwards from the dorsal surface of the cells (Ridley et al, 1999).

CDC42 stimulates the formation of filopodia (Allen et al, 1997). Filopodia are similar to the lamellipodia in both structure and function. They are tiny membrane protrusions compared to the lamellipodia, and extend from the leading edge of migrating cells and adhere to the substratum (Lauffenurger and Horwitz, 1996). 
It is not too clear how cell signals stimulate these Rho-like GTPases and thereafter the activated Rho-like GTPases affect actin filaments. Several protein kinases and cellular proteins have been identified that bind to Rho-like GTPase in a GTP dependent way and transfer the signals to actin filaments (Aelst and D'Souza-schorey, 1997). Ser-Thr kinase $\mathrm{p} 160^{\mathrm{ROK}}$ has been shown to interact with Rho, and either overexpression or constitutive activation of $\mathrm{p} 160^{\mathrm{ROK}}$ can mimic Rho activities in vivo (Leung et al, 1996). ERM (ezrin, radixin and moesin) has been proposed to serve as regulatory scaffold protein to anchor both actin filaments, and Rho and Rac (Hall A, 1998). Recently, both Ser-Thr kinase $\mathrm{p} 65^{\mathrm{PAK}}$ and PIP5-kinase have been reported to be potential Rac target proteins (Tapon et al, 1998). Rho-like GTPases influence actin filaments through multimolecular complexes and there are lots of cross-talk and redundancy among them. Identification of the individual component among these multimolecular complexes will lead to an understanding of the fundamental cellular processes to regulate the functions of actin filaments (Hall, 1998).

\section{Changes of actin filaments in tumor cells}

Changes in cell shape and morphology are characteristics of tumor cells. Cell shape is governed by actin filaments and their associated proteins (Ben-Ze'ev, 1985). In the process of malignant transformation, the change in cell shape could be the first phenomena (Holme, 1990). In most tumor cells, the pathological changes are directly related to the alteration of actin filament integrity. The actin filaments undergo tremendous rearrangement and remodeling upon either RNA or DNA tumor virus infection, or chemical carcinogen treatments (Carley et al, 1981). The typical example is 
Src transformation. It decreases actin filament bundles, alters the integrity of actin filaments into dot or rosette like structure and induces the formation of lamellipodia (Felice et al, 1990; Wang et al, 1976).

In neoplastic cells, the disordered motility is concomitant with the changes of actin filament structures at the lead edge of malignant cells, which showed the increased numbers of membrane ruffle and focal adhesion (Gabbiani and Gocher, 1983). In the development of colon carcinoma, the transition of noninvasive benign colonic tumors to invasive malignant tumors is marked with the loss of actin filament organization. The benign colonic tumors, adenomas, have highly organized actin filaments and the actin filaments are disrupted when adenomas become malignant adenocarcinomas.

Furthermore, the actin filaments undergo rearrangement and remodeling when the preneoplastic cells from the benign adenomas are treated with tumor promoters in cell culture. It was thought that the disrupted actin filaments enabled colonic carcinoma cells to be more deformable and would more easily penetrate the surrounding tissue (Friedman et al. 1984). Reverse experiments showed that a decrease in the tumorigenicity of rat mammary tumor cells was concomitant with partial restoration of integrity of actin filaments and cell surface fibronectins (Paulin et al, 1979).

Genetic studies found the alteration of cell morphology in transformed cells was often accompanied with the decreased expression of actin binding proteins, such as thymosin, tensin, vinculin, tropomyosin, merlin, gelsolin and 1-plastin. The restore or increase of the expression of these actin binding proteins reverts or suppresses the malignant phenotype of cells (Janmey and Chaponnier, 1995). 


\section{Src protein kinase}

\section{Structure of Src protein kinase}

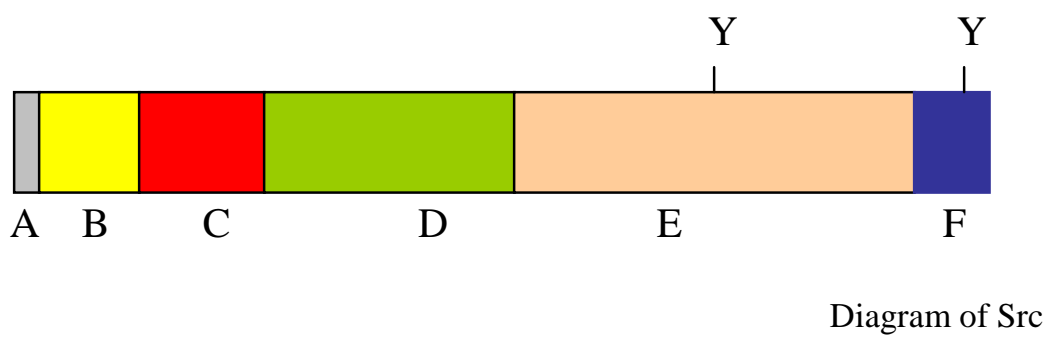

c-Src is the one of the non-receptor tyrosine kinases. It is a proto-oncogene that functions in the regulation of cell differentiation and proliferation (Brown and Cooper, 1996). It is composed of several functional domain structures. At the N-terminus, there is a myristylation domain (A), which permits c-Src to associate with cell membrane. The membrane association is necessary for both cell signal transduction and transformation (Kamps et al, 1986). Downstream of the myristylation domain is a unique domain (B), which is the most diverse domain among Src family membranes. Its function is unknown, however, some researchers hypothesized that it might act as a space to give other Src protein domains a convenient distance from the cell membrane or it might be important for the potential interactions between Src and other cellular proteins (SupertiFurga and Courtneidge, 1995). The protein interaction domains are located downstream of the unique domain and are composed of SH3 domain (C, Src-homology 3) and SH2 domain ( D, Src-homology 2). These domains play a major role in regulating Src protein 
functions. Both SH3 domain and $\mathrm{SH} 2$ domain function in the protein-protein interactions and are conserved among Src family proteins. The SH3 domain recognizes a proline-rich motif (Pawson and Schlessinger, 1993; Morton and Campbell, 1994). The SH3 domain frequently exists in the proteins which are involved in the interactions with the cytoskeleton and cell membrane (Drubin et al, 1990; Rodaway et al, 1989). Some experimental data suggest that the SH3 domain may interact with the guanine nucleotide exchange factors and the GTPase-activating protein, and may link Src to the small Raslike guanine nucleotide-binding (G) protein (Pawson and Gish, 1992). The SH2 domain specifically binds to tyrosine phosphorylated proteins when these phosphotyrosines are within a specific amino acid sequence (Pendergast et al, 1991; Pawson and Gish, 1992). Downstream of the homology domain is a kinase domain (E) that is a catalytic domain of Src protein. There are ATP binding sites and the tyrosine autophosphorylation sites within this kinase domain (Parsons and Weber, 1989). c-Src has a C-terminal regulatory domain $(\mathrm{F})$ that is responsible for the negative regulation of cSrc activity by Csk in vivo. This domain has 19 amino acids and contains a regulatory tyrosine residue at amino acid 527. The phosphorylation of Tyr-527 by c-terminal Src kinase (Csk) results in the interaction between phosphorylated Tyr-527 and its own SH2 domain, and this intramolecular interaction forces c-Src to adopt the conformation to mask the kinase domain, which keeps c-Src enzymatically inactive (Courtneidge, 1985; Cooper and Howell, 1993; Superti-Furga et al, 1993). Mutation at Tyr-527 to phenylanine creates a constitutively activated Src kinase that is sufficient to transform the cells (Parsons and Weber, 1989). 


\section{Oncogene v-Src}

$\mathrm{v}-\mathrm{Src}$ is encoded by Rous Sarcoma Virus. It is a mutant form of c-Src without the c-terminal negative regulatory domain. It is an active tyrosine kinase. vSrc transformation increases the steady state levels of cellular tyrosine phosphorylation (Parsons and Weber, 1989). vSrc exhibits tyrosine kinase activity both in vivo and in vitro and is sufficient to transform cells to become tumors (Jove and Hanafusa, 1987). Therefore, vSrc is an onco-protein.

\section{c-Src in cell signal transduction}

c-Src plays a major role in normal cell signal transduction. It is involved in the growth factor receptor tyrosine kinases (RTK) mediated signal transduction. The autophosphorylated RTKs recruit and activate c-Src upon the binding of growth factors. The activated c-Src might phosphorylate Shc, and then recruit Grb2 and Sos to activate the Ras pathway ( McGlade et al, 1992; Lutterll et al, 1996). c-Src can mediate intergrin activated Ras pathway. The autophosphorylated intergrin recruits and activates FAK (focal adhesion kinase) and c-Src upon the binding of fibronectin, and then the activated c-Src eventually initiates activation of the Ras pathway (Schlaepfer and Hunter, 1996). c-Src also links G protein coupled receptors to the Ras pathway through Shc or Pyk2 (Luttrell et al, 1996; Dikic et al, 1996). Recently, it was found that c-Src could activate c-Myc via a Ras independent pathway (Barone and Courtneidge, 1995). c-Src may be transiently activated when fibroblast cells go from $\mathrm{G}_{2}$ to $\mathrm{M}$ phase, and microinjections of antibodies directly against to cSrc, and its relative kinases arrest fibroblast cells at $\mathrm{G}_{2}$ phase (Roche S, 1995), indicating c-Src may be involved in the control of cell cycle ( 
Taylor and Shalloway, 1996). It was found that c-Src could regulate EGF induced actin filament dissembly and reassembly through the phosphorylation of p190RhoGAP (Chang et al, 1995). There are some clues that c-Src may be directly involved in the NF$\mathrm{kB}$ activation through the tyrosine phosphorylation of IkB- $\alpha$, which causes the dissociation of IkB- $\alpha$ from the NF-kB and activates the NF-kB pathway (Imbert et al, 1996; Eicher et al, 1994).

\section{Phenotype change of Src transformation}

Activated variants of Src, both v-Src and constitutively activated cSrc, are sufficient for transformation. There is a theory that transformation by Src is due to the up regulation of normal c-Src induced signal pathways (Brown and Cooper, 1996). There are five phenotype changes upon Src transformation: 1) The cell's cytoskeleton is disrupted and reorganized; 2) The cell's growth characteristics are changed. The requirement for serum in culture is reduced, and the density dependent growth regulation is lost, and, as a consequence, the Src transformed cells are able to grow to a high cell density; 3) The cell's extracellular matrix is changed, the cells are able to grow in suspension or semi-solid medium, and don't need to attach to the substratratum to grow; 4) A lot of gene expression levels are changed; 5) Intercellular communication is decreased (Parson and Weber, 1989; Jove and Hanafusa, 1987).

\section{Src transformation changes the integrity of actin filaments}

The activities of Src are related to the rearrangement of actin filaments. During $\mathrm{G}_{2} / \mathrm{M}$ cell cycle transition, cSrc is transiently activated and at the same time the bundles 
of actin filaments are relaxed and rearranged (Jackson et al, 1989). Upon stimulation by growth factors, the transient increase in kinase activity of $\mathrm{cSrc}$ is concomitant with an increase in cell motility that is related to the rearrangement of actin filaments (Belsches et al, 1997; Broome and Hunter, 1996). cSrc is involved in the formation of receptorinduced lamellipodia, filopodia and member ruffle (Thomas and Brugge, 1997). cSrc knockout cells lack both lamellipodia and member ruffle, and reintroduction of either cSrc or kinase-defective mutant cSrc into these cells are able to fully rescue both lamellipodia and membrane ruffle structures (Boyce et al, 1992; Schwartzberg et al, 1997). These indicate that cSrc may have the ability to regulate the rearrangement and remodeling of actin filaments via protein interactions.

Src transformation is partially characterized by the disruption of actin filaments (Felice et al, 1990; Reynolds et al, 1989). Src transformation induces the formation of lamellipodia and increases cell motility (Thomas and Brugge, 1997). Studies found Src transformation reduced actin filament bundles, decreased the expression of stress fibers and disrupted the integrity of actin filaments. Using electronmicroscope techniques, Boschek et al, found that during the early stage of Src transformation, the cells protruded on the dorsal cell surface as ruffle-like flowers that were full of actin filaments and actin binding proteins, and after a while the stress fibers disappeared and the cells rounded up (Boschek et al, 1981).

The changes in integrity of actin filaments in Src transformation are due to the reorganization of actin filaments, instead of depolymerization of F-actin into G-actin. Using ts-mutant Src, Felice et al, found that the amount of F-actin in cells was unchanged between permissive (transforming ) and restrictive (nontransforming) temperature, and 
the loss of microfilament bundles and stress fibers was due to the reorganization of polymeric actin (F-actin) to other polymeric forms (Felice et al, 1990). Holme found that the formation of punctate filament aggregates was associated with the incorporation of actin into the actin filament core fraction in Src transformation (Holme et al, 1986). Src transformation may change the actin filaments in three ways: 1) structural crosslinking is reduced, 2) actin filament lengths are shorter and 3) the membrane association is weaker (Felice et al, 1990).

The mechanisms by which Src affects the actin filaments is not clear. There are several Src substrates that may be involved in mediating the effects of Src upon actin filaments. The Src substrate cortactin may be one of these candidates. It is an F-actin cross-linking protein and is enriched in lamellipodia and membrane ruffles. In vitro, both cortactin's F-actin cross-link and binding activities are reduced upon tyrosine phosphorylation of cortactin by Src. (Huang et al, 1997). Another Src substrate is vinculin. It is an actin binding protein and attaches actin filaments to the plasma membrane. Research found that tyrosine phosphorylation of vinculin by Src might have some functional roles in the disruption of actin filaments, and the changes of cell shape and adhesion (Sefton et al, 1981). Gelsolin is the most thoroughly studied actin binding protein. It is an actin filament severing, capping and nucleation protein. It is also a PIP2dependent substrate of Src, and PI 3 kinase associated gelsolin can form a stable complex with Src. Gelsolin severs the assembled actin filaments, caps both free actin (filaments) and newly severed actin filaments. The activity of gelsolin is regulated by $\mathrm{Ca}^{2+}, \mathrm{Mg}^{2+}$ binding and phosphoinositides. It has been hypothesized that Src might have some 
regulatory roles in gelsolin mediated dynamic changes of the integrity of actin filaments (Kwiatkowski DJ, 1999; De Corte et al, 1997 and 1999).

\section{Types of actin binding protein}

There are enormous amounts of actin binding proteins in eukaryotic cells, and they play major roles in a wide variety of cell processes in vivo. Functionally, the actin binding proteins can be divided into two major catalogs: regulatory proteins which are involved in the regulation of dynamic assembly and disassembly of actin filaments, and structural proteins which are involved in stabilizing actin filaments and constructing cell structures (Ayscough KR, 1998). Some examples include tropomyosin, which binds along with actin filaments to mediate cell movement; fimbrin, which cross-links and bundles actin filaments to form high order structure; ABD-120, which cross-links actin filaments to form gel-like networks; myosin, which binds actin filaments to involve in cell contraction and profilin, which binds to G-actin to sequest G-actin and to regulate actin polymerization. Both capping protein (CP) and gelsolin cap and sever actin filaments to regulate the growth rate of actin filaments (Ayscough KR, 1998). I will summarize the types of actin binding proteins into three major classes same as the order of recent review papers (Taylor et al, 1998; Puius et al, 1998; Ayscough KR, 1998).

\section{Actin cross-linking proteins}

Actin cross-link proteins usually bind to and cross-link actin filaments by using two discrete actin binding domains to control cell morphology and motility. Some of 
these proteins themselves have two actin binding domains like fimbrin, and some proteins have only one actin binding domain and create two actin binding domains by forming non-covalent dimers, like $\alpha$ actinin and ABP-120. These proteins share a common actin binding domain that contains 250 amino acids and is composed of two tandem repeat calponin homology $(\mathrm{CH})$ domains and a helix connector. Each $\mathrm{CH}$ domain is composed of six helical structures (Castresana and Saraste , 1995). The two actin binding domains are tightly linked to each other. Fimbrin's two actin binding domains are closely located on the same polypeptide chain in a tandem manner, and both $\alpha$-actinin and ABD-120 form homodimers and two actin binding domains are tightly bound to the dimerization core structure that is arranged in head-to-tail fashion. These topologies rigidly pack the cross-linked actin filaments when two actin binding domains bind to actin filaments individually (Puius et al, 1998).

These actin cross-linking proteins not only direct the construction of actin filament network, but also involve in regulating cellular functions, which are modulated by the concentrations of cross-link proteins and calcium (De Arrudea et al, 1990).

\section{Actin severing and capping proteins}

Both actin severing and capping proteins are the most dynamic actin binding proteins to regulate the assembly and disassembly of actin filaments in vivo. There are two major families: gelsolin family and cofilin family. Their functions are regulated by calcium, polyphosphoinositdes and pH (Puius et al, 1998). Structurally, they share a 15 $\mathrm{kDa}$ common actin binding domain. The secondary structure of this actin binding domain is known. It is composed of a central five stranded $\beta$-sheets, flanked by a 
paralleled long helix. There is a short helix located perpendicularly against the central $\beta$ sheets (Puius et al, 1998). Usually, these proteins have three to six repeat $15 \mathrm{kDa}$ actin binding domains, which are coordinately involved in several different functions.

\section{G-actin binding proteins}

Examples of G-actin binding proteins are profilin and gelsolin. They regulate actin filaments through monomer sequestration, nucleation and catalytic enhancement of ADP/ATP exchange. There is no clear sequence identity of actin binding domains among profilin family members, but it was found that the overall structure of actin binding domains of the profilin family were the same as the secondary structure of gelsolin's $15 \mathrm{kDa}$ actin binding domain modular (M Van Troy et al, 1999; McLaughlin and Weeds, 1995). Interestingly, profilin can bind to proline rich sequence in actin filaments and competitively bind to other proline rich sequences with SH3 and WW domains in vitro. It implies that profilin may be involved in transferring multiple signals from SH3 and WW domain containing proteins to actin filaments (Mahoney and Almo, 1998).

\section{Consensus sequences for actin binding domains (Taylor et al, 1998)}

Actin binding domain-1 (ABD-1) is a conserved 26 amino acid sequence among actin binding domain of actin cross-link proteins. In vitro studies found the polypeptide representing this conserved sequence is sufficient to bind to actin filaments $\left(\mathrm{K}_{\mathrm{d}} 4 \mu \mathrm{M}\right)$. The actin cross linking proteins that have this consensus sequence are spectrin, dystrophin, fimbrin, filmin and tensin (see Table 1 of Taylor et al, 1998). 
Actin binding domain-2 (ABD-2) is a conserved basic amino acid sequence $(\mathrm{KYKXL} ; \mathrm{K}=\mathrm{K} / \mathrm{R})$ among actin binding domains of capping proteins and $\mathrm{G}$-actin binding proteins. The actin binding proteins that have this consensus sequence are radixin, tensin, talin, capping protein (CP), gelsolin and profilin (see Table 1 of Taylor et al, 1998).

Actin binding domain-3 (ABD-3) has a consensus sequence KLKR. It exists in some F-actin binding proteins such as VASP, vinculin, thymosin $\beta 4$, villin and dementin (see Table 1 of Taylor et al, 1998).

\section{AFAP-110}

\section{Structure of AFAP-110}

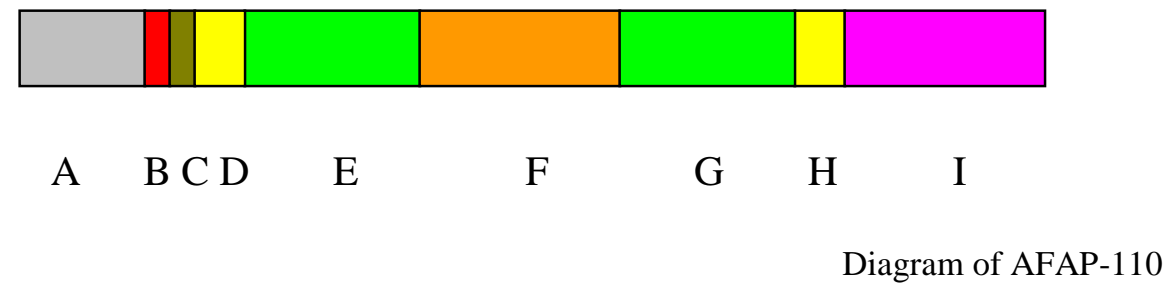

AFAP-110 is an acronym for an actin-filament-associated protein of $110 \mathrm{kDa}$. It has 637 amino acids and is composed of several protein signaling motifs (Flynn et al, 1993; Qian et al, 1998). Fragment A (between amino acid 1-61) has an unknown function. Fragment B (between 62 and 71) is a SH3 binding motif. The SH3 binding domain is defined as proline-rich sequences of 10 amino acids in length (Ren et al, 1993). There is a conserved a PXXP structure at the $7-10^{\text {th }}$ residues within the proline 
rich motif, forming ppII helix. The two conserved prolines directly bind to the SH3 domain of Src, and other residues serve as a molecular scaffold to promote the formation of the ppII helix (Yu et al, 1994). The two XX residues are generally composed of hydrophobic residues. Fragment $\mathrm{C}$ (between 75 and 84 ) is a proline rich sequence and a possible WW domain binding site (Sudd, personal communication). There are two SH2 binding motifs in AFAP-110 (D and H, between 85-152 and 450-510) (Guappone et al, 1998). The first proposed Src family SH2 binding motif was $\mathrm{Y}^{\mathrm{P}} \mathrm{XEI}$ (Cantley et al, 1991). Later it was found that the unique sequence of the Src SH2 binding motif was pTyr-x-x, here at least one $x$ residue is acidic and hydrophilic(Songyang et al, 1993). Recently, it was confirmed that the Src SH2 binding motif was $\mathrm{Y}^{\mathrm{P}}$-AEI (Eide et al, 1995). There are two pleckstrin homology (PH) domains (E and G, between 153-248 and 347450) (Gibson et al, 1994; Shaw, 1996; Ma et al, 1997). The PH domain was originally named for the pleckstrin. Both the pleckstrin's $\mathrm{N}$ and $\mathrm{C}$ termini are the prototypes of the PH domain and they are about 100 amino acids in size (Musacchio et al, 1993). This domain is mainly found in signaling and cytoskeleton proteins. Many Ser/Thrphosphorylated proteins, such as pleckstrin and spectrin, have this domain (Gilson et al, 1994). Its function is not clear, but it was proposed that it might interact with the plasma membrane, the organeller membranes, the $\beta \gamma$ - complexes of heterotrimeric $\mathrm{G}$ protein and the protein kinase $\mathrm{C}$ (Gibson et al, 1994). Some researchers found that the PH domain could recognize the short peptide chains with phosphorylated serine and/or threonine residues (Fowler and Adam, 1992). Between the two PH domains of AFAP-110, there is a serine/threonine kinase substrate region (F, between 210-360) (Flynn et al, 1993). This region is rich in serine and threonine residues. Of these serine and threonine residues, 15 
are postulated to be the phosphorylation sites of protein kinase C. The presence of this region indicates that AFAP-110 may be a substrate of protein kinase $\mathrm{C}$ and other serine/threonine kinase. At the C-terminal domain (I, between 511-637), there is a Leucine zipper motif (Qian et al, 1998)and two actin binding domains (ABD-1 and ABD3) (Qian et al, submitted).

\section{Leucine Zipper Motif}

Leucine zipper motif was first discovered in dimerized DNA binding proteins in 1988 (Landschultz et al, 1988). Later it was found in both transcription factors and cytoskeleton proteins ( Hurst, 1994). It is composed of two amphipathic, right handed $\alpha-$ helices. It was first hypothesized that the leucine zipper motif functions through its two helical side chain interaction with each other to form zipper like structure and later nuclear magnetic resonance and X-ray studies confirmed the leucine zipper motif existed as the coiled coil structure (Oas et al, 1990; O'SHEA et al, 1991). The difference between the general coiled coil structure and the leucine zipper motif is that the leucine zipper motif has the highly conserved leucine residues while the general coiled coil structure substitutes these conserved leucines with other hydrophobic residues (Kouzarides et al, 1991).

The leucine zipper motif is composed of two right handed $\alpha$-helices, and each of $\alpha$-helix is composed of $30-40$ amino acids and contains a repeating heptad pattern of sequence designated by amino acid positions (abcdefg)n ( Alber, 1992). The general right handed $\alpha$ helix is usually composed of 3.6 residues per turn while the right handed $\alpha$ helix of leucine zipper motif undergoes a twist in a left hand fashion. Thus, there are 
3.5 residues per turn in the right $\alpha$-helix of leucine zipper motif, and two turns constitute one heptad repeat (Lupas, 1996). The conserved hydrophobic leucine is always at position $\mathbf{d}$ and the alternate hydrophobic residue is located at position a ( see diagram below) (Alber, 1992). These alternated hydrophobic resides are often composed by $\beta$ branched amino acids: valine, threonine and isoleucine (Alber, 1992). So each conserved leucine residue locates three residues after and four residues before the alternate hydrophobic residue, and, as a result, forms $4 / 3$ hydrophobic residue repeats (Hodges, 1992). These bulky hydrophobic residues form a continuous hydrophobic core structure and their side chains are buried inside (O'Shea et al, 1991). With the above basic sequence structure, the leucine zipper motif forms the coiled-coil structure by hydrophobic force.

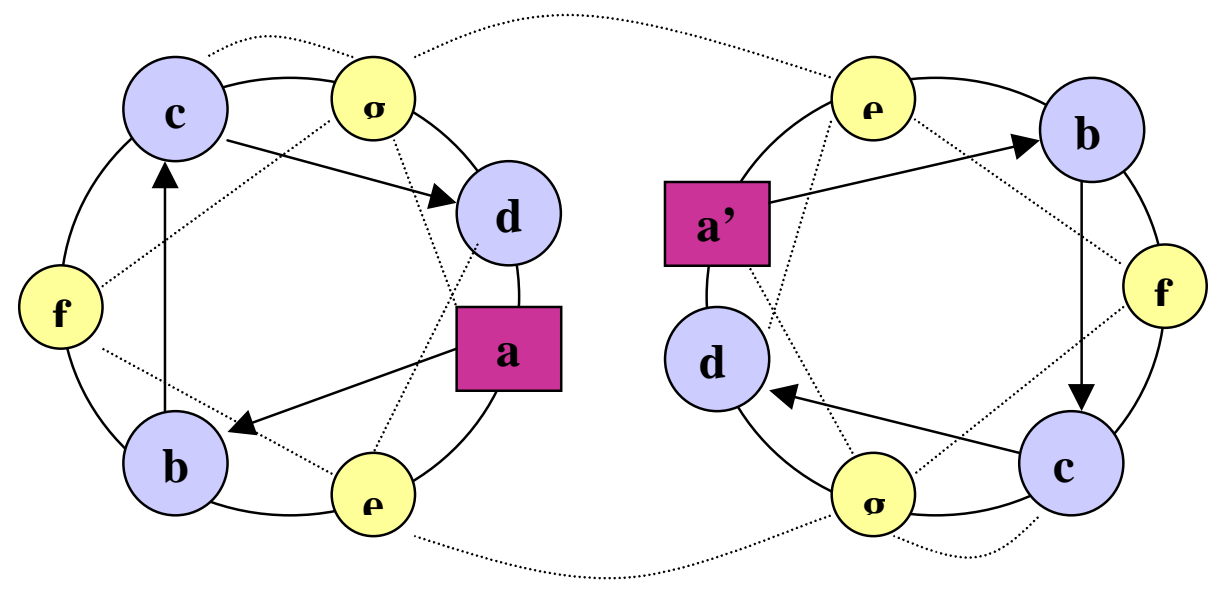

Diagram of the leucine zipper motif (modified from Alber, 1992) 
There are some intra- and inter-ionic interactions that contribute to the stabilization of the dimer. The ionic attractions and repulsion between g-e' and e-g' help to maintain the dimerization, and the zero net charge between two monomers' inner faces favored the dimerization too (see diagram above) (Stone et al, 1978; O'Shea et al, 1992). The amino acids (g) ahead of the alternative hydrophobic residues and the amino acids (e) after the next conserved leucines are opposite charged (Letai and Fuches, 1994). These opposite charged residues are spaced by exactly four residues. Biochemical studies found that they could form intra ion pairs within the helical monomer, and also form inter ion pairs between the two monomers (Letai and Fuches, 1994).

There is a conserved polar residue, asparagine, in the center of the leucine zipper motif and it is usually located at the alternate hydrophobic position a (Alber, 1992). This asparagine has three important functions (Alber, 1992): First, this asparagine creates the force to maintain the helices to be parallel and in register; Second, the interaction between this asparagine and another polar residue of binding partner determine the specificity of dimerization; Third, this asparagine also destabilizes the dimer, as the replacement of Asn16 in the GCN4 leucine zipper by valine dramatically stabilizes the dimerization. It was thought that this destabilization could allow for more rapid reassortment of dimer proteins.

The leucine zipper motif is involved in both homo- and hetero-dimerization, and the dimers can be in either parallel or antiparallel fashion. If the dimer is formed in parallel, the conserved leucine (d) interacts with another monomer's alternate hydrophobic residue (a') and, at the same time, the another monomer's conserved 
leucine (d') contacts with its counterpart (a). If the dimer is formed antiparallel, $\mathbf{d}$ and $\mathbf{a}$ interact with d' and a', respectively (see diagram below) (Alber, 1992).

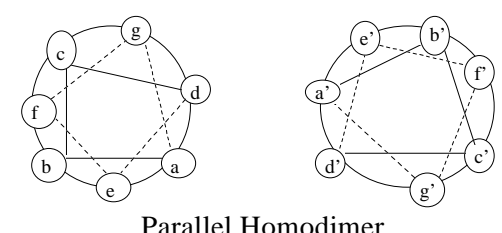

Parallel Homodimer

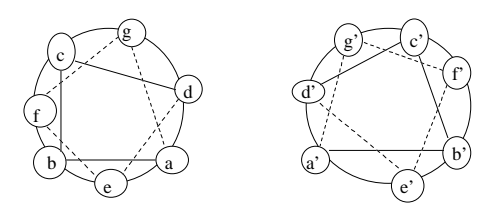

Antiparallel Homodimer

Diagram of homodimerization of the leucine zipper motif

Leucine zipper motif plays a major role in the formation of keratin filaments, neurofilament and vimentin filaments. All of them have the same basic structure that is consisted of several long leucine zipper motifs and some short irregular regions interspersed within these long leucine zipper motifs (Steinett et al, 1994). Each protein subunit first interacts with each other to form dimers through leucine zipper motifs, and then the leucine zipper motifs within the dimers mediate the formation of bundle filament structures that are in antiparallel and axial register (Parry et al, 1985; Kouklis, 1992).

Leucine zipper motifs can function as the structural linkers for the cellular apparatuses from different cell compartments. One example is the complicated interactions of tropomyosin, troponin $\mathrm{T}$, myosin and dystrophin. Both the tropomyosin and the myosin are actin binding proteins, troponin $\mathrm{T}$ is a skeletal muscle protein and dystrophin is a muscle-membrane cytoskeleton protein. All of these proteins have leucine zipper motifs and form homodimers. They interact with each other to form heterodimers through the leucine zipper motifs. The tropomyosin interacts with the 
troponin $\mathrm{T}$ through their leucine zipper motifs and this tropomyosin:troponin $\mathrm{T}$ complex regulates the myosin's binding to the actin filaments in $\mathrm{Ca}^{2+}$ dependent manner (Hitchcock-DeGregori and An, 1996). The dystrophin dimerizes with both the oligomeric, membrane-spanning protein complex ( $\beta$-dystroglycan, syntrophine and $\alpha$ dystroglycan) and troponin $\mathrm{T}$ through the leucine zipper motifs to link the muscle cell membrane to the contractile apparatus (Blake et al, 1995 and Pearlman et al, 1994). Zipper protein is a newly cloned tropomyosin like protein. There is a leucine zipper motif in its cytoplasm tail. The leucine zipper motifs mediate the binding of brush-border myosin to the actin filaments at the intestinal brush border same as the tropomyosin regulates the actin filament-myosin interactions (Bikle et al, 1996).

Leucine zipper motifs are also involved in the intercellular junctions. Desmoplakin is one of major component proteins within desmosomes. It links many cells together through the association with intermediate filaments among adjacent cells. The main force to mediate this interaction is the leucine zipper motif that locates at the nterminus of desmoplakin. Desmoplakin has a long leucine zipper motif and the conserved charged amino acids within the long leucine zipper motif form the heptad charge repeats. The heptad charge repeats of amino acids match well with that of the intermediate filaments, and the electoral interactions are then formed to link the desmosomes to the intermediate filaments (Green et al, 1990).

\section{AFAP-110 may mediate the effect of Src upon actin filaments}

AFAP-110 was first identified as a 110-kDa protein that forms a stable complex with activated variants of Src (Reynolds et al, 1989). Kanner et al (1991) found that Src 
transformation not only increased tyrosine phosphorylation of AFAP-110, but also increased serine/threonine phosphorylation of AFAP-110. The domain structure of AFAP-110 indicates AFAP-110 may have the capability to facilitate the effects of multiple signal proteins upon actin filaments. Immunoprecipitation shows that AFAP110 can bind to Src, and immunoflurosecence shows AFAP-110 associates with actin filaments and the cortical actin matrix in both normal and transformed chick embryo fibroblast (CE) cells, indicating that AFAP-110 is both a Src substrate and actin filament associated protein (Flynn et al, 1992; Flynn et al, 1993). The transformation of CE cells by $\mathrm{v}-\mathrm{Src}$ is coincident with an increase of tyrosine phosphorylation and relocalization of AFAP-110, and the rearrangement of the actin filaments into rosette-like structure (Flynn et al, 1993). The interaction between Src and AFAP-110 depends upon SH3 and/or SH2 domains (Kanner et al, 1991; Reynolds et al, 1987; Guoppone et al, 1998).

Transformation of SH2 and SH3 deletion mutants of Src has no change of the localization of AFAP-110 and the integrity of actin filaments in vivo and AFAP-110 was unable to form a stable complex with either $\mathrm{SH} 2$ or $\mathrm{SH} 3$ deletion mutants of Src, or kinase inactivated Src in vitro (Kanner et al, 1991; Reynolds et al, 1987). Protein binding assay shows GST-SH3 can affinity absorb AFAP-110, but is unable to absorb tyrosine phosphorylated AFAP-110, indicating Src transformation may induce a conformational change within AFAP-110 (Flynn et al, 1993). Taken together, these data indicate that AFAP-110 may have the ability to mediate the effects of Src (and other cellular signal proteins) upon actin filaments. 


\section{Overall goals of this thesis.}

1) AFAP-110 has an alternatively process form in vivo, named AFAP-120 (Flynn et al,1995). AFAP-120 encodes an additional 86 amino acids compared to AFAP-110, and these 86 amino acids are inserted just amino terminal to the carboxy terminal 127 amino acids of AFAP-110. The carboxy terminus is conserved between AFAP-110 and AFAP-120. It indicates that the carboxy terminus is important for AFAP-110. In this thesis, we studied the functional roles of the carboxy terminus of AFAP-110.

2)AFAP-110 has been shown to colocalize with actin filaments in vivo in chicken embryo fibroblast (CE) cells (Flynn et al, 1993). However, we don't know whether AFAP-110 interacts with actin filaments directly or indirectly. In this thesis, we tested whether AFAP-110 interacts with actin filaments directly. 


\section{Reference}

Adam T, Giry M, Boquet P, Sansonetti P (1996): Rho-dependent membrane folding causes Shigella entry into epithelial cells. EMBO J 15:3315-21

Alber T (1992) Structure of the leucine zipper. Curr Opinion in Gene Development 2:205-210

Albert B; Bray D; Lewis J; Raff M; Roberts K; Watson JD (1994): Molecular biology of the cell 3th., Chapter 16. New York, USA. Garland Publishing, Inc. Allen WE, Jones GE, Pollard JW, Ridley AJ (1997): Rho, Rac and Cdc42 regulate actin organization and cell adhesion in macrophages. J Cell Sci 110 ( Pt 6):707-20 Ayscough KR (1998): In vivo functions of actin-binding proteins. Curr Opin Cell Biol 10:102-11

Barone MV and Courtneidge SA (1995) Myc but not Fos rescue of PDGF signalling block caused by kinase-inactive Src. Nature 378:509-512

Belsches AP; Haskell MD; Parsons SJ (1997): Role of c-Src tryosine kinases in EGFinduced mitogenesis. Front Biosci. 2:501-518

Ben-Ze'ev A (1985): The cytoskeleton in cancer cells. Biochim Biophys Acta 780:197212

Bikle DD, Munson S, Morrison N and Eisman J (1993) Zipper protein, a newly described tropomyosin-like protein of the intestinal brush border. J. Biol. Chem. 268:620-626

Blake DJ, Tinsley JM and Davies KE (1995) Coiled-coil regions in the carboxyterminal domains of dystrophin and related proteins: potentials for proteinprotein interactions. TIBS 20:133-135 
Boschek CB, Jockusch BM, Friis RR, Back R, Grundmann E, Bauer H (1981): Early changes in the distribution and organization of microfilament proteins during cell transformation. Cell 1981 24:175-84

Boyce BF, Yoneda T, Lowe C, Soriano P, Mundy GR (1992): Requirement of pp60csrc expression for osteoclasts to form ruffled borders and resorb bone in mice. J Clin Invest 90:1622-7

Broome MA; Hunter T (1996): Requireent for c-Src catalytic activity and the SH3 domain in platelet-derived growth factor BB and epidemal growth factor migogenic signaling J Biol Chem 271:16798-16806

Brown MT and Cooper JA (1996) Regulation, substrates and functions of src. Biochim. Biophys.Acta.Gene Struct.Expr. 1287:121-149

Cantley LC, Auger KR, Carpenter C, Duckworth B, Grajiani A and Kapeller R (1991) Oncogenes and signal transduction Cell: 64:281-302

Carley WW, Barak LS, Webb WW (1981): F-actin aggregates in transformed cells. J Cell Biol 90:797-802

Castresana J, Saraste M (1995): Does Vav bind to F-actin through a CH domain? FEBS Lett 374:149-51

Chang J, Grill S, Settleman and Parsons SJ (1995) c-Src regulates the simultaneous rearrangement of actin cytoskeleton, p190RhoGAP, and p120RasGAP following epidermal growth factor stimulation. J Cell Biol. 130:355-368

Cooper JA and Howell B (1993) The when and how of Src regulation. Cell 73, 10511054 
Courtneidge SA (1985) Activation of the pp60v-src kinase by middle T antogen binding or by dephosphorylation. EMBO J 4:1471-1477

De Arruda MV, Watson S, Lin CS, Leavitt J, Matsudaira P (1990): Fimbrin is a homologue of the cytoplasmic phosphoprotein plastin and has domains homologous with calmodulin and actin gelation proteins. J Cell Biol 111:1069-79

De Corte V, Gettemans J, Vandekerckhove J (1997): Phosphatidylinositol 4,5bisphosphate specifically stimulates PP60(c-src) catalyzed phosphorylation of gelsolin and related actin-binding proteins. FEBS Lett 401(2-3):191-6

De Corte V, Demol H, Goethals M, Van Damme J, Gettemans J, Vandekerckhove J (1999): Identification of Tyr438 as the major in vitro c-Src phosphorylation site in human gelsolin: a mass spectrometric approach. Protein Sci 8:234-41

Dikic I, Tokiwa G, Lev S, Courtneidge SA and Schlessinger J (1996) A role for Pyk2 and Src in linking G-preotein-coupled receptors with MAP kinase activation. Nature $383: 547-550$

Drubin DG, Mulholland J, Zhou Z and Botsstein D (1990) Homology of a yeast actinbinding protein to signal transduction proteins and myosin-I. Nature 343:288-290 Eicher DM, Tan T, Rice NR, O'Shea JJ and Kennedy ICS (1994) Expression of csrc in T cells correlates with nuclear expression of NF-kB. J Immunol 152:2710-2719 Eide BL, Turck CW and Escobede JA (1995) Identification of Tyr-397 as the primary site of tyrosine phosphorylation and pp60src association in the focal adhesion kinase, pp125fak. Mol and Cell Biol 15: 2819-2827 
Felice GR, Eason P, Nermut MV, Kellie S (1990): pp60v-src association with the cytoskeleton induces actin reorganization without affecting polymerization status. Eur $\mathbf{J}$ Cell Biol 52:47-59

Flynn DC, Schaller MD and Parsons JT (1992) Tyrosine phosphorylation of a 120,000 dalton membrane-associated protein by the neural form of pp60c-src, pp60c-srct. Oncogene 7:579-583

Flynn DC, Horme TL, Reynolds AB and Parsons JT (1993) Identification and sequence analysis of cDNA encoding a 110 kilodalton actin filament associated pp60src substrate. Mol and Cell Biol 13:7892-7900

Flynn DC, Koay TC, Humphries CG and Guappone AC (1995) A variant form of the src SH2/SH3-binding parner AFAP-110 is detected in brain and contains a novel internal sequence which binds to a 67-kda protein. J Biol Chem 270:3894-3899

Fowler VM and Adam EJ (1992) Spectrin redistributes to the cytosol and is phosphorylated during mitosis I in cultured cells. J Cell Biol 119: 1559-1572

Friedman E, Verderame M, Winawer S, Pollack R (1984): Actin cytoskeletal organization loss in the benign-to-malignant tumor transition in cultured human colonic epithelial cells. Cancer Res 44:3040-50

Gabbiani G, Kocher O (1983): Cytocontractile and cytoskeletal elements in pathologic processes. Pathogenetic role and diagnostic value. Arch Pathol Lab Med 107:622-5

Gibson TJ, Hyvonen M, Musacchio A, Saraste M, Birney E (1994): PH domain: the first anniversary. Trends Biochem Sci 19:349-53

Green KJ, Parry DAD, Steinert PM, Virata MLA, Wagner RM, Angst BD and Nilles LA (1990) Structure of the human desmoplakins. J Biol Chem 265:2603-2612 
Hall A (1994): A biochemical function for ras--at last. Science. 264:1413-4

Hall A (1998): Rho GTPases and the actin cytoskeleton. Science 279(5350):509-14

Hirata K, Kikuchi A, Sasaki T, Kuroda S, Kaibuchi K, Matsuura Y, Seki H, Saida

K, Takai Y (1992): Involvement of rho p21 in the GTP-enhanced calcium ion sensitivity of smooth muscle contraction. J Biol Chem 267:8719-22

Hitchcock-DeGregori SE and An Y (1996) Integral repeats and a continuous coiled coil are required for binding of striated muscle tropomyosin to the regulated actin filament. 271:3600-3603

Hodges RS (1992) Unzipping the secrets of coiled-coils. Curr Biol 2:122-124 Hurst HC (1994) Transcription factors 1: bZip protein. In protein profile. Academic Press, inc., San Dewgo, CA. 1:123-168

Holme TC, Kellie S, Wyke JA, Crawford N (1986): Effect of transformation by Rous sarcoma virus on the character and distribution of actin in Rat-1 fibroblasts: a biochemical and microscopical study Br J Cancer 53:465-76 Holme TC (1990): Cancer cell structure: actin changes in tumour cells--possible mechanisms for malignant tumour formation. Eur J Surg Oncol 16:161-9

Huang C, Ni Y, Wang T, Gao Y, Haudenschild CC, Zhan X (1997): Down-regulation of the filamentous actin cross-linking activity of cortactin by Src-mediated tyrosine phosphorylation. J Biol Chem 272:13911-5

Imbert V, Rupec RA, Livolsi A, Pahl HL, Traenckner EB, Mueller-Dieckmann C, Farahifar D, Rossi B, Auberger P, Baeuerle PA and Peyron J (1996) Tyrosine phosphorylation of IkB- $\alpha$ activates NF-kB without proteolytic degradation of IkB- $\alpha$. Cell 86:787-798 
Janmey PA, Chaponnier C (1995): Medical aspects of the actin cytoskeleton. Curr Opin Cell Biol. 7:111-7

Jackson P and Bellett AJ (1989): Releationship between organization of the actin cytoskeleton and the cell cycle in normal and adenovirus-infected rat cells. J Virol $63: 311-318$

Jove R and Hanafusa J (1987) Cell transformation by the viral Src oncogene. Ann Rev Cell Biol 3:31-56

Kamps MP, Buss JE and Sefton BM (1986) Rous sarcom virus transforming protein lacking myristic acid phosphorylates known polypeptide substrates without inducing trnsformation. Cell 45:105-112

Kanner SB, Reynolds AB, Wang R and Parsons JT (1991) The SH2 and SH3 domains of p60src direct stable asociation with tyrosine phosphorylated proteins p130 and p110. EMBO J 10:1689-1698

Koch CA, Anderson D, Moran MF, Ellis C and Pawson T (1991) SH2 and Sh3 domains: elements that control interactions of cytoplasmic signaling proteins. Science, 252:668-674

Kouklis PD, Traub P and Georgatos SD (1992) Involvement of the consensus sequence motif at coil $2 \mathrm{~b}$ in the assemble and stability of vimentin filaments. J Cell Science 102:31-41

KouzaridesT, Packman G, Cook A and Farrell PJ (1991) The BZIF1 protein of EBV has a coiled coil dimerisation domain without a heptad leucine repeat but with homology to the C/EBP leucine zipper. Oncogene 252:1162-1164 
Kwiatkowski DJ (1999): Functions of gelsolin: motility, signaling, apoptosis, cancer. Curr Opin Cell Biol 11:103-8

Landschultz Whm Johnson PF and McKnknight SL (1988) The Leucine Zipper: a hypothetical structure common to a new class of DNA binding proteins. Science 240:1759-1764

Lauffenburger DA, Horwitz AF (1996): Cell migration: a physically integrated molecular process. Cell 84:359-69

Letai A and Fuchs E (1995) The importance of intramolecular ion pairing in intermediate filaments. Proc. Natl. Acad. Sci. USA 92:92-96

Leung T, Chen XQ, Manser E, Lim L (1996): The p160 RhoA-binding kinase ROK alpha is a member of a kinase family and is involved in the reorganization of the cytoskeleton. Mol Cell Biol 16:5313-27

Lupas A (1996) Coiled coils: new structures and new functions TIBS 21:375-382 Luttrell DK, Lee A, Lansing TJ, Crosby RM, Jung KD, Willard D, Luther M, Rodriguez M, Berman J, and Gilmer TM (1994) Involvement of pp60c-src with two major signaling pathways in human breast cancer. Proc Natl Acad Sci USA 91:83-87 Luttrell LM, Hawes BE, Biesen TV, Luttrell DK, Lansing TJ and Lefkowitz RJ (1996) Role of c-Src tyrosine kinase in G protein-coupled receptor and G $\beta \gamma$ subunitmediated activation of mitogen-activated protein kinases. J. Biol Chem. 271:1944319450

Ma AD, Brass LF and Abrams CS (1997) Pleckstrin associates with plasma membranes and induces the formation of membrane projections: requirements for phosphorylation and the NH2-terminal PH domain. J Cell Biol. 136:1071-9 
McLaughlin PJ, Weeds AG (1995): Actin-binding protein complexes at atomic resolution. Annu Rev Biophys Biomol Struct 24:643-75

Mahoney NM, Almo SC (1998): Crystallization and preliminary X-ray analysis of human platelet profilin complexed with an oligo proline peptide. Acta Crystallogr D Biol Crystallogr 54 ( Pt 1):108-10

Mazurenko NN, Kogan EA, Zborovskaia IB, Sukhova NM and Kisiliv FL (1991) [The detection of the c-src protein gene product in human lung tumors]. Vopr Onkol $37: 683-690$

McGlade J, Cheng A, Pelicci G, Pelicci PG and Pawson T (1992) Shc proteins are phosphorylated and regulated by the v-Src and v-Fps protein-tyrosine kinases. Proc. Natl. Acad.Sci. USA 89:8869-8873

Mitchison TJ, Cramer LP (1996): Actin-based cell motility and cell locomotion. Cell 84:371-9 Morton CJ and Campbell ID (1994) Molecular 'Velcro'. Curr Biol 4:615-617 Musacchio A, Gibson T, Riche P, Thompson J and Saraste (1993) The PH domain: a common piece in the structural patchwork of signelling proteins. Trens Biochem Sci 18: 343-348

Oas TG, Mcintosh LP, O'shea EK, Dahlquist FW and Kim PS (1990) Secondary structure of a leucine zipper determined by nuclear magnetic resonance spectroscopy. Biochemistry 29:2891-2864

O'Shea EK, Klemm JD, Kim PS and Alber T (1991) X-ray structure of the GCN4 leucine zipper, a two-stranded, parallel coiled coil. 254:539-544 
Parry DAD, Steven AC and Steinert PM (1985) The coiled-coil molecules of intermediate filaments consist of two parallel chains in exact axial register. Bichem Biophys Res Commun 127:1012-1018

Paulin D, Perreau J, Jakob H, Jacob F, Yaniv M (1979): Tropomyosin synthesis accompanies formation of actin filaments in embryonal carcinoma cells induced to differentiate by hexamethylene bisacetamide. Proc Natl Acad Sci U S A 76:1891-5 Pawson T and Gish GD (1992) SH2 and SH3 domains: from stucture to function. Cell $71: 359-362$

Pawson T and Schlessinger J (1993) SH2 and SH3 domains. Curr Biol 3:434-442 Parsons JT and Weber MJ (1989) Genetics of src: structure and functional organization of a protein tyrosine kinase. Curr Topics Micro Immunol 147:79-127

Pendergast AM, Muller AJ, Havilk MH, Maru Y and Witte ON (1991) BCR seqquences essential for transformation by the BCR-ABL oncogene bind to the ABL SH2 regulatory domain in a non-phosphotyrosine-dependent manner. Cell 66, 161-171 Pearlman JA, Powaser PA, Elledge SJ and Caskey T (1994) Troponin T is capable of binding dystrophin via a leucine zipper. FEBS Letters 354: 183-186

Puius YA, Mahoney NM, Almo SC (1998): The modular structure of actin-regulatory proteins. Curr Opin Cell Biol 10:23-34

Ren R, Mayer BJ, Cicchetti P and Baltimore (1993) Identification of a ten-amino acid proline-rich SH3 binding site. Science 259: 1157-1161

Reynolds AB, Kanner SB, WangHC and Parsons JT (1989) Stable association of activated pp60src with two tyrosine phosphorylated cellular proteins. Mol Cell Biol 9:3951-3958 
Reynolds, A.B., Roussell, D.J., Kanner, S.B., and Parsons, J.T. (1989):

Transformation-specific tyrosine phosphorylation of a novel cellular protein in chicken cells expressing oncogenic variants of the avian cellular src gene. Mol Cell Biol 9:629638.

Ridley AJ, Allen WE, Peppelenbosch M, Jones GE (1999): Rho family proteins and cell migration. Biochem Soc Symp 65:111-23

Ridley AJ, Hall A (1992): The small GTP-binding protein rho regulates the assembly of focal adhesions and actin stress fibers in response to growth factors. Cell 70:389-99

Roche S, Fumagalli S and Courtneidge SA (1995) Rsrquirement for Src family protein tyrosine kinases in $\mathrm{G}_{2}$ for fibroblast cell division Science 269:1567-1569

Rodaway ARF, Sternberg MJE and Bentley (1989) Similarity in membrane proteins. Nature 342:624

Schaller MD, Borgman CA and Parsons JT (1993) Autonomous expression of a noncatalytic domain of the focal adhesion-associated protein tyrosine kinase $\mathrm{pp} 125^{\mathrm{fak}}$. Mol Cell Biol 13:785-791

Schlaepfer DD and Hunter T (1996) Ecidence for in vivo phosphorylation of the Grb2 SH2-domain binding site on focal adhesion kinase by Src-family protein-tyrosine kinases. Mol. Cell. Biol. 16:5623-5633

Schmidt, A., Hall, M.N.(1998): Signaling to the actin cytoskeleton. Annu Rev Cell Dev Biol 14:305-38

\section{Schwartzberg PL, Xing L, Hoffmann O, Lowell CA, Garrett L, Boyce BF, Varmus} HE (1997): Rescue of osteoclast function by transgenic expression of kinase-deficient Src in src-/- mutant mice. Genes Dev 11:2835-44 
Sefton BM, Hunter T, Ball EH, Singer SJ (1981):Vinculin: a cytoskeletal target of the transforming protein of Rous sarcoma virus. Cell 24:165-74

Songyang Z, Shoelson SE, Chaudhuri M, Gish G, Pawson T, Haser WG, King F, Roberts T, Ratnofsky S, Lecleider RJ, Neel BG, Birge RB, Fajardo JE, Chou MM, Hanafusa H, Schaffhausen B and Cantley LC (1993) SH2 domains recognize specific phosphopeptide sequences. Cell 72:767-778

Steinert PM, North AC and Parry DA (1994) Structural features of keratin intermediate filaments. J Invest Dermatol 103:19S-24S

Stone D, Smillie LB (1978): The amino acid sequence of rabbit skeletal alphatropomyosin. The NH2-terminal half and complete sequence. J Biol Chem 253:1137-48 Superti-Furga G and Courtneikge SA (1995) Structure-function relationships in Src family and related protein tyrosine kinases. BioEssays 17: 321-330

Superti-Furga G, Fumagalli S, Koegl M, Courtneidge SA and Draetta G (1993) Csk inhibition of Src activity requires both the $\mathrm{SH} 2$ and $\mathrm{SH} 3$ domains of Src. EMBO J $12: 2625-2634$

Tapon N, Hall A (1997): Rho, Rac and Cdc42 GTPases regulate the organization of the actin cytoskeleton. Curr Opin Cell Biol. 9:86-92

Tapon N, Nagata K, Lamarche N, Hall A (1998): A new rac target POSH is an SH3containing scaffold protein involved in the JNK and NF-kappaB signalling pathways. EMBO J 17:1395-404

Taylor JM, Hildebrand JD, Mack CP, Cox ME, Parsons JT: (1998): Characterization of graf, the GTPase-activating protein for rho associated with focal adhesion kinase. 
Phosphorylation and possible regulation by mitogen-activated protein kinase. J Biol Chem 273:8063-70

Taylor JM, Richardson A, Parsons JT (1998): Modular domains of focal adhesionassociated proteins. Curr Top Microbiol Immunol 228:135-63

Taylor SJ an Shalloway D (1996) Src and the control of cell division. BioEssays 18:911

Thomas SM, Brugge JS (1997): Cellular functions regulated by Src family kinases. Annu Rev Cell Dev Biol 13:513-609

Towbin JA (1998): The role of cytoskeletal proteins in cardiomyopathies. Cur Opin Cell Biol 10:131-139

Van Aelst L, D'Souza-Schorey C (1997): Rho GTPases and signaling networks. Genes Dev 11:2295-322

Van Troys M, Vandekerckhove J, Ampe C (1999): Structural modules in actin-binding proteins: towards a new classification. Biochim Biophys Acta 1448:323-48

Wang E, Goldberg AR (1976): Changes in microfilament organization and surface topogrophy upon transformation of chick embryo fibroblasts with Rous sarcoma virus. Proc Natl Acad Sci U S A 73:4065-9

Welch MD, Mallavarapu A, Rosenblatt J, Mitchison TJ (1997): Actin dynamics in vivo. Curr Opin Cell Biol 9:54-61

Yu H, Chen JK, Feng S, Dalgarno DC, Brauer AW and Schreiber SL (1994)

Structure basis of the binding of proline-rich peptides to SH3 domains. Cell 76: 933-945 


\section{CHAPTER 2}

\section{Monoclonal Antibodies Directed Against AFAP-110 Recognize Species-specific and Conserved Epitopes}

Yong Qian, Anne C. Guappone, Joseph M. Baisden, M. Wynn Hill, Justin M. Summy and Daniel C. Flynn

Mary Babb Randolph Cancer Center and the Department of Microbiology and

Immunology, West Virginia University, Morgantown, WV 26506-9300

This manuscript was published in the April 1999 issue of Hybridoma

(Vol 18, Number 2, 1999, P. 167-175) 


\begin{abstract}
The SH2/SH3 binding partner AFAP-110 is a tyrosine phosphorylated substrate
\end{abstract} of Src. It has the ability to modulate the integrity of actin filaments. AFAP-110 has several protein signal domains. It has a SH3 binding motif, two $\mathrm{SH} 2$ binding motifs and two PH domains at its amino terminus, and has a leucine zipper motif at its carboxy terminus. There are two monoclonal antibodies to recognize AFAP-110. Mab 4C3 recognizes the amino terminus of AFAP-110 while Mab AFAP-110 recognizes the carboxy terminus of AFAP-110. Site directed mutagenesis of prolines at SH3 binding motif and the adjacent proline rich motif abrogates Mab 4C 3 binding, and this same mutation has been shown to prevent $\mathrm{SH} 3$ interactions between $\mathrm{Src}^{527 \mathrm{~F}}$ and AFAP-110, indicating the epitope of Mab 4C3 is within SH3 binding motif. Importantly, Mab 4C3 is unable to efficiently react with mammalian AFAP-110. Sequence analysis of the amino terminus of putative human AFAP-110 reveals two amino acid differences compared to that of avian of AFAP-110, indicating a mechanism for species-specific binding for Mab 4C3. Mab AFAP-110 recognizes AFAP-110 across the species, and its epitope is located at the carboxy terminus of AFAP-110, including and around the $5^{\text {th }}$ leucine of the leucine zipper motif heptad repeat. The leucine zipper motif may mediate AFAP-110's self-association and regulate the function of AFAP-110. These two monoclonal antibodies are useful tools to study AFAP-110 in the regulation of cell morphology and the actin filament integrity. In addition, Mab 4C3 may be used to study the function of avian AFAP-110 expressed in mammalian cells by providing an internal epitope tag. 


\section{Introduction}

One of hallmarks of Src transformation is the disruption of actin filaments (Reynolds et al, 1989 and Felice et al, 1990). AFAP-110 (Actin Filament Associated Protein, $110 \mathrm{kDa}$ ) is both a Src substrate and an actin binding protein (Flynn et al, 1993). It is a candidate protein to mediate the effects of Src on the integrity of actin filaments. Early studies found that AFAP-110 was located on actin filaments, cortical actin matrix and the leading edge of the cell (Flynn et al, 1993). Immunofluorescence found that the carboxy terminal 84 amino acids within AFAP-110 were essential for the binding to actin filaments (Qian et al, 1998). Deletion of the leucine zipper motif within these 84 amino acids, followed by cellular expression, results in actin filaments being repositioned into rosette like structures, this mutated AFAP-110 still locates with the altered actin filaments (Qian et al, 1998). These data indicate that AFAP-110 is capable of binding to actin filaments, which is mediated through carboxy terminal 84 amino acids. They also indicate that AFAP-110 may have an intrinsic ability to alter the integrity of actin filaments, which is regulated by the leucine zipper motif within the carboxy terminal 84 amino acids. It is our hypothesis that AFAP-110 may mediate the effects of Src transformation, and other cellular signals, upon actin filaments.

AFAP-110 has both SH3 and SH2 binding motifs and is a SH3/SH2 binding

partner for Src ${ }^{527 \mathrm{~F}}$ (Flynn et al, 1993; Reynolds et al, 1989; Kanner et al, 1991; Guappone and Flynn, 1997 and Guappone et al, 1998). It was found that tyrosine phosphorylated AFAP-110 could form a stable complex with activated variants of Src (such as $\mathrm{Src}^{527 F}$ ) in primary cultures of chick embryo fibroblast (CE) and rat lung embryo fibroblast cells 
(Flynn et al, 1993 and Liu et al, 1996). There is an SH3 binding motif within AFAP-110 between amino acids $62-71$, and adjacent to the $\mathrm{SH} 3$ domain is a proline rich motif between amino acids 75-84. Earlier data showed that the integrity of SH3 binding motif is important for the binding of $\mathrm{Src}^{527 \mathrm{~F}}$ to AFAP-110 while the adjacent proline rich motif is not necessary for the binding. AFAP-110 also contains two SH2 binding motifs at $\mathrm{Tyr}^{94}$ and $\mathrm{Tyr}^{451 / 453}$ (Guappone et al, 1998). The interaction of $\mathrm{Src}^{527 \mathrm{~F}}$ with AFAP-110 is also dependent on the integrity of either of these two SH2 binding motifs. Therefore, the formation of a stable complex depends on the integrity of both $\mathrm{SH} 2$ and $\mathrm{SH} 3$ interactions. AFAP-110 also contains two pleckstrin homology (PH) domains (Gibson et al, 1994 and Shaw G, 1996) and a serine/threonine kinase substrate region between two PH domains (Flynn et al, 1993). Thus, it is possible that AFAP-110 may be involved in transferring cellular signals from different signaling pathways to actin filaments, which may affect the integrity of actin filaments.

Currently, there are three different kinds of antibodies to AFAP-110. They are MAb 4C3, polyclonal Ab F1 and MAb anti-AFAP-110. The early work by Kanner et al led to the development of $\mathrm{MAb} 4 \mathrm{C} 3$, which is reactive with an epitope in the amino terminus of AFAP-110 (Kanner et al, 1990). Using MAb 4C3, Flynn et al screened $\lambda$ gt11c cDNA library to get a cDNA that expresses an immunoreactive epitope, defined as amino acid 53-356 (Flynn et al, 1993). Polyclonal antibody F1 was created using this fragment of amino acids to immunize the animal (Flynn et al, 1993). Monoclonal antibody MAb anti-AFAP-110 was made against the carboxy terminal amino acids 469637. Interestingly, MAb 4C3 can only react with avian isoform of AFAP-110. Neither the murine isoform nor human isoforms of AFAP-110 are reactive with MAb 4C3 (Flynn 
et al, 1993 and Kanner et al, 1990), while both polyclonal Ab F1 and MAb antiAFAP110 can react with avian, murine and human isoforms of AFAP-110. Therefore, the immunoreactive epitope for MAb 4C3 may be unique for the avian isoform of AFAP110.

In this paper, we report two MAbs, MAb 4C3 and MAb anti-AFAP-110, recognize epitopes that are defined as functional domains within AFAP-110. MAb 4C3 recognizes the partial SH3 binding domain of avian AFAP-110 that has two amino acid differences from the predicted sequence of putative human AFAP-110. MAb antiAFAP-110 recognizes an epitope within carboxy terminal leucine zipper motif that is adjacent to the actin binding domain.

\section{Materials and Methods}

\section{Generation of antibodies}

MAb was created as previously described (Kanner et al, 1990 and 1989). Src transformed CE cell lysates were immunoprecipitiated by anti-tyrosine antibody to fish out tyrosine phosphorylated proteins. The precipitated proteins were purified, concentrated and injected into mice. The resulting MAbs recognized a panel of Src substrates. The MAb that recognized AFAP-110 was named as MAb 4C3. Ab F1 was created as previously described. MAb Anti-AFAP-110 was developed by Transduction Labs, Inc. (Lexington, KY) by challenging mice with fusion protein containing carboxy terminal amino acids 469-637 of avian isoform of AFAP-110. (See Transduction Laboratories 1998 Antibodies catalog, page 43). 


\section{Generation of point and deletion mutants and expression vectors}

Point mutations were generated using the Muta-Gene phagemid in vitro mutagenesis kit (Bio-Rad laboratories, Richmond, CA) as previously described (Guappone and Flynn, 1997). Oligonucleotides were synthesized that were 18bp in length and contained a single mismatch to mutate a specific proline residue to alanine. In the SH3 binding motif (SH3bm I), Pro $^{71}$ was mutated to Ala (referred to as AFAP ${ }^{71 \mathrm{~A}}$ ), while Pro ${ }^{77}$ was mutated to Ala (referred to as $\mathrm{AFAP}^{77 \mathrm{~A}}$ ) in the adjacent proline rich sequence. In addition, a double mutant was created, referred as AFAP ${ }^{71 / 77 \mathrm{~A}}$. Deletion of the carboxy terminal 84, 44, 22 amino acids were accomplished by generation of a stop codon in place of Lys ${ }^{554}$, Lys ${ }^{593}$ and Lys ${ }^{616}$, respectively (Qian et al, 1998 and Qian et al, unpublished data). The leucine zipper motif was removed by deleting amino acids 559593, as previously described (Qian et al, 1998).

Both the wild type of AFAP-110 and different mutant AFAP-110s were subcloned into pCMV-1 expression vector, under the control of CMV promoter as previously described (Guappone et al, 1996).

\section{Cell culture and expression of cDNA constructs in CE, C3H10T1/2 and Cos-1 cells.}

Both CE cells and Cos-1 cells are maintained as previously described (Flynn et al, 1993). C3H10T1/2 cells are maintained in Dulbecco's modified eagle's minimal essential medium (DMEM) containing 5\% fetal calf serum, $2 \mu \mathrm{M}$ glutamine, and $1 \%$ penicillin/streptomycin, as previously described (Guappone et al, 1996 and Luttrell et al, 1988). The different AFAP-110s were transfected into Cos- 1 cells using the method as 
Chen and Okayama described (Guappone et al, 1996; Chen and Okayama, 1987), and transfected into C3H10T1/2 cells using Superfectamine (Qiagen, Corp., Valencia, CA). The efficiency of transfection is around $1-5 \%$ of total cells.

RCAS-AFAP ${ }^{1-145}$ was generated by deleting bp 452-2260 of AFAP-110. Deletion was accomplished as described below. pKS(+/-)-AFAP-110 was digested with StuI and religated, and the resulting construct was cut with ClaI and shuttled into pRCAS via unique ClaI site. The construct expressed amino acids 1-145 of AFAP-110 plus three novel amino acids and a stop codon. RCAS-AFAP ${ }^{1-145}$ was transfected into CE as previously described (Boyer et al, 1993), with the resulting avian retrovirus infected all cells by day 12 post-transfection (Flynn et al, 1993). Using polyclonal Ab F1, Western Blot analysis was applied to detect the presence of 37-kDa immunoreactive polypeptide to confirm the expression of $\mathrm{AFAP}^{1-145}$.

\section{Generation of GST-encoded fusion proteins and competitive inhibition}

GST-SH3 was generated from the avian form of c-Src, as previously described (Flynn et al, 1993). The preparation of bacterial lysates containing the encoded fusion protein, and immobilization on glutathione-sepharose beads were done according to the method of Smith and Johnson (Smith and Johnson, 1988). Twenty micoliters of sonicated and centrifuged bacterial lysates were mixed with $100 \mu \mathrm{l}$ of glutathione coated sepharose beads (pharmacia, Uppsala, Sweden; 50\% w/v in MTPBS-1\% Triton: 150mM $\mathrm{NaCl}, 16 \mathrm{mM} \mathrm{Na}_{2} \mathrm{HPO}_{4}, 4 \mathrm{mM} \mathrm{NaH} \mathrm{PO}_{4}, \mathrm{pH} 7.3$ ) for 1 hour at $4^{\circ} \mathrm{C}$. The beads were washed 4 times with $200 \mu$ MTPBS-1\% Triton and resuspended to $100 \mu$ with MTPBS$1 \%$ Triton. The resulting $100 \mu \mathrm{l}$ of glutathione-sepharose bead conjugated to fusion 
proteins were mixed for $1.5 \mathrm{hr}, 4^{\circ} \mathrm{C}$, with $250-500 \mu \mathrm{g}(1.0 \mu \mathrm{g} / \mu \mathrm{l})$ cellular lysates that had been lysed in RIPA lysis buffer. The beads were washed two times with RIPA lysis buffer and two times with Tris-buffered saline ( $\mathrm{pH} 7.3$ ), resuspended in $100 \mu \mathrm{l} 2 \mathrm{x}$ Laemmli sample buffer, boiled for 5 minutes to remove bound proteins, centrifuged and the supernatant was processed for western blot analysis. Competitive inhibition of affinity absorption of AFAP-110, or AFAP ${ }^{1-145}$, by GST-SH3 ${ }^{\text {src }}$ was achieved by preincubating CE cellular lysates containing AFAP-110 with $1 \mu 1$ of mAb 4C 3 ascites or 1.2 $\mu \mathrm{g}$ of Ab F1 $(1.2 \mu \mathrm{g} / \mu \mathrm{l})$ in $500 \mu \mathrm{l}$ of CE cell lysate $(500 \mu \mathrm{g} / \mathrm{ml})$ for $2 \mathrm{hr}$, followed by affinity absorption with GST-SH3 $3^{\text {src }}$. Bound AFAP-110 was eluted by boiling the immobilized proteins in $50 \mu \mathrm{l}$ of 2x Laemelli sample buffer, bound proteins resolved by 8\% SDS-Page, subjected to western transfer and western blot analysis with Ab F1. Affinity absorption of $\mathrm{AFAP}^{1-145}$ was achieved in an identical fashion.

\section{Protein characterization, analysis and immunofluorescence localization}

Cos-1 cellular lysates were prepared using NP-40 lysis buffer (1\% NP-40, 150 $\mathrm{mM} \mathrm{NaCl}, 50 \mathrm{mM}$ Tris, $\mathrm{pH}$ 7.5) containing protease and phosphatase inhibitors, as previously described (Guappone et al, 996)). Isolation of immune complexes, western transfer and western blot analysis with $\mathrm{Ab} \mathrm{F} 1, \mathrm{mAb} 4 \mathrm{C} 3$ or mAb anti-AFAP-110, followed by quantitation using HRP-conjugated secondary antibody were done as previously described, using chemiluminescence technology for detection (Guappone and Flynn, 1997). Cells were processed for immunofluorescence localization as previously described (Qian et al, 1998 and Qian et al, unpublished data). 


\section{Results}

\section{MAb 4C3 recognizes an epitope within AFAP-110 that contains the Src SH3 binding motif.}

The early immunoprecipitation experiments showed that specific antibodies to Src can co-precipitate AFAP-110 in Src transformed CE cell lysates, while the reverse experiments can not co-precipitate Src (Flynn et al, 1993). Here, either MAb 4C3 or F1 was used to precipitate AFAP-110 from Src transformed CE cell lysates, and there was no detectable associated $\mathrm{Src}^{527 \mathrm{~F}}$ with AFAP-110. It was demonstrated that AFAP-110 can directly associate with kinase activated Src, and no other protein binding partners were needed to mediate formation of AFAP-110/Src ${ }^{527 \mathrm{~F}}$ complex (Guappone and Flynn, 1997 and Guappone et al, 1998). This indicates that both MAb 4C3 and F1 may bind competitively to an epitope that is also the site for Src binding. Thus, both MAb 4C3 and F1 may selectively bind to AFAP-110 that is not in association with Src.

Src binds to AFAP-110 through both the SH3 binding motif (amino acids 62-71) and SH2 binding motif (phosphorylated $\mathrm{Tyr}^{94}$ and/or $\mathrm{Tyr}^{451 / 453}$ ) (Guappone and Flynn, 1997 and Guappone et al, 1998). In order to determine whether MAb 4C3 and F1 reacted with either of these epitopes, $500 \mu \mathrm{g}$ of $\mathrm{CE}$ cell lysates were first preincubated with either $1 \mu \mathrm{l}$ of MAb 4C3 or $1.2 \mu \mathrm{l}$ of F1, and then absorbed by either GST-SH3 ${ }^{\text {Src }}$ or GST (Fig 1). The data show GST-SH3 ${ }^{\text {Src }}$ binds to AFAP-110 (Fig 1A, Lane 4) while there is no binding for GST (Fig 1A, Lane5). However, the preincubation of CE cell lysates with either MAb 4C3 or F1 reduces the binding activities of AFAP-110 by GST-SH3 ${ }^{\mathrm{Src}}$ (Fig 
$1 \mathrm{~A}$, lane 2 and 3). There is no effect upon preincubation of preimmune rabbit antibodies (data not shown). A polypeptide representing amino acids 1-145 of AFAP-110 was subcloned into the pRCAS expression vector and the construct was transfected into CE cells. Similar results were obtained indicating that the binding activities of GST-SH3 ${ }^{\mathrm{Src}}$ to AFAP-110 were reduced when AFAP-110 (1-145) was preincubated with either MAb 4C3 or F1(Fig 1B). The scanning densitometry showed MAb 4C3 reduced GST-SH3 ${ }^{\text {Src }}$ binding activities to AFAP-110 about three-fold, while F1 reduce the binding activities about two-fold, which approximated background detection levels of AFAP-110 that non specifically bound to GST (Fig. 1C). There is no effect on the affinity absorption of AFAP-110 by GST-SH2 ${ }^{\text {Src }}$ when AFAP-110 is preincubated with either MAb 4C3 or F1 (data not shown). These data indicate that the epitopes of both MAb 4C3 and F1 may be located within AFAP-110's SH3 binding motif, or the binding of either MAb 4C3 or F1 to AFAP-110 induces a confirmation change within AFAP-110's SH3 binding motif.

In order to determine whether MAb 4C3's epitope is located within the SH3 binding motif, site-directed mutagenesis was used to make mutant AFAP-110s. AFAP ${ }^{71 \mathrm{~A}}$ has mutation within $\mathrm{SH} 3$ binding motif, $\mathrm{AFAP}^{77 \mathrm{~A}}$ has mutation at the adjacent proline rich motif while $\mathrm{AFAP}^{71 \mathrm{~A} / 77 \mathrm{~A}}$ is double mutant. These mutants were transfected into Cos1 cells to express the proteins as previously described (Guappone and Flynn, 1997). Western blot analysis was applied to determine the expression of mutant AFAP-110s by using either MAb 4C3 or F1. Data show F1 is able to detect both normal AFAP-110 and different mutated AFAP-110s, which demonstrates the successful expression of each construct (Fig 2A, Lane 1-4). MAb 4C3 is able to recognize normal AFAP-110, but is deficient in recognization of both $\mathrm{AFAP}^{71 \mathrm{~A}}$ and $\mathrm{AFAP}^{77 \mathrm{~A}}$ (Fig 2B, lane 2and 3). MAb 
$4 \mathrm{C} 3$ is also unable to recognize the $\mathrm{AFAP}^{71 / 77 \mathrm{~A}}$ mutant (Fig 2B, lane 4). These data indicate $\mathrm{MAb} 4 \mathrm{C} 3$ 's epitope is located within the $\mathrm{SH} 3$ binding motif and part of the adjacent proline rich sequence, which is defined between amino acids 71 to 77 .

MAb 4C3 specifically recognizes avian isoform of AFAP-110 and doesn't efficiently recognize the mammalian homolog. Immunofluorescence was applied to determine MAb 4C3's specificity for the avian isoform of AFAP-110 (Reynolds et al, 1989 and Felice et al, 1990). First, normal murine C3H10T1/2 cells were labeled with F1 to detect endogenous AFAP-110, followed by anti-rabbit antibody conjugated to rhodamine, and phalloidin conjugated to FITC to label actin filaments. It was found that endogenous AFAP-110 co-localized with actin filaments (Fig. 3A and AB). Then, C3H10T1/2 cells were transfected with avian AFAP-110 cDNA and labeled with MAb 4C3 to detect AFAP-110, followed by anti-rabbit antibody conjugated to rhodamine, and phalloidin conjugated to FITC to label actin filaments. The data show MAb 4C3 only recognize the avian construct in a subset of cells successfully transfected with the avian AFAP-110 cDNA (Fig. 3C) and this avian AFAP-110 is also colocalize with actin filaments (Fig 3D).

Kuneida et al, found an unknown cDNA sequence of 75 amino acids called Urf that is $94 \%$ homologous to avian AFAP-110 predicted amino acid sequence (Table 1) (Kuneida et al, 1991). The Urf sequence is from human stomach tumor and is predicted to fuse to the kinase domain of the receptor tyrosine kinase Ret. Recently, Liu et al, isolated the human isoform of AFAP-110, and Urf sequence turned out to be identical to the 75 amino acids of human isoform of AFAP-110 (Liu et al, personal communication). The predicated amino acid sequence of Urf indicates a Pro residue at amino acid position 
73, while avian isoform of AFAP-110 has a Gln residue at the same position. This implies that amino acid Gln at position 73 may be essential for MAb reactivity with AFAP-110.

\section{MAb anti-AFAP-110 recognizes an epitope in the carboxy terminal leucine zipper motif}

The MAb anti-AFAP-110 was generated against the carboxy terminal 167 amino acid sequence that is defined as amino acids 469 to 637 . This sequence contains the leucine zipper motif and long $\alpha$-helix (Fig. 4A). The carboxy terminal mutants of AFAP110 were generated (Fig. 4B). AFAP $^{\Delta 22}$ lacks last twenty two amino acids of the carboxy terminus, $\mathrm{AFAP}^{\Delta 44}$ lacks last fourty four amino acids of the carboxy terminus, $\mathrm{AFAP}^{\Delta \mathrm{lzip}}$ has no leucine zipper motif and $\mathrm{AFAP}^{\Delta 84}$ has neither leucine zipple motif nor long $\alpha$ helix. These different mutants were transfected into Cos-1 cells as previously described. The Cos-1 cell lysates were resolved by SDS-PAGE. Western blot was applied to detect the deletion mutants of AFAP-110, using F1 and MAb anti-AFAP-110 (Fig. 5). F1 was used to measure the expression levels of different forms of AFAP-110s (Fig 5, lane 1-5). The data determined the $\mathrm{M}_{\mathrm{r}}$ of the deletion mutants as well as an $82 \mathrm{kDa}$ polypeptide that was hypothesized to be a proteolytic breakdown product of AFAP-110 as before (Flynn et al, 1995). Western blot using MAb anti-AFAP-110 only detected AFAP-110 and $\mathrm{AFAP}^{\Delta 22}$. Neither $\mathrm{AFAP}^{\Delta 44}, \mathrm{AFAP}^{\Delta 1 \mathrm{zip}}$ nor $\mathrm{AFAP}^{\Delta 84}$ were recognized by MAb antiAFAP-110. The only common sequence that $\mathrm{AFAP}^{\Delta 44}, \mathrm{AFAP}^{\Delta \mathrm{zip}}$ and $\mathrm{AFAP}^{\Delta 84}$ each lack is Lys ${ }^{593}$, which is part of the $5^{\text {th }}$ heptad repeat in the leucine zipper motif. These data indicate that Lys ${ }^{593}$ is a part of the epitope for MAb anti-AFAP-110. 
There is an $82 \mathrm{kDa}$ polypeptide found in Cos-1 lysates (Fig. 5, lane 5A), and this 82-kDa polypeptide was also detected in CE cells. It was hypothesized to be as a proteolytic breakdown product (Flynn et al, 1993; Guappone and Flynn, 1997; Flynn et al, 1995). MAb anti-AFAP-110 is unable to detect this proteolytic product in both AFAP-110 and AFAP ${ }^{\Delta 22}$. This indicates $82 \mathrm{kDa}$ proteolytic product may lack carboxy terminal sequence. $\mathrm{AFAP}^{\Delta 84}$ has a similar or slightly retarded $\mathrm{M}_{\mathrm{r}}$ compared with this proteolytic product. This implies that the loss of carboxy terminal sequence may result from loss of upstream sequence at or near $\mathrm{Tyr}^{553}$ (Fig.5A, lane 2).

\section{Discussion}

The data in this report demonstrate that MAb 4C3, polyclonal F1 and MAb antiAFAP-110 each recognize different epitopes within AFAP-110. Preincubation of CE cell lysates with either MAb 4C3 or F1 block the affinity absorption of GST-SH3 ${ }^{\text {Src }}$ to AFAP-

110. This indicates that both MAb 4C3 and F1 recognize AFAP-110's SH3 binding motif and, as a consequence, block the interaction between SH3 and AFAP-110.

Alternatively, the binding of either MAb 4C3 or F1 to a distinct epitope within AFAP110 may induce a conformational change to alter the structure of SH3 binding motif. Previous studies showed that amino acids 62-71 are defined as the Src SH3 binding motif, while the adjacent proline rich motif (amino acids 75-84) is not required for SH3 binding (Guappone and Flynn, 1997). Site directed mutagenesis and immunoprecipitation show that $\mathrm{F} 1$ reacts with either of two single point mutated forms of 
AFAP-110 (SH3 binding motif, AFAP ${ }^{71 \mathrm{~A}}$ and the adjacent proline rich motif, $\mathrm{AFAP}^{77 \mathrm{~A}}$ ) and double mutant $\left(\mathrm{AFAP}^{71 / 77 \mathrm{~A}}\right)$. This indicates that $\mathrm{F} 1$ may either recognize the $\mathrm{SH} 3$ binding motif or a distinct epitope, preventing SH3 binding by steric hindrance or by conformational change upon SH3 binding motif. However, MAb 4C3 is less reactive with either $\mathrm{AFAP}^{71 \mathrm{~A}}$ or $\mathrm{AFAP}^{77 \mathrm{~A}}$, and not efficiently reactive with the double mutant, $\mathrm{AFAP}^{71 / 77 \mathrm{~A}}$. These data imply MAb 4C3 recognizes an epitope between amino acids 7177, and both Pro71 and Pro77 within AFAP-110 are important for immunoreactive with MAb 4C3 antibody. Structural predictions and mutagenesis analysis indicate that $\mathrm{SH} 3$ binding motif is defined as PEIP ${ }^{71}$ sequence (Guappone and Flynn, 1997; Ren et al, 1993; Weng et a, 1994; Cheadle et al, 1994; Rickles et al, 1994; Sparks et al, 1994), thus Pro ${ }^{71}$ represents an important residue within the SH3 binding motif and locates at one end of this motif. Mutagenesis of Pro ${ }^{77}$ affects MAb 4C3's immunoreactivity. This indicates MAb 4C3's epitope includes the SH3 binding motif and the adjacent proline rich sequence as well. Because SH3 interactions are important for the formation of $\mathrm{Src}^{527 \mathrm{~F}} / \mathrm{AFAP}-110$, these data may explain why preincubation of AFAP-110 with either MAb 4C3 or F1can block co-immunoprecipitation of AFAP-110 with Src ${ }^{527 F}$. It seems likely that both MAb 4C3 and F1 selectively bind to AFAP-110 that doesn't form complex with $\mathrm{Src}^{527 F}$. There is one amino acid difference between avian and human isoforms of AFAP-110 in the epitope recognized by MAb 4C3. This may explain why $\mathrm{MAb} 4 \mathrm{C} 3$ is unable to react with mammalian isoform of AFAP-110. The data are useful, because the epitope recognized by MAb 4C3 may be used as an internal epitope-tag to localize and characterize mutants of avian AFAP-110 expressed in mammalian cells. This is important, because AFAP-110 is a signal protein and this internal epitope may 
help us to identify the mechanism by which AFAP-110 influenzes the integrity of actin filaments in vivo.

MAb anti-AFAP-110 recognizes an epitope around the carboxy terminal region, including $\mathrm{Lys}^{593}$. This is based on the observation that deletion of either leucine zipper motif (AFAP ${ }^{\Delta l z i p}$, amino acids 550-593) or the last 44 carboxyl terminal amino acids (AFAP ${ }^{\Delta 44}$, amino acids 593-637) will prevent the binding of AFAP-110 by this antibody. The deletion of last 22 carboxy terminal sequence $\left(\mathrm{AFAP}^{\Delta 22}\right.$, amino acids 615-637) had no effect on binding. The common sequence lacking between $\mathrm{AFAP}^{\Delta l z i p}$ and $\mathrm{AFAP}^{\Delta 44}$ is $\mathrm{Lys}^{593}$. Therefore, we hypothesize that the epitope for MAb anti-AFAP-110 is defined by sequence including and flanking Lys ${ }^{593}$. This sequence is part of predicted leucine zipper motif, which is at $5^{\text {th }}$ haptad repeat (Qian et al, 1998). In addition, MAb anti-AFAP-110 recognizes this epitope across species, indicating that this epitope is conserved among different species. Interestingly, this epitope is adjacent to the actin binding domain (amino acids 600-618).

There is an F1 recognizable $82 \mathrm{kDa}$ polypeptide detected by Western blot analysis when AFAP-110 is expressed in Cos-1 cells. It was hypothesized this may be a proteolytic breakdown product of AFAP-110 (Flynn et al, 1995). This same size polypeptide is also detected in CE cells and was hypothesized as a proteolytic breakdown product of endogenous AFAP-110 (Flynn et al, 1993). MAb anti-AFAP-110 can not detect this polypeptide. Similar observations were found in the neuronal AFAP-120 (Flynn et al, 1993). AFAP-120 is a neuronal isoform of AFAP-110, and contains an additional 86 amino acid insertion between $\mathrm{Se}^{510}$ and $\mathrm{Phe}^{511}$. This insertion doesn't disrupt the downstream reading frame and adds approximately $10 \mathrm{kDa}$ of $\mathrm{M}_{\mathrm{r}}$ to AFAP- 
120 compared to AFAP-110. Western blot analysis with F1 found a 95kDa immunoreactive polypeptide as for cell lysates expressing AFAP-120. This $95 \mathrm{kDa}$ polypeptide is also not immunoreactive with MAb anti-AFAP-110, similar to $82 \mathrm{kDa}$ polypeptide. In addition, $\mathrm{AFAP}^{\Delta 84}$ has similar or slightly increased $\mathrm{M}_{\mathrm{r}}$ compared to the $82 \mathrm{kDa}$ proteolytic polypeptide. Taken together, these data indicate that the $82 \mathrm{kDa}$ proteolytic breakdown product lacks carboxy terminal sequence of AFAP-110, and the unidentified proteolytic site may be between $\mathrm{Phe}^{511}$ and Try ${ }^{553}$. The proteolytic breakdown polypeptide should be unable to set on actin filaments same as $\mathrm{AFAP}^{\Delta 84}$ phenotype (Qian et al, 1998). Therefore, it may provide a regulatory mechanism by which AFAP-110 is removed from actin filaments. AFAP-110 has been shown to have the ability to bind to actin filaments and may have the ability to mediate effects of other signaling proteins upon actin filaments through its $\mathrm{PH}$ domains, $\mathrm{SH} 2$ and/or SH3 binding motifs (Flynn et al, 1993; Guappone and Flynn, 1997; Qian et al, 1998; Guappone et al, 1998; Gibson et al, 1994; Shaw G, 1996). There are several examples whereby proteolysis regulates the function of cytoskeleton associated proteins. Ezrin is one of these examples, which may affect the motility of epithelial cells by proteolysis (Yao et al, 1993; Shuster and Herman, 1995). Some integrins can be cleaved by calpain in motile cells and may be associated with motility via disruption of cell-matrix interactions (Huttenlocher et al, 1997). In addition, calpain can cleave some isoforms of protein kinase $\mathrm{C}$ as well as pp $125^{\mathrm{FAK}}$ by which the remodeling of actin filaments can be regulated (Melloni et al, 1985; Cooray et al, 1996; Vuori and Rouslahti, 1993; Lewis et al, 1996). These proteins are substrates of calpain which preferentially cleaves amino acid sequences that contain residue with bulky side groups in position 1 (e.g., Arg, Lys, Tyr 
and Met) and a hydrophobic amino acid in position 2 (Croall an Demartino, 1997). Although there are several sequence sites that could be cut by calpain between amino acid 511 and 553 of AFAP-110, no evidence has been demonstrated whether AFAP-110 can be digested by calpain either in vivo or in vitro. Nevertheless, it is possible that proteolysis may regulate AFAP-110 function.

In summary, both MAb 4C3 and MAb anti-AFAP-110 will provide useful tools to study the functional roles of AFAP-110. MAb 4C3 will provide a useful internal epitope tag to characterize and localize both normal and different mutant variants of avian AFAP-110 expressed in mammalian cell lines, while MAb anti-AFAP-110 will provide a useful tool to determine the mechanism by which AFAP-110 regulates the integrity of actin filaments in response to cellular signals.

\section{Acknowledgements}

This work was supported by a grant from the National Institutes of Health CA60731 (DCF). JMS was supported by the Arlen G. and Louise Stone Swiger Foundation and JMB was supported by the West Virginia University Medical Scientist Training Program.

\section{Tables}




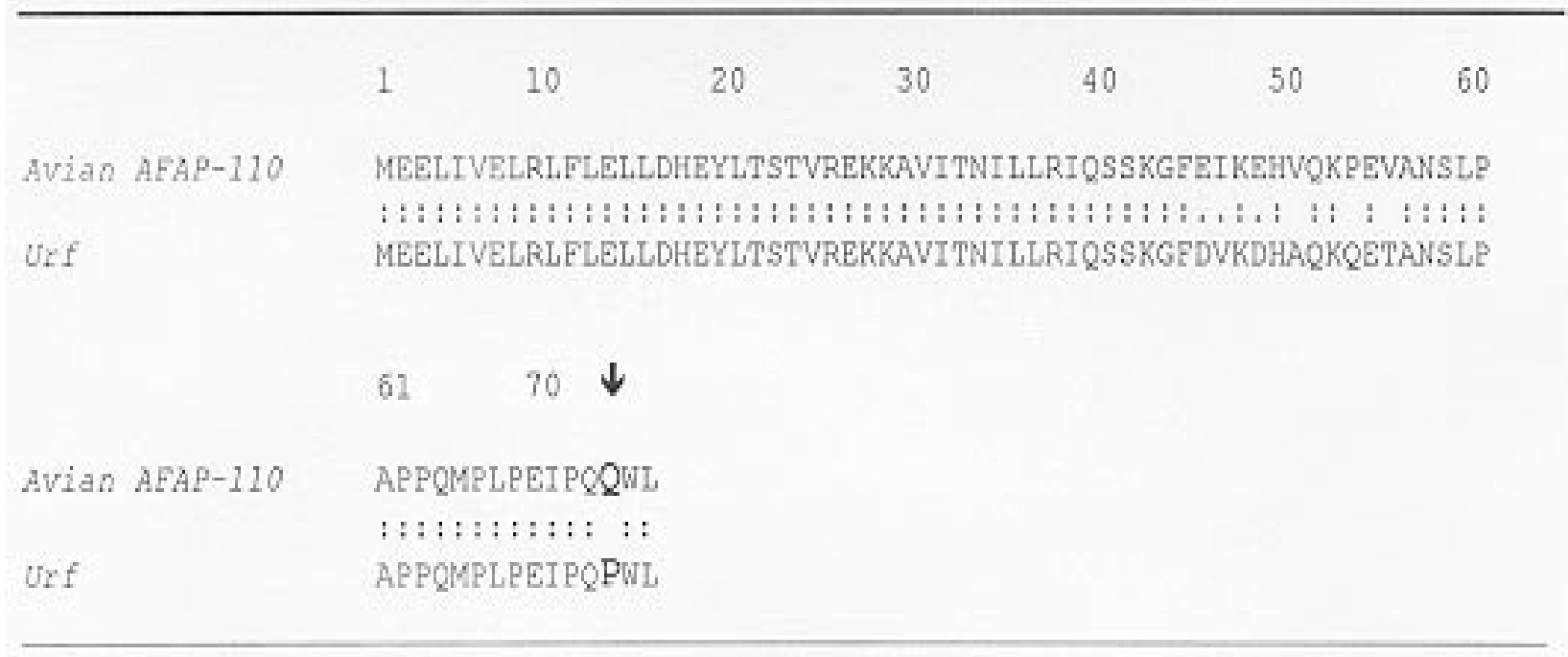

TABLE 1 Homolgy of the 75 amino acids of AFAP-110 and Urf- a putative human homolog of AFAP-110. The avian AFAP-110 and Urf amino acid sequences are 94\% homologus. The arrow denotes the single amino acid change in the mAB $4 \mathrm{C} 3$ epitope.

\section{Figures and Figure legends}


A

Affinity absorption of AFAP-110 is

blocked by mAb $4 \mathrm{C} 3$ and $\mathrm{Ab} \mathrm{F} 1$

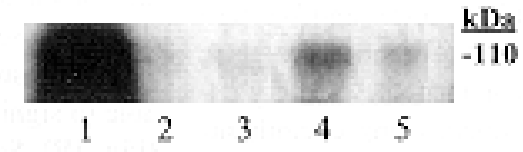

B

Affinity absorption of AFAP ${ }^{1-145}$ is

blocked by $\mathrm{mAb} 4 \mathrm{C} 3$ and $\mathrm{Ab} F 1$

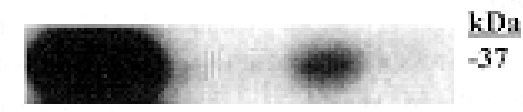

12345

C

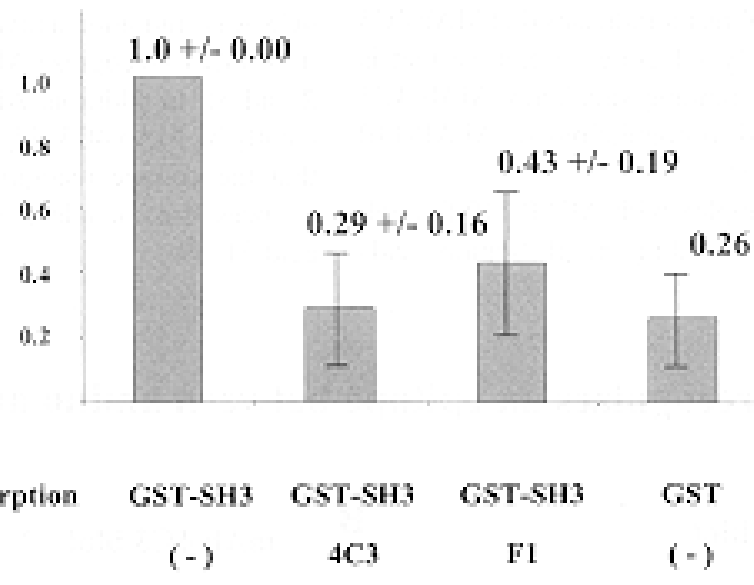

Figure 1. (A) MAb 4C3 Competitively Blocks SH3 Absorption of AFAP-110 and $\mathrm{AFAP}^{1-145}$ from Cell Lysates. CE cells were lysed and preincubated with mAb 4C3 (Lane 
2), Ab F1 (Lane 3) or PBS (Lane 4 and 5). Affinity absorption with GST-SH3 ${ }^{\text {src }}$ (Lanes 2-4) or GST (Lane 5) followed by western blot analysis. Twenty-five $\mu \mathrm{g}$ of CE cell lysate was resolved for comparison (Lane 1). (B) Cell lysates containing AFAP ${ }^{1-145}$ were preincubated with mAb 4C3 (Lane 2), Ab F1 (Lane 3) or PBS (Lane 4 and 5). Affinity absorption was done with GST-SH3 ${ }^{\text {scc }}$ (Lanes 2-4) or GST (Lane 5). AFAP ${ }^{1-145}$ was resolved for comparison (Lane 1). (C) Scanning densitometric analysis of affinity absorbed AFAP-110, relative to affinity absorption of AFAP-110 by GST-SH3 ${ }^{\text {src }}$. The bar graph demonstrates the average reduction of AFAP-110 affinity absorption in two experiments upon mAb $4 \mathrm{C} 3$ or $\mathrm{Ab} \mathrm{F} 1$ preincubation. 


\section{Mab $4 C 3$ recognizes an epitope between amino acids 71 and 77}
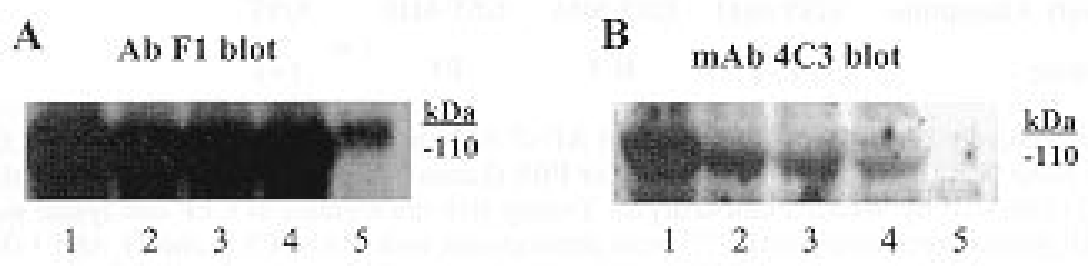

Figure 2. Identification of the Epitope Recognized by mAb 4C3. Cos-1 cell

expressing AFAP-110 (Lane 1), AFAP ${ }^{\Delta 71 \mathrm{~A}}$ (Lane 2), $\operatorname{AFAP}^{77 \mathrm{~A}}$ (Lane 3), or AFAP $\mathrm{AP}^{71 \mathrm{~A} / 77 \mathrm{~A}}$ (Lane 4) or Cos-1 cells were lysed and $25 \mu \mathrm{g}$ of lysate resolved by $8 \%$ SDS-PAGE. (A) Western blot analysis was performed with Ab F1, then stripped and reprobed with (B) $\mathrm{mAb} 4 \mathrm{C} 3$. 

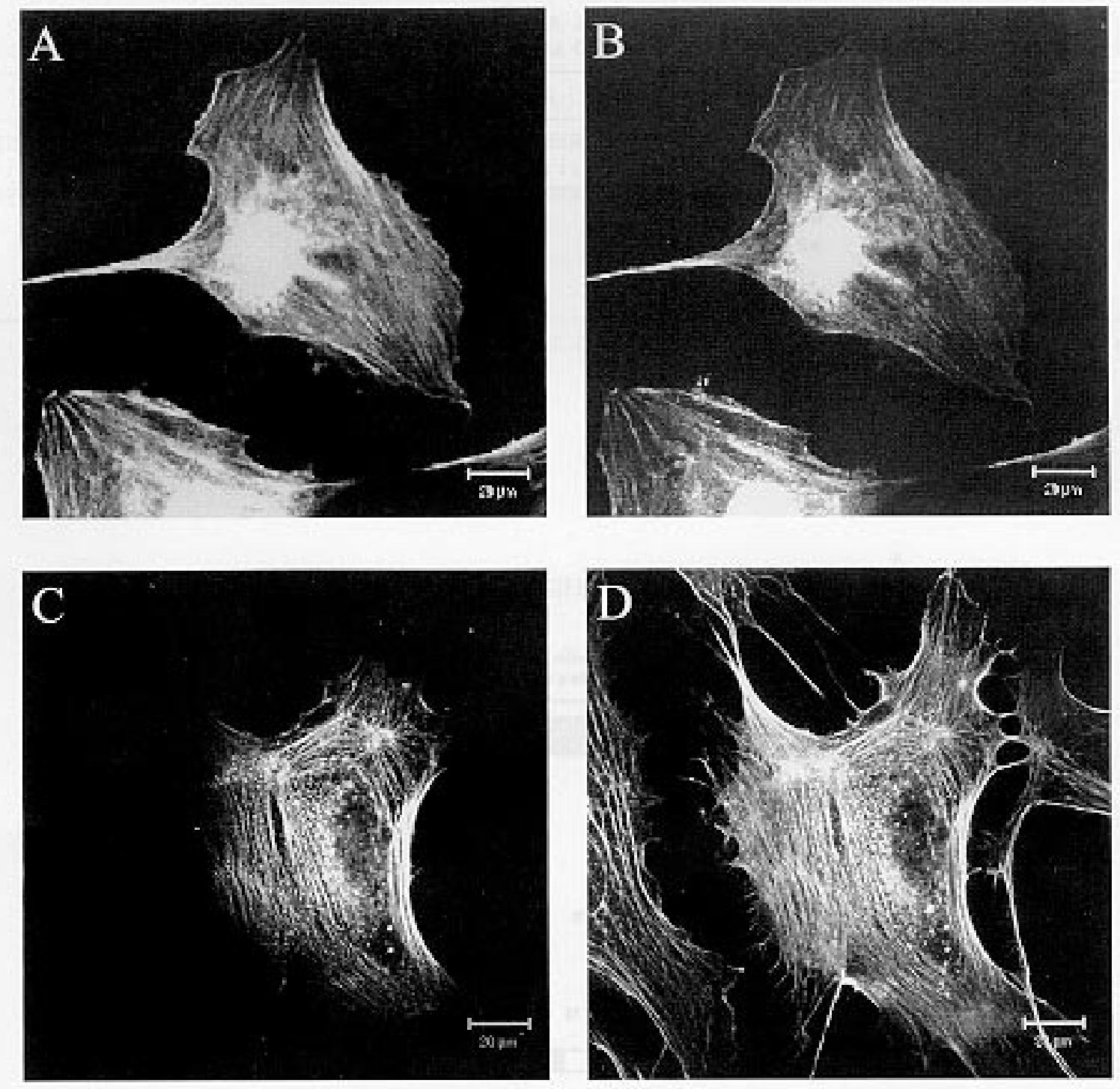

Figure 3. MAb 4C3 Recognizes an Avian-Specific Epitope. C3H10T1/2 murine fibroblast cells were processed for immunofluorescence localization of endogenous 
AFAP-110 using Ab F1, followed by detection with anti-rabbit antibodies conjugated to TRITC (Panel A) and FITC-conjugated phalloidin, to highlight actin filaments (Panel B). C3H10T1/2 cells were transiently transfected with a cDNA encoding avian AFAP-110 and immunofluorescence labeling performed by incubating the cells with either mAb $4 \mathrm{C} 3$ followed by anti-mouse antibodies conjugated to TRITC (Panel C) and FITC-conjugated phalloidin to highlight actin filaments (Panel D). 
A

Detail view of ATAP-110 carboxy terminus

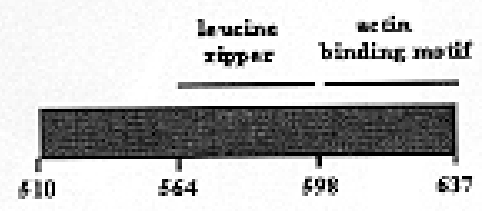

B

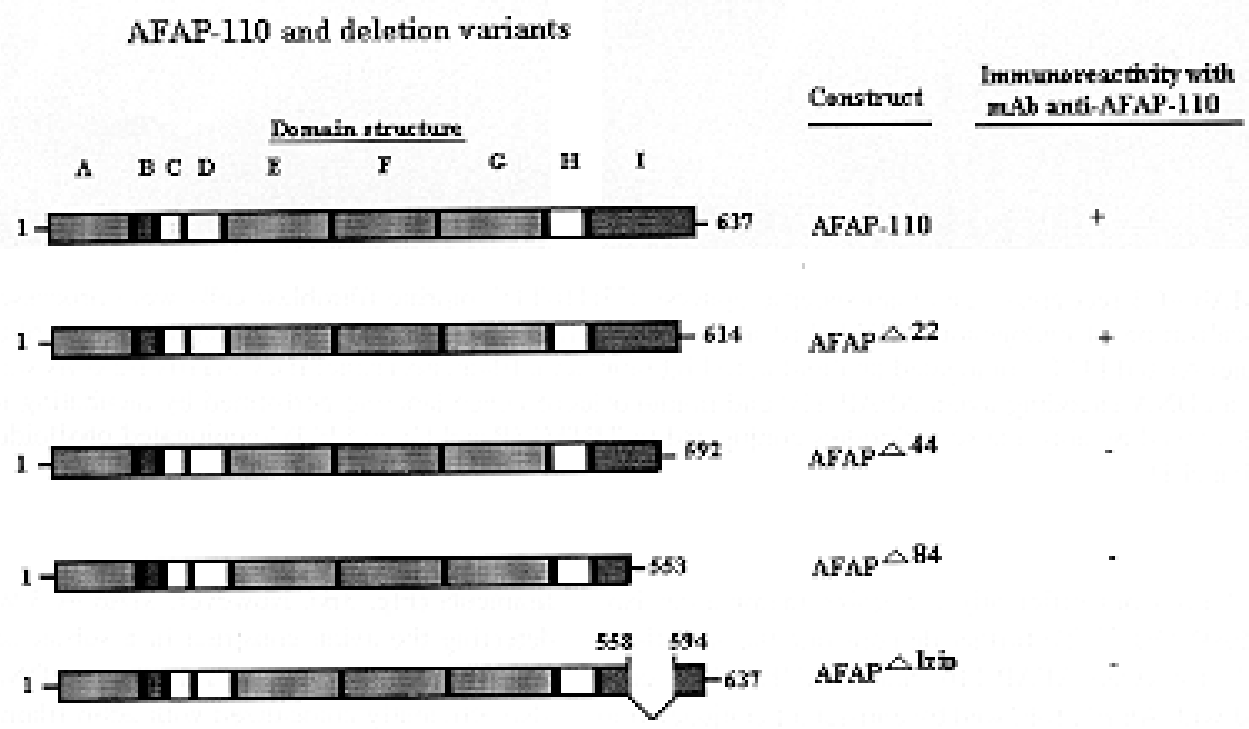

Figure 4. (A) The Carboxy Terminus of AFAP-110 Contains a Leucine Zipper Motif, defined by amino acids 564-598, and an actin binding motif, defined by amino acids 599-637. (B) Deletion variants of AFAP-110 were generated by engineering in stop 
codons in place of the codons at amino acid positions $615\left(\mathrm{AFAP}^{\Delta 22}\right), 593\left(\mathrm{AFAP}^{\Delta 44}\right)$ or $554\left(\mathrm{AFAP}^{\Delta 84}\right) . \mathrm{AFAP}^{\Delta \mathrm{lzip}}$ lacks amino acids 559-593. These deletions remove part or all of the actin binding motif ( $\mathrm{AFAP}^{\Delta 22}$ and $\mathrm{AFAP}^{\Delta 44}$, respectively), as well as the leucine zipper motif $\left(\mathrm{AFAP}^{\Delta 84}\right)$, or only the leucine zipper motif $\left(\mathrm{AFAP}^{\Delta l \mathrm{zip}}\right)$. Domain structure: (A) amino acids 1-61 - unknown function, (B) amino acids 62-71 - SH3 binding motif, (C) amino acids 75-84 - proline-rich motif, (D) amino acids 85-152 - SH2 binding motif contain $\mathrm{Y}^{94}$, (E) amino acids 153-248 - pleckstrin homology domain I, (F) amino acids 210-360 - target site for serine/threonine kinases, (G) amino acids 347-450 - pleckstrin homology domain II, (H) amino acids 450-510 - SH2 binding motif containing $\mathrm{Y}^{451 / 453}$, (I) amino acids 511-637 in AFAP-110 carboxy terminal leucine zipper motif and actin binding domain. 


\section{Mab anti-AFAP-110 recognizes an epitope in the carboxy terminus}

A

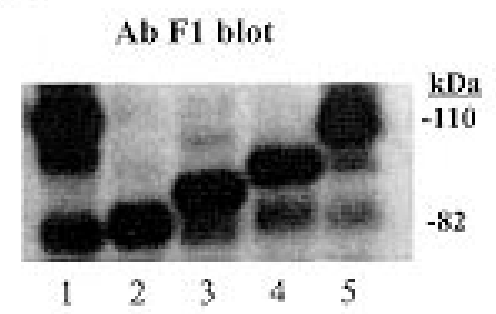

B

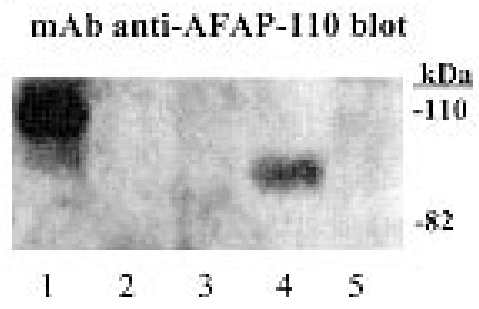

Figure 5. MAb anti-AFAP-110 Recognizes an Epitope that Includes Lys ${ }^{593}$ in the Leucine Zipper Motif. Cos-1 cell lysates were transfected with AFAP-110 (Lane 1), $\operatorname{AFAP}^{\Delta 84}$ (Lane 2), $\operatorname{AFAP}^{\Delta 44}$ (Lane 3), $\operatorname{AFAP}^{\Delta 22}$ (Lane 4) and $\operatorname{AFAP}^{\Delta l z i p}$ (Lane 5). Twenty-five $\mu \mathrm{g}$ of cell lysate resolved by $8 \%$ SDS-PAGE and transferred to PVDF by western transfer. (A) Western blot of cell lysates with Ab F1, then stripped and reprobed with (B) mAb anti-AFAP-110. 


\section{Reference}

Baisden, J.M., Qian Y., Zot H.G., and Flynn D.C. AFAP-110 interacts with and alters actin filament integrity through carboxy terminal interactions. Submitted.

Boyer P.L., Colmenares C., Stavnezer E., Hughes S.H. (1993) Sequence and biological activity of chicken snoN cDNA clones. Oncogene 8,457-466 Cheadle C., Ivashchenko Y., South V., Searfoss G.H., French S., Howk R., Ricca G.A., and Jaye M. (1994) Identification of a Src SH3 domain binding motif by screening a random phage display library. J. Biol. Chem. 269,24034-24039.

Chen C., and Okayama H. (1987) High-efficiency transformation of mammalian cells by plasmid DNA. Mol. Cell. Biol. 7,2745-2752.

Cooray, P., Yuan, Y., Schoenwaelder, S.M., Mithcell, C.A., Salem, H.H., and Jackson, S.P. (1996) Focal adhesion kinase (pp125FAK) cleavage and regulation by calpain. Biochem. J. 318,41-47.

Croall, D.E. and Demartino, G.N. (1991) Calcium-activated neurtal protease (calpain) system: structure, function, and regulation. Physiol. Rev. 71,813-847.

Felice G.R., Eason P., Nermut M.V., and Kellie S. (1990) Pp60v-src association with the cytoskeleton induces actin reorganization without affecting polymerization status. Eur. J. Cell. Biol. 52,47-59.

Flynn D.C., Horne T.-L., Reynolds A.B., and Parsons J.T. (1993) Identification and sequence analysis of DNAs encoding a 110 kilodalton actin filament associated pp60src substrate. Mol. and Cell. Biol. 13,7892-7900. 
Flynn D.C., Koay T.C., Humphries C.G., and Guappone A.C. (1995) AFAP-120: A variant form of the $\mathrm{Src} \mathrm{SH} / \mathrm{SH} 3$ binding partner AFAP-110 is detected in brain and contains a novel internal sequence which binds to a $67 \mathrm{kDa}$ protein. J. Biol. Chem. 270,3894-3899.

Gibson T.J., Hyvonen M., Musacchio A., Saraste M., Birney E. (1994) PH domain: the first anniversary. Trends Biochem. Sci. 19,349-353.

Guappone A.C., Qian Y., Weimer T.G., and Flynn D.C. (1996) An in vivo system for analysis of stable complex formation between Src and AFAP-110. Meth. in Cell Sci. $18,1-11$.

Guappone, A.C. and Flynn D.C. (1997) The Integrity of the SH3 Binding Motif of AFAP-110 is Required to Facilitate Tyrosine Phosphorylation by, and Stable Complex Formation with, Src., Mol. and Cell. Biochem. 175,243-252.

Guappone, A.C., Weimer T., and Flynn D.C. (1998). Formation of a stable Src-AFAP110 complex through either an amino terminal or a carboxy terminal SH2-binding motif. Molecular Carcinogenesis 22,110-119.

Huttenlocher, A., Palecek, S.P., Lu, Q., Zhang, W., Mellgren, R.L., Lauffenburger, D.A., Ginsberg, M.H., and Horowitz, A.F. (1997) Regulation of cell migration by the calcium-dependent protease calpain. J. Biol. Chem. 272,32719-32722.

Kanner S.B., Reynolds A.B., Parsons J.T. (1989) Immunoaffinity purification of tyrosine-phosphorylated cellular proteins. J. Immunol. Methods 120,115-124.

Kanner S.B., Reynolds A.B., Vines R.R., Parsons J.T. (1990) Monoclonal antibodies to individual tyrosine-phosphorylated protein substrates of oncogene-encoded tyrosine kinases. Proc. Natl. Acad. Sci. U. S. A. 87,3328-3332. 
Kanner S.B., Reynolds A.B., Wang, H.-C., and Parsons J.T. (1991) The SH2 and SH3 domains of pp60src direct stable association with tyrosine phosphorylated proteins p130 and p110. EMBO J. 10,1689-1698.

Kuneida, T., Matsui, M., Nomura, N., and Ishizaki, R. (1991) Cloning of an activated human ret gene with a novel 5' sequence fused by DNA rearrangement. Gene 107,323328.

Lewis J.M., Cheresh D.A., Schwartz M.A. (1996) Protein kinase C regulates alpha v beta 5-dependent cytoskeletal associations and focal adhesion kinase phosphorylation. $\mathrm{J}$. Cell Biol. 134,1323-1332.

Liu M., Qin Y., Liu J., Tanswell A.K., Post M. (1996) Mechanical strain induces pp60src activation and translocation to cytoskeleton in fetal rat lung cells. J. Biol. Chem. $271,7066-7071$

Luttrell, D.K., Luttrell, L.M., and Parsons, S.J. (1988) Augmented mitogenic responsiveness to epidermal growth factor in murine fibroblasts that overexpress pp60csrc. Mol. Cell. Biol. 8,497-501.

Melloni, E., Pontremoli, S., Michetti, M., Sacco, O., Sparatore, B., Salamino, F., and Horecker, B.L. (1985) Binding of protein kinase C to neutrophil membranes in the presence of $\mathrm{Ca}+2$ and its activation by a $\mathrm{Ca}+2$-requiring proteinase. Proc. Natl. Acad. Sci., U.S.A. 82,6435-6439.

Qian, Y., Baisden J. M., Westin E. H., Guappone A. C., Koay T., and Flynn D.C. (1998) Src can regulate carboxy terminal interactions with AFAP-110 which modulate self-association and cell localization. Oncogene 16,2185-2195. 
Reynolds A.B., Kanner S.B., Wang H.-C., and Parsons J.T. (1989) Stable association of activated pp $60^{\mathrm{src}}$ with two tyrosine phosphorylated cellular proteins. Mol. Cell. Biol. 9,3951-3958.

Reynolds A.B., Roesel D.J., Kanner S.B., and Parsons J.T. (1989) Transformationspecific tyrosine phosphorylation of a novel cellular protein in chicken cells expressing oncogenic variants of the avian cellular Src gene. Mol. Cell. Biol. 9,629-638.

Rickles R.J., Botfield M.C., Weng Z., Taylor J.A., Green O.M., Brugge J.S., and Zoller M.J. (1994) Identification of Src, Fyn, Lyn, PI3-K and Abl SH3 domain ligands using phage display libraries. EMBO J. 13,5598-5604.

Rickles R.J., Botfield M.C., Zhou X.-M., Henry P.A., Brugge J.S., and Zoller M.J. (1995) Phage display selection of ligand residues important for Src homology 3 domain binding specificity. Proc. Natl.. Acad. Sci., U.S.A. 92,10909-10913.

Shaw G. (1996) The pleckstrin homology domain: an intriguing multifunctional protein module. Bioessays 18,35-46.

Shuster, C.B., and Herman, I.M. (1995) Indirect association of ezrin with F-actin: isoform specificity and calcium sensitivity. J. Cell Biol. 128,837-848.

Smith D.B. and Johnson K.S. (1988) Single-step purification of polypeptides expressed in Escherichia coli as fusions with gultathione S-transferase. Gene 67,31-40.

Sparks A.B., Quilliam L.A., Thorn J.M., Der C.J., and Kay B.K. (1994) Identification and characterization of Src SH3 ligands from phage-displayed random peptide libraries. J. Biol. Chem. 269,23853-23856.

Ren R., Mayer B.J., Cicchetti P., Baltimore D. (1993) Identification of a ten-amino acid proline-rich SH3 binding site. Science 259,1157-1161. 
Vuori, K., and Ruoslahti, E. (1993) Activation of protein kinase C precedes $\alpha 5 \beta 1$

integrin-mediated cell spreading on fibronectin. J. Biol. Chem. 268,21459-21462.

Weng A., Thomas S.M., Rickles R.J., Taylor J.A., Brauer A.W., Seidel-Dugan C.,

Michael W.M., Dreyfuss G., and Brugge J.S. (1994) Identification of Src, Fyn, and

Lyn SH3-binding proteins: Implications for a function of SH3 domains. Mol. Cell. Biol. $14,4509-4521$.

Yao, X., Thibodeau, A., and Forte, J.G. (1993). Exrin-calpain I interactions in gastric parietal cells. Am. J. Physiol. 265,C36-46. 


\title{
CHAPTER 3
}

\section{Src can regulate carboxy terminal interactions with AFAP-110, which influence self-association, cell localization and actin filament integrity}

\author{
Yong Qian, Joseph M. Baisden, Eric H Westin, Anne C. Guappone, Thomas C \\ Koay and Daniel C. Flynn \\ Mary Babb Randolph Cancer Center and the Department of Microbiology and \\ Immunology, West Virginia University, Morgantown, WV 26506-9300
}

This manuscript was published in the April 1998 issue of Oncogene (Vol 36, No. 17, P. 2185-2195) 


\begin{abstract}
AFAP-110 is a tyrosine phosphorylated substrate of Src. It has both SH2 and SH3 binding motifs, and has been hypothesized to link Src to actin filaments and facilitate the effects of Src upon actin filaments. But, it is not clear how Src affects both the structure and function of AFAP-110, or whether AFAP-110 has the ability to modulate the integrity of actin filaments. In this report, we found that AFAP-110 has a leucine zipper motif within its carboxy terminus, indicating AFAP-110 has the potential to selfassociate. Expression of carboxy terminus of AFAP-110 as a GST-fusion protein enabled affinity absorption of AFAP-110 from Cos-1 cell lysates that overexpressed AFAP-110. The integrity of leucine zipper motif is required for affinity absorption, but the affinity absorption is not due to a classical leucine zipper motif. Expression of $\mathrm{Src}^{527 \mathrm{~F}}$, but not cSrc, abrogates affinity absorption, indicating Src transformation induces a conformational change in AFAP-110. Superose chromatography demonstrates that AFAP-110 exists as either a monomer or multimer (tetramer or trimer) in cell lysates, indicating AFAP-110 does have the ability to self-association in vivo. Expression of $\mathrm{Src}^{527 \mathrm{~F}}$ only permit the detection of a singer multimer form of AFAP-110, indicating the profile of AFAP-110's self-association is changed upon $\mathrm{Src}^{527 \mathrm{~F}}$ transformation, in vivo. Deletional mutagenesis experiments indicate a regulatory role for the carboxy terminus in AFAP-110. Deletion of the entire carboxy terminal long $\alpha$-helix prevents colocalization with actin filaments, while deletion of only leucine zipper motif repositions both AFAP$110^{\Delta \mathrm{lzip}}$ and actin filaments into rosette like structure, similar to the phenotype of $\mathrm{Src}^{527 \mathrm{~F}}$ transformation. Therefore, these data indicate that AFAP-110 may play an important role
\end{abstract}


in modulating the integrity of actin filaments through a motif that also affects multimerization. 


\section{Introduction}

cSrc is one of non-receptor tyrosine kinases, which is enzymatically maintained in repressed form in vivo (Cooper and Brown, 1996). The transient activation of $\mathrm{cSrc}$ is observed during $\mathrm{G}_{2} / \mathrm{M}$ transition of the cell cycle, indicating the tyrosine kinase activity of cSrc is tightly controlled and that activation of cSrc is important for cell cycle progression (Roche et al, 1995; Taylor and shalloway, 1996). Constitutive activation of cSrc is sufficient for the transformation of cells in culture. One characteristic of cSrc transformation is a change in cell morphology that is linked to the disruption of actin filaments (Cooper and Brown, 1996; Felice et al, 1990; Reynolds et al, 1989; Flynn et al, 1993). The transition of $\mathrm{G}_{2} / \mathrm{M}$ within the cell cycle is marked by the relaxation of actin filaments, which is prior to the onset of mitosis (Jackson and Bellet, 1989). Therefore, one consequence of cSrc transformation may be the disruption of actin filaments, which in turn affects the phenotype and growth of cells that express activated cSrc. There is some evidence that constitutively activated cSrc is observed in some cancer cells (Rosen et al, 1986; Jacobs and Rubsamen, 1983; Cartwright et al, 1989; Cartwright et al, 1990; Bolen et al, 1987; Staley et al, 1997), indicating constitutively activated cSrc may contribute to the formation of the cancer phenotype. The disruption of actin filaments is the hallmark of transformation by both vSrc and constitutively activated cSrc (Reynolds et al, 1989; Felice et al, 1990). The mechanism whereby activated cSrc affects cell growth and morphology is unknown. It is hypothesized that $\mathrm{cSrc}$ phosphorylates protein substrates on tyrosine and, as a consequence, these phosphorylated substrates may modulate the transfer of cellular signals to influence cell growth and transformation (Schaller et al, 1993). It is clear that understanding the mechanism by which activated 
variants of cSrc affect their substrates is important for understanding how non-receptor tyrosine kinase modulates cellular signals that affect cell growth and transformation.

One model system for understanding the affects of Src upon actin filaments is AFAP-110 (Actin Filament Associated Protein, 110 kDa; Flynn et al, 1993; Flynn et al, 1995). AFAP-110 is a tyrosine phosphorylated Src substrate and binding partner. It was found that AFAP-110 can form a stable complex with activated variants of Src, and formation of the stable complex is dependent on the integrity of $\mathrm{SH} 2$ and $\mathrm{SH} 3$ interactions (Reynolds et al, 1989; Kanner et al, 1991; Flynn et al, 1993; Guappone et al, submitted). It has been hypothesized that AFAP-110 may facilitate interactions between SH2 and/or SH3 containing signal proteins and actin filaments, and facilitate the effects of these proteins on actin filaments (Flynn et al, 1993). The consequences of Src and AFAP-110 interaction are unknown. It is hypothesized that AFAP-110 may serve to facilitate the effects of Src upon actin filaments. Therefore, understanding the function of AFAP-110 and the effects of Src upon AFAP-110 may provide the clue to the mechanism by which AFAP-110 is involved in Src mediated signal transduction and, eventually, to dissect the mechanism by which Src affects cell growth and morphology.

One strategy to characterize the function of AFAP-110 is to identify its domain structure (Figure 1). It has one SH3 binding motif, which is shown to facilitate interactions with Src, Fyn and Lyn (Flynn et al, 1993; Guoppone and Flynn, 1997). SH3 interaction between Src and AFAP-110 is important to present AFAP-110 for the phosphorylation (Kanner, et al, 1991; Guoppone and Flynn, 1997). There is a possible WW domain binding site adjacent to SH3 binding motif. AFAP-110 also contains two SH2 binding motifs and two pleckstrin domains (PH) (Gibson et al, 1994; Shaw, 1996; 
Flynn et al, 1993). There is a serine/threonine substrate region between two PH domains, indicating AFAP-110 may be phosphorylated at serine/threonine as well. Both AFAP110's domain structure and localization within the cells indicate that AFAP-110 may have the ability to facilitate the interactions between $\mathrm{SH} 2 / \mathrm{SH} 3$ containing signal proteins, and/or other signal proteins, and actin filaments.

Interestingly, there is an isoform of AFAP-110 in brain tissue cells called AFAP120 (Flynn et al, 1995). It encodes additional 86 amino acids, inserted between Ser ${ }^{510}$ and Phe ${ }^{511}$, termed novel insert (NINS, Figure 1). It was found that NINS doesn't disrupt the downstream reading frame of carboxy terminal 127 amino acids, which is common between AFAP-110 and AFAP-120 (Flynn et al, 1995). This indicates that the carboxy terminal 127 amino acids may have an important function for both AFAP-110 and AFAP-120. This report is designed to address the function of carboxy terminal 127 amino acids in AFAP-110.

\section{Materials and methods}

\section{Cell culture in vivo expression and immunofluorescence localization}

Cos- 1 cells were maintained in DMEM containing 5\% fetal calf serum, $2 \mathrm{mM}$ glutamine and $1 \%$ penicillin/streptomycin. Transfection of pCMV-1 plasmid constructs into Cos-1 cells was carried out according to the method of Chen and Okayama, (1987). 
pCMV-1 constructs containing pp60 $0^{527 \mathrm{~F}}$ and/or AFAP-1 10 were generated as previously described (Guappone et al., 1996). AFAP ${ }^{\Delta 84}$ encodes Met $^{1}-\mathrm{Tyr}^{553}$ and lacks the carboxy terminal 84 amino acids. $\mathrm{AFAP}^{\Delta 84}$ was created by generating a stop codon by site-directed mutagenesis. Sequence analysis confirm the presence of this stop codon and the integrity of flanking sequences. The carboxy terminus was sequenced in its entirety and subcloned into AFAP-110, to ensure that no spurious mutations could be present. AFAP- $110^{\Delta 84}$ was subcloned from pBluescript KS+ into pCMV-1 using the KpnI and $\mathrm{XbaI}$ restriction sites, similar to the cloning of AFAP-110 into pCMV-1 (Guappone et al., 1996). AFAP ${ }^{\Delta l z i p}$ lacks the leucine zipper motif. Deletion of the leucine zipper motif was accomplished by generating a second BgIII restriction site in the carboxy terminus by site directed mutagenesis. The mutations did not affect the coding sequence outside of the deleted leucine zipper motif. The BglII site was engineered at bp 1689 (using the AFAP-110 sequence numbering system -accession number L20303). A second BglII site exists at bp 1798. Digestion with Bg1II and religation removed bp 1689-1798 and created pCMV ${ }^{\mathrm{AFAP} A \mathrm{zip}}$, which lacks amino acids 554 - 598. The leucine zipper motif is defined by amino acids 564-593.

For immunofluorescence analysis, transfected cells were grown on coverslips. Sixty to 66 h post-transfection, the transfected Cos-1 cells were fixed with $3.7 \%$ formaldehyde, $30 \mathrm{~min}, 4^{\circ} \mathrm{C}$. The cell membranes were permeabilized with $0.1 \%$ Triton $\mathrm{X}-100,4 \mathrm{~min}, 21^{\circ} \mathrm{C}$. Immunofluorescence localization of transiently expressed AFAP-110 or AFAP $110^{\Delta 84}$ was accomplished using Ab F1, as previously described (Flynn et al, 1993). Concentrations of Ab F1 were reduced to $1 \mu \mathrm{g} / \mu \mathrm{l}$ to preferentially image transiently expressed proteins and not Cos- I cellular AFAP-110, by immunofluor- 
escence. Ab F1 was detected with donkey a-rabbit TRITC (Sigma). Actin filaments were imaged using FITC-phalloidin (Sigma). After the final wash, the coverslips were mounted on slides for image analysis. Immunofluorescence images for actin filaments, AFAP-110, AFAP $^{\Delta 84}$ and AFAP ${ }^{\Delta l z i p}$ were acquired and analyzed in the WVU Anatomy department Image Analysis Lab using a Zeiss confocal microscope and scanning different planes of the cell. Images presented reflect single scanned planes. The images were collected as color and reprocessed for black and white.

\section{Generation of GST encoded fusion proteins and affinity absorption}

pGex-cterm was created by PCR amplification (with engineered BamHI and EcoRI restriction sites at the end of each primer) of the coding sequence in AFAP-110 encoding Phe ${ }^{511}$ to $\mathrm{Asp}^{637}$ and was subcloned into the novel BamHI and EcoRI sites in pGex-2T. Similarly, deletion variants of the GST-cterm were created by PCR amplification of the specified region and subcloned into pGex-2T via the unique BamHI and EcoRI sites. Deletion of the leucine zipper motif in pGex-cterm was accomplished by engineering a Bg1II site at bp 1689-1693 (using the AFAP-110 sequence numbering system -accession number L20303) in pGEX-cterrn. Creation of this new BglII site required site-directed mutagenesis of bp 1689 from $\mathrm{G} \rightarrow \mathrm{A}$ and at bp $1680 \mathrm{~A} \rightarrow \mathrm{G}$. A second BglII site exists at bp 1798. Digestion with BgIII and religation removed bp 16891798, which removes amino acids 558-593. All constructs were verified by sequence analysis over the amplified region. The preparation of bacterial lysates containing these fusion proteins as well as immobilization of the fusion proteins to glutathione-coated sepharose beads, was accomplished as previously described (Guappone et al., 1996). All 
immobilized fusion proteins were quantitated before absorption by resolving the immobilized protein on a $12 \%$ SDS-PAGE and quantitating by Coomassie staining. Twenty $\mu \mathrm{g}$ of fusion protein was immobilized upon $100 \mu \mathrm{g}$ glutathione-coated sepharose beads (50\% slurry, Pharmacia). Cell lysates were prepared with NP40 lysis buffer (1\% NP-40; 50 mM Tris, $\mathrm{pH}$ 7.5; 150 mM NaCl; 2 mM Sodium Vanadate; 2 mM PMSF; 50 $\mu \mathrm{g} / \mathrm{ml}$ aprotinin; $2 \mathrm{mM}$ EGTA). Lysis buffers containing ionic detergents, e.g., RIPA containing SDS and/or $0.25 \%$ deoxycholate, did not permit efficient and reproducible affinity absorption (data not shown).

Immobilized fusion proteins were incubated with $100 \mu \mathrm{g}$ Cos- 1 cell lysates $(0.2$ $\mu \mathrm{g} / \mu \mathrm{l})$ for $\mathrm{I} \mathrm{h}, 4^{\circ} \mathrm{C}$, while rotating on an orbital shaker. Immobilized cellular proteins were washed twice with NP-40 lysis buffer (200 A) and twice with trisbuffered saline (200 $\mu \mathrm{l} ; 50 \mathrm{mM}$ tris, pH 7.5; $150 \mathrm{mM} \mathrm{NaCl}$ ) then eluted by adding $50 \mu 12 \mathrm{x}$ Laemmli sample buffer and boiling for 3-5 min. The solubilized proteins were separated from the sepharose beads by centrifugation, and resolved by SDS -PAGE, as previously described (Guappone et al., 1997; Flynn et al., 1995).

\section{FPLC analysis and gel filtration}

Gel filtration of Cos-1 cellular lysates was accomplished using a Superose 6 10/30 chromatography column and FPLC. The column was equilibrated with 1\% NP40 lysis buffer and molecular weight standards were run independently of each other, using dimeric Jack Bean Urease, Alcohol dehydrogenase, dimeric BSA, ovalbumin, dimeric carbouic anhydrase and $\beta$-amylase as standards. One hundred $\mu 1$ of transfected Cos-I

cellular lysates was injected into the column. This represents approximately $1 / 10^{\text {th }}$ of the 
total cell lysate obtained from a $100 \mathrm{~mm}$ plate (approximately $100 \mu \mathrm{g}$ of total cellular protein lysate $)$. Fractions were collected every $2 \mathrm{~min}(0.4 \mathrm{ml} /$ fraction with a flow rate of $0.2 \mathrm{ml} / \mathrm{min}$ ), beginning after $12 \mathrm{mls}$ of buffer had been eluted through the column.

One-hundred $\mu \mathrm{l}$ from each fraction were resolved by $8 \%$ SDS-PAGE and probed for the presence of AFAP-I 10 by Western blot analysis with Ab Fl.

\section{Protein characterization and analysis}

The monoclonal antibody 4C3 (Kanner et al., 1989) was used as previously described (Kanner et al., 1990) and the polyvalent antibody (Ab) FI was prepared as previously described (Flynn et al., 1993). Isolation of immune complexes, Western transfer and Western blot analysis with Ab F1 were done as previously described (Flynn et al., 1993). Bound primary antibody was quantitated using an HRP-conjugated secondary antibody followed by detection using chemiluminescence.

\section{Results}

\section{The carboxy terminus of AFAP-110 contains a leucine zipper motif.}

AFAP-120 is a variant form of AFAP-110, and encodes an additional $256 \mathrm{bp}$ sequence that is predicted to encode 86 amino acids, referred to as a novel insert (NINS) (Flynn et al, 1995). Because NINS doesn't disrupt the downstream reading frame of carboxy terminal 127 amino acids that are conserved between AFAP-110 and AFAP-120 (Figure 1), we projected that the carboxy terminal 127 amino acids may have some 
important functions. A homology search found that there are two classes of proteins: cytoskeleton proteins and transcriptional factors, which have homologous domain as the carboxy terminus of AFAP-110 (Table 1). The detailed study found that homologous domain is located between amino acids 553 and 593 and may exist as a heptad repeat called leucine zipper motif. The leucine zipper motif is a well known protein interaction domain structure in transcription factors as well as cytoskeleton proteins (Hurst, 1994; Busch and Sassone-Vorsi, 1990). Sequence analysis found there is no basic region upstream the leucine zipper motif of AFAP-110, indicating that AFAP-110's leucine zipper may not be able to bind to DNA (data not shown).

\section{Affinity absorption of AFAP-110 from cell lysates with a GST-encoded fusion protein expressing the carboxy terminal 127 amino acid fragment}

The leucine zipper motif is a well-characterized domain structure, which mediates protein-protein interaction (Busch and Sassone-Corsi, 1990). Many leucine zipper containing proteins are able to self-associate. The homology data implies that AFAP-110 may have the ability to associate with itself or other proteins through its carboxy terminal 127 amino acids. To determine whether AFAP-110 has the ability to self-associate, the affinity absorption experiments were applied. We used GST fusion protein that expresses carboxy terminal AFAP-110 (GST-cterm) to affinity absorb cellular AFAP-110, which was over-expressed in Cos-1 cells. The secondary structure of the carboxy terminus of AFAP-110 was evaluated. It was shown that the first 42 amino acids of the carboxy terminus exist as a combination of coil, $\beta$-sheath and turn, referred as coil/turn region (Figure 2a). The carboxy 84 amino acids is predicted to be a single long $\alpha$-helical 
structure, and the leucine zipper motif in part of this long $\alpha$-helix, located at the amino terminus of this $\alpha$-helix (Figure 2a). Four deletion variants of GST-cterm were created to determine which region within carboxy terminus is important for self-association (Figure 2a). All of the fusion proteins were immobilized on glutathione-coated sepharose beads, and used to absorb Cos-1 cell lysates overexpressing AFAP-110. The data showed GSTcterm, GST-CT ${ }^{\Delta 42}$ and GST-CT ${ }^{\Delta 44}$ were able to affinity absorb cellular AFAP-110 while GST alone was unable to affinity absorb AFAP-110 (Figure 2b). There is a slight decrease in affinity absorption of GST-CT ${ }^{\Delta 42}$ and a slight increase in affinity absorption for GST-CT ${ }^{\Delta 44}$, indicating a structural or regulatory role for these regions in affinity absorption. There is also an $82 \mathrm{kDa}$ band below AFAP-110, and we hypothesized it was an AFAP-110's proteolytic breakdown product (Flynn et al, 1995; Qian et al, 1999). GST-CT $^{\Delta L z i p}$ was deficient in binding of cellular AFAP-110 while GST-CT ${ }^{\Delta 84}$ was unable to bind to cellular AFAP-110 altogether (Figure 2b). These data indicate the long $\alpha$-helical structure including leucine zipper motif is important for affinity absorption of AFAP-110. Therefore, AFAP-110 may have the ability to self-associate through carboxy terminal interaction, and the long $\alpha$-helical region is required for the interaction.

Leucine zipper motifs mediate protein-protein interactions by forming a hydrophobic interaction with other similar or identical leucine zipper motifs (Busch and Sassone-Vorsi, 1990). To determine whether affinity absorption is mediated by the hydrophobic interactions defined by a classic leucine zipper interaction, or by other interactions defined in the $\alpha$-helix, point mutations were targeted within the integral part of the leucine zipper. Leu ${ }^{581}$ is the third leucine within the heptad repeat and this leucine was mutated to Pro within GST-cterm (GST-CT ${ }^{\mathrm{L} 581 \mathrm{P}}$ ). This mutation is predicted to 
create a short turn in the $\alpha$-helical region. $\mathrm{Leu}^{574}$ is the second leucine within the heptad repeat and this leucine was mutated to Arg. This mutation was predicted to disrupt the hydrophobic interaction that normally mediated by leucine zipper residues. The second leucine mutation was introduced into GST-CT ${ }^{\mathrm{L} 581 \mathrm{P}}\left(\mathrm{GST}-\mathrm{CT}^{\mathrm{L} 574 \mathrm{R} / \mathrm{L} 581 \mathrm{P}}\right)$. The affinity absorption using both normal and mutated GST-cterms show that GST-cterm, GST$\mathrm{CT}^{\mathrm{L} 581 \mathrm{P}}$ and GST-CT ${ }^{\mathrm{L} 574 \mathrm{R} / \mathrm{L} 581 \mathrm{P}}$ each can affinity absorb cellular AFAP-110 (Figure 2c). These data indicate that affinity absorption of AFAP-110 is not mediated by hydrophobic interactions defined by the classic leucine zipper motif, and might be mediated by a distinct interaction within the carboxy terminal $\alpha$ - helix instead.

\section{Co-expression of $\mathrm{Src}^{527 \mathrm{~F}}$, but not cSrc, prevent GST-cterm from absorbing AFAP- 110 from Cos-1 cell lysates.}

To determine how the putative AFAP-110's self-association is regulated in vivo, the affinity absorption was performed using AFAP-110, co-expressed either with enzymatically activated $\mathrm{Src}^{527 \mathrm{~F}}$ or enzymatically inactivated cSrc, to evaluate the effects of Src on the ability of GST-cterm to absorb cellular AFAP-110. AFAP-110 was transiently expressed in Cos- 1 cells alone, co-expressed with either $\mathrm{Src}^{527 \mathrm{~F}}$ or cSrc (Figure 3), as previously described (Guappone et al, 1996). The expressed AFAP-110s were immunoprecipitated with F1 antibody and the level of tyrosine phosphorylation was quantitated using rabbit anti-phosphotyrosine. The data show there are equal amounts of AFAP-110 immunoprecipitated from Cos-1 cell lysates, expressing AFAP-110 alone,

coexpressing with $\mathrm{Src}^{527 \mathrm{~F}}$ and coexpressing with cSrc (Figure 3a). Both $\mathrm{Src}^{527 \mathrm{~F}}$ and cSrc can phosphorylate AFAP-110 to significantly high levels while expression of AFAP-110 
is not tyrosine phosphorylated in the absent of Src (Figure 3b). Affinity absorption show GST-cterm can affinity absorb both AFAP-110 expressed alone and AFAP-110 coexpressed with cSrc, but it is unable to absorb AFAP-110 coexpressing with $\mathrm{Src}^{527 \mathrm{~F}}$ (Figure 3c). The abrogation of the affinity absorption may not be due to tyrosine phosphorylation, as both $\mathrm{cSrc}$ and $\mathrm{Src}^{527 \mathrm{~F}}$ can phosphorylate AFAP-110 on tyrosines (Figure 3b), and GST-cterm can affinity absorb tyrosine phosphorylated AFAP-110 that coexpresses with cSrc (Figure 3d). These data indicate that enzymatically activated $\mathrm{Src}^{527 \mathrm{~F}}$ might direct a molecular event that disrupts the interaction between GST-cterm and AFAP-110. It is possible that this molecular event is independent of tyrosine phosphorylation. Alternatively, $\mathrm{Src}^{527 \mathrm{~F}}$ may phosphorylate some tyrosine residues that are not phosphorylated by cSrc, and these $\mathrm{Src}^{527 \mathrm{~F}}$ phosphorylated tyrosines may modulate some structure changes within AFAP-110 to prevent affinity absorption by GST-cterm.

\section{AFAP-110 can exist as a monomer or multimer in cell lysates}

The affinity absorption of AFAP-110 by GST-cterm indicates that AFAP-110 may have the ability to self-associate, in vivo. To test this possibility, Cos-1 cell lysates expressing AFAP-110 were resolved by gel filtration. We used FPLC and a Superose 6 10/30 column to collect fractions of cell lysates. Superose $610 / 30$ column has the capability to resolve protein complexes between $29 \mathrm{kDa}$ and $500 \mathrm{kDa}$. The predicted size of AFAP-110 is $72,315 \mathrm{Da}$ and its relative mobility $\left(\mathrm{M}_{\mathrm{r}}\right)$ on SDS-PAGE is $110 \mathrm{kDa}$ (Flynn et al, 1995). Therefore, the Superose 6 10/30 column can identify AFAP-110 multimeric complexes, in vivo. Nineteen $400 \mu \mathrm{l}$ fractions were collected and $100 \mu \mathrm{l}$ of each was resolved on 8\% SDS-PAGE (Figure 4a). Western blot was applied to detect 
AFAP-110 using F1 antibody. The data show that AFAP-110 can be detected in two major peaks defined as fractions 7-12 and 16-18, and the $\mathrm{M}_{\mathrm{r}}$ of AFAP-110 appears as doublet bands (Figure 4a, lanes 7-12, 16-18). Scanning densitometry was used to quantitate the resolved fractions (Figure 4d), and it shows there are at least two, possibly three, peaks of distribution of AFAP-110. The first peak predicates a multimeric population of AFAP-110 around 410 to $150 \mathrm{kDa}$ represented by fraction 7-12 while second peak is around $250 \mathrm{kDa}$ represented by fraction 8-9.

These peaks predict AFAP-110 exists as a monomer to tetramer complexes in cell lysates, with fractions 9 and 10 predicting a tetramer. Fractions 11 and 12 appear as a shoulder adjacent to the tetrameric peak. Interestingly, there is a distinct peak from fractions 16 to 18 . The predicted size for this peak is around 70 to $42 \mathrm{kDa}$, indicating a monomeric population, in vivo. The peak shown at fraction 14 is likely artifact (Figure 4d), and appears as an unknown shadow shown by western blot and was read by scanning densitometry (Figure 4b). Lastly, there is very little detectable endogenous AFAP-110 in Cos-1 cell lysates (data not shown). These data indicate AFAP-110 does have the ability to self-associate in NP-40 cell lysates overexpressing AFAP-110.

Gel filtration of Cos- 1 cell lysates coexpressing AFAP-110 with Src $^{527 F}$ shows a different profile (Figure 4b). There is one peak between fractions 8-12 that represents $M_{r}$ of $340-150 \mathrm{kDa}$ (Figure $4 \mathrm{~b}$ ). The monomeric AFAP-110 peak is gone. The $\mathrm{M}_{\mathrm{r}}$ of AFAP110 is shifted. Fraction 19 from gel filtration of AFAP-110 is resolved on the lane marked $* *$ (Figure 4b). The size of AFAP-110 is slightly retarded and there is no doublet band when AFAP-110 is coexpressed with $\mathrm{Src}^{527 \mathrm{~F}}$. The retarded $\mathrm{M}_{\mathrm{r}}$ may represent a change of post-translational modification after expressing with $\mathrm{Src}^{527 \mathrm{~F}}$. Stripping and 
reprobing of this western blot with monoclonal antibody to $\mathrm{Src}^{527 \mathrm{~F}}$ show $\mathrm{Src}^{527 \mathrm{~F}}$ exists in fraction 10 (Figure 4c). The predicted size for fraction 10 is $240 \mathrm{kDa}$ (Figure 4d) and the $\mathrm{M}_{\mathrm{r}}$ of a single AFAP-110/Src ${ }^{527 \mathrm{~F}}$ complex is $130 \mathrm{kDa}$. Therefore, it indicates that there may be two molecules of AFAP-110 and two molecules of $\mathrm{Src}^{527 \mathrm{~F}}$, or three molecules of AFAP-110 and one molecule of $\mathrm{Src}^{527 \mathrm{~F}}$ within this $240 \mathrm{kDa}$ fraction. It is also possible that the association of $\mathrm{Src}^{527 \mathrm{~F}}$ with AFAP-110 may mask a population of AFAP-110 that exists as tetramers that are not bound to $\mathrm{Src}^{527 \mathrm{~F}}$ and elute coincident with fractions 8-12. The data indicate coexpression of AFAP-110 with Src $^{527 F}$ changes the profile of AFAP110 in cell lysates and the monomeric AFAP-110 is significantly reduced.

\section{The integrity of the carboxy terminal $\alpha$-helix influences cellular localization of}

\section{AFAP-110}

Experiments were designed to test the effects of the integrity of carboxy terminal $\alpha$-helical domain on AFAP-110's subcellular localization. Two deletion mutant variants were created. $\mathrm{AFAP}^{\Delta 84}$ lacks the entire carboxy terminal $\alpha$-helical region, while $\mathrm{AFAP}^{\Delta \text { lzip }}$ has no leucine zipper motif (one-half this $\alpha$-helix). AFAP-110, $\mathrm{AFAP}^{\Delta 84}$ and $\mathrm{AFAP}^{\Delta \mathrm{lzi}}$ were transiently transfected into Cos-1 cells (Figure 5), to determine the functional role of the carboxy terminal $\alpha$-helical region in AFAP-110's subcellular localization. Either AFAP-110 was expressed alone (Figure 6a and 6b) in Cos-1 cells, or AFAP-110 was coexpressed with either Src ${ }^{527 F}$ (Figure 6c and 6d)or cSrc (Figure 6e and 6f). The data show that AFAP-110 colocalizes with both actin filaments and cell membrane when it is expressed alone in Cos-1 cells (Figure 6a and 6b), or cSrc (Figure $6 \mathrm{c}-6 \mathrm{fb})$, and when it is coexpressed with $\mathrm{Src}^{527 \mathrm{~F}}$, the actin filaments are disrupted and 
repositioned into rosette-like structure, same as earlier finding in CE cells (Flynn et al, 1993). Compared to $\mathrm{Src}^{527 \mathrm{~F}}$, the effects of $\mathrm{cSrc}$ on actin filaments was much weaker, both the number and size of rosette-like structure were smaller and fewer. The deletion variant $\mathrm{AFAP}^{\Delta 84}$ is unable to colocalize with either actin filaments or cell membrane (Figure $6 \mathrm{~g}$ and $6 \mathrm{~h})$ ). It is located in the cytoplasm and exhibited in diffuse staining pattern. The data indicate that the carboxy terminal $\alpha$-helical domain is important for both AFAP-110's colocalization with actin filaments and the cell membrane.

Interestingly, deletion of only the leucine zipper motif region $\left(\mathrm{AFAP}^{\Delta \mathrm{lzip}}\right)$ resulted in the redistribution of both $\mathrm{AFAP}^{\Delta \mathrm{zip}}$ and actin filaments into rosette-like structures (Figure 6i and $6 j$ ). These data indicate that the carboxy terminal $\alpha$-helical region is important for AFAP-110's association with actin filaments and cell membrane, and the removal of leucine zipper motif will induce a change of integrity of actin filaments similar to the effects of $\operatorname{Src}^{527 \mathrm{~F}}$ transformation.

\section{Discussion}

AFAP-110 has a leucine zipper motif in its carboxy terminus, implying that AFAP-110 may have the potential to self-associate through this region, in vivo. The experiments in this report addressed whether AFAP-110 had the ability to self-associate through the carboxy terminus and whether Src regulated AFAP-110's self-association, such that we can understand the role of the leucine zipper motif in AFAP-110. Cellular AFAP-110 can be affinity absorbed by GST-cterm fusion protein, indicating AFAP-110 may have the ability to self-associate. Deletion of the carboxy terminal 84 amino acids 
from GST-cterm abrogates this affinity absorption, indicating the carboxy terminal domain has enough sequence to mediate AFAP-110's self-association. Our data show the affinity absorption is not mediated by a classical leucine zipper interaction. Leucine zipper motifs are a well-characterized protein domain involved in both homedimerization and hetrodimerization in different kinds of cellular proteins, including transcription factors (Hurst, 1994), cellular kinases (Ruth et al, 1997; Gamm et al, 1995; Kitigawa et al, 1995), transmembrane receptors (Saras et al, 1994; Kein et al, 1993; Rodrigues an Park, 1993; Chen et al, 1993) and cytoskeletal proteins (Klein et al, 1993; Bikle et al, 1996; Pearlman et al, 1994; Ward an Kirshner, 1990; Maekawa and Kuriyama, 1993). The mechanism by which the leucine zipper motif mediated dimerization is mainly through a hydrophobic interaction between two heptad repeat monomers (Hodges, 1996). Our data show that mutation of either one leucine residue (Leu $\rightarrow$ Pro) or two leucine residues (Leu $\rightarrow$ Arg; Leu $\rightarrow$ Pro) within GST-cterm do not disrupt its affinity absorption with AFAP-110. Mutation of leucine to Proline is predicted to create a turn structure at third leucine residue within the heptad repeat, while mutation of leucine to arginine is predicted to disrupt the hydrophobic interaction at second leucine residue within the heptad repeat. Therefore, the data indicate the affinity absorption is not likely mediated by a classical leucine zipper motif in AFAP-110. It should be noted that other motifs within the carboxy terminus of AFAP-110 may also contribute to affinity absorption. Although the coil/turn region (amino acids 511 to 553) doesn't permit GST-CT ${ }^{\Delta 84}$ to affinity absorb cellular AFAP-110, GST-CT ${ }^{\Delta 42}$, which lacks the coil/turn region has a slightly reduced ability to bind AFAP-110. Therefore, the coil/turn region may also

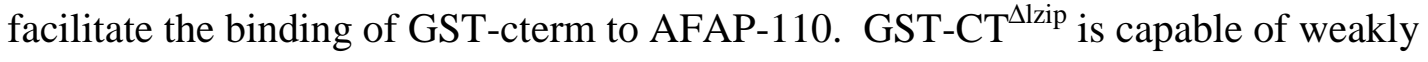


binding AFAP-110, indicating the last 44 amino acids of AFAP-110 (594 to 637) could contribute the affinity absorption. It is noteworthy that the carboxy terminus of AFAP110 has a net charge of +10 , and the leucine zipper region contributes most of this positive charge $(+8)$. It is possible that charge repulsion could destabilize multimers enough to permit affinity absorption, and the removal of this region (leucine zipper region) may stabilize either GST-cterm multimer or AFAP-110 multimer to impede the affinity absorption. Therefore it will be important to determine 1) where are the exact amino acids that bind GST-cterm; 2) where the opposite binding site is and 3) the functional role of the leucine zipper motif in the affinity absorption.

GST-cterm is unable to affinity absorb cellular AFAP-110 coexpressed with $\mathrm{Src}^{527 \mathrm{~F}}$. We cloned both AFAP-110 and Src ${ }^{527 \mathrm{~F}}$ into the same pCMV vector and place them under different promoters. This system enables us to generate high yields of both AFAP-110 and Src ${ }^{527 F}$, and to generate tyrosine phosphorylated AFAP-110 (Flynn et al, 1993; Guappone et al, 1996; Guappone and Flynn, 1997). The fact that GST-cterm is unable to absorb AFAP-110 coexpressed with $\mathrm{Src}^{527 \mathrm{~F}}$ indicates that $\mathrm{Src}^{527 \mathrm{~F}}$ kinase may modulate some molecular events to alter the structure of the carboxy terminus and impede affinity absorption. The molecular mechanism is unclear, but there are three possibilities: 1) AFAP-110 is tyrosine phosphorylated by $\mathrm{Src}^{527 \mathrm{~F}}$, which may alter the structure. GST-cterm is able to affinity absorb AFAP-110 coexpressed cSrc. It is possible that $\mathrm{Src}^{527 \mathrm{~F}}$ may phosphorylate one or more specific tyrosines that are not phosphorylated by cSrc, which may contribute to abrogating the affinity absorption. 2) The formation of the stable complex between $\mathrm{Src}^{527 \mathrm{~F}}$ and AFAP-110 may sterilely block affinity absorption. Mutated forms of either Src ${ }^{527 F}$ or AFAP-110 that fail to form a 
stable complex should provide some clues. 3) $\mathrm{Src}^{527 \mathrm{~F}}$ may activate a second protein or molecule that affects AFAP-110's structure and prevent the affinity absorption. One possible mechanism is Ser/Thr phosphorylation. Earlier data showed that both $\mathrm{Src}^{527 \mathrm{~F}}$ and vSrc can activate some Ser/Thr kinases (Blenis and Ericson, 1985; Blenis et al, 1987; Sturgill et al, 1988; Morrison, 1988; Spangler et al, 1989; Nori et al, 1990; Qureshi et al, 1991; Sternberg et al, 1993). As for AFAP-110, it has a Ser/Thr substrate region and demonstrates increased levels of Ser/Thr phosphorylation in the presence of $\mathrm{Src}^{527 \mathrm{~F}}$ (Flynn et al, 1993; Kanner et al, 1991) Experiments are in progress to uncover the mechanism by which $\mathrm{Src}^{527 \mathrm{~F}}$ abrogates the affinity absorption of AFAP-110 by GSTcterm.

Affinity absorption in vitro predict AFAP-110 may have the ability to selfassociation in vivo. Gel filtration of AFAP-110 overexpressed in Cos-1 cells confirms that it can be detected in fractions that predict either a multimer or monomer. The $\mathrm{M}_{\mathrm{r}}$ of AFAP-110 is $72,315 \mathrm{Da}$, and the peak from FPLC that indicates AFAP-110 as a monomer is predicted as $70-45 \mathrm{kDa}$. The slightly retarded $\mathrm{M}_{\mathrm{r}}$ of AFAP-110 from FPLC may be due to the different shape of AFAP-110 and the way it was resolved in FPLC column or post translational modification. AFAP-110 is also predicted to exist as a multimer forming a trimer or tetramer in FPLC fractions. One possibility is that other cellular proteins from Cos- 1 cells may also join with AFAP-110 complexes in NP-40 treated Cos1 cell lysates. It should be pointed out that AFAP-110 is overexpressed in these Cos-1 cell lysates and AFAP-110 is supposed to be overexpressed to very high levels per transfected Cos-1 cell (Guappone et al, 1996; Guappone and Flynn, 1997). Therefore, we think the majority of these complexes are AFAP-110, and other cellular proteins may not 
be expressed at high enough levels to change the $\mathrm{M}_{\mathrm{r}}$ of these complexes. These data indicate that AFAP-110 may have the ability to self-associate and form mutimeric complexes in vivo. Identification of the amino acids that are involving in mediating selfassociation and affinity absorption is in progress.

When AFAP-110 is coexpressed with $\mathrm{Src}^{527 \mathrm{~F}}$ in Cos-1 cells, it is only be detected in a single peak by gel filtration, which predicts a multirmer with a $\mathrm{M}_{\mathrm{r}}$ around 350-150 $\mathrm{kDa}$. There is no monomeric fraction resolved by gel filtration. The data indicate coexpression of $\mathrm{Src}^{527 \mathrm{~F}}$ induces AFAP-110 to exist in one fraction. $\mathrm{Src}^{527 \mathrm{~F}}$ is also found in AFAP-110 multimeric fraction 10 in FPLC. As $\mathrm{Src}^{527 \mathrm{~F}}$ can form a stable complex with AFAP-110, it is possible that AFAP-110/Src ${ }^{527 \mathrm{~F}}$ complex is formed by either two molecules of AFAP-110 and two molecules of $\mathrm{Src}^{527 \mathrm{~F}}$ or three molecules of AFAP-110 and one molecule of $\mathrm{Src}^{527 \mathrm{~F}}$. It is unlikely that one molecule of AFAP-110 and three molecules of $\mathrm{Src}^{527 \mathrm{~F}}$ compose the complex. The earlier data show that one molecule of AFAP-110 can only bind to one or two molecules of $\operatorname{Src}^{527 F}$ (Guappone and Flynn, 1997; Guappone et al, 1998). It should be point out that the peak resolved by FPLC may reveal a subpopulation of AFAP-110 that is self-associated and is not in stable complex with $\mathrm{Src}^{527 \mathrm{~F}}$. This subpopulation of AFAP-110 would be predicted to exist as a tetramer and may be resolved coincident with AFAP-110/Src ${ }^{527 F}$ complex. Therefore, the data show that coexpression of $\mathrm{Src}^{527 \mathrm{~F}}$ changes the profile of AFAP-110 in two ways: 1) No monomer population of AFAP-110 can be detected and 2) AFAP-110 is resolved in a single band and has a slightly retarded $\mathrm{M}_{\mathrm{r}}$. These data indicate that Src ${ }^{527 \mathrm{~F}} / \mathrm{AFAP}-110$ complex may result in either 1) $\mathrm{Src}^{527 \mathrm{~F}}$ may preferentially bind to monomeric AFAP-110 and then induce $\mathrm{Src}^{527 \mathrm{~F}}$ bound monomeric AFAP-110 to multerize or 2) $\mathrm{Src}^{527 \mathrm{~F}}$ may 
disrupt the large multimer of AFAP-110 so that the AFAP-110/Src ${ }^{527 F}$ complex can be composed with either two molecules of AFAP-110 and two molecules of $\mathrm{Src}^{527 \mathrm{~F}}$ or three molecules of AFAP-110 and one molecule of $\mathrm{Src}^{527 \mathrm{~F}}$. As for the retarded $\mathrm{M}_{\mathrm{r}}$ of AFAP110 in FPLC, it should be point out that there is no molecular weight change in Fig 3a. It may be due to the amount of AFAP-110 resolved on the gel or the minor difference in gel conditions. The earlier data show that the $\mathrm{M}_{\mathrm{r}}$ of $\mathrm{Src}^{527 \mathrm{~F}}$ coexpressed AFAP-110 is changed, but in a less apparent way, when significantly higher amounts of AFAP-110 are resolved on $8 \%$ SDS-PAGE (Flynn, unpublished data).

Most significantly, our data show the integrity of carboxy terminal $\alpha$-helical region of AFAP-110 is important for both AFAP-110 and actin filament association, in vivo, indicating there are some biological functions for the carboxy terminal region. The earlier data showed AFAP-110 colocalized with actin filaments when it was expressed in CE cells, and coexpresson of AFAP-110 with $\mathrm{Src}^{527 \mathrm{~F}}$ in CE cells repositioned both AFAP-110 and actin filaments into rosette like structure, which is concomitant with $\mathrm{Src}^{527 \mathrm{~F}}$ transformation (Flynn et al, 1993). In this report, we found similar results in Cos1 cells. AFAP-110 is colocalized with actin filaments when it is expressed alone in Cos1 cells, and coexpression of $\mathrm{Src}^{527 \mathrm{~F}}$ repositions both AFAP-110 and actin filaments into rosette like structure. cSrc has no significant effects on actin filaments in either CE cells or Cos-1 cells, and AFAP-110 maintains colocalizaion with actin filaments in the presence of cSrc (Reynolds et al, 1989). Our data also showed the association of AFAP110 on either actin filaments or cell membrane are dependent on the integrity of carboxy terminal $\alpha$-helical region. $\mathrm{AFAP}^{\Delta 84}$ is expressed in a diffuse pattern when its carboxy terminal $\alpha$-helical region is deleted, and is unable to localize with either actin filaments 
or cell membrane. Interestingly, deletion of only the leucine zipper motif will permit $\mathrm{AFAP}^{\Delta l \mathrm{zip}}$ to localize on either actin filaments or cell membrane, but both actin filaments and $\mathrm{AFAP}^{\Delta \text { lzip }}$ are repositioned into rosette like structure, similar to the effects on $\mathrm{Src}^{527 \mathrm{~F}}$ on AFAP-110 and actin filaments.

Our data show that deletion of the carboxy terminal 84 amino acids ( $\alpha$-helix region) doesn't permit AFAP-110 to colocalize with actin filaments while deletion of only leucine zipper motif allow AFAP-110 to retain actin filament localization. The data indicate the last 44 amino acids of carboxy terminal $\alpha$-helix region are important for the actin filament association. Experiments are in progress to localize actin binding domains within this region using deletion mutants. The deletion of the leucine zipper motif $\left(\mathrm{AFAP}^{\Delta \mathrm{lzip}}\right)$ repositions both $\mathrm{AFAP}^{\Delta \mathrm{lzip}}$ and actin filaments into rosette like structure, similar to the effects of $\mathrm{Src}^{527 \mathrm{~F}}$ on actin filaments and AFAP-110 in either Cos-1 cells or CE cells (Reynolds et al, 1989; Flynn et al, 1993). The data indicate AFAP-110 may be important in modulating the molecular events of $\operatorname{Src}^{527 \mathrm{~F}}$ upon the integrity of actin filaments, and the integrity of leucine zipper motif is central to this role. We think it is possible that effects of $\mathrm{Src}^{527 \mathrm{~F}}$ to disrupt actin filaments are in part mediated by the signals that target the structure and function of carboxy terminal $\alpha$-helical region of AFAP-110.

\section{Acknowledgments}

Special thanks to Jeff Altemus and Richard Dey, Department of Anatomy, WVU, for assistance in acquiring immunofluoresecnce, and Drew Shiemke, Department of 
Biochemstry, WVU, for assistance for FPLC. Also, our thanks to J Summy for helpful comments. This work was supported by DHHS grant CA 60731 (to DCF) from the National Institute of Health. JB is supported by the West Virginia University Medical Scientist Training Program. 


\section{Tables}

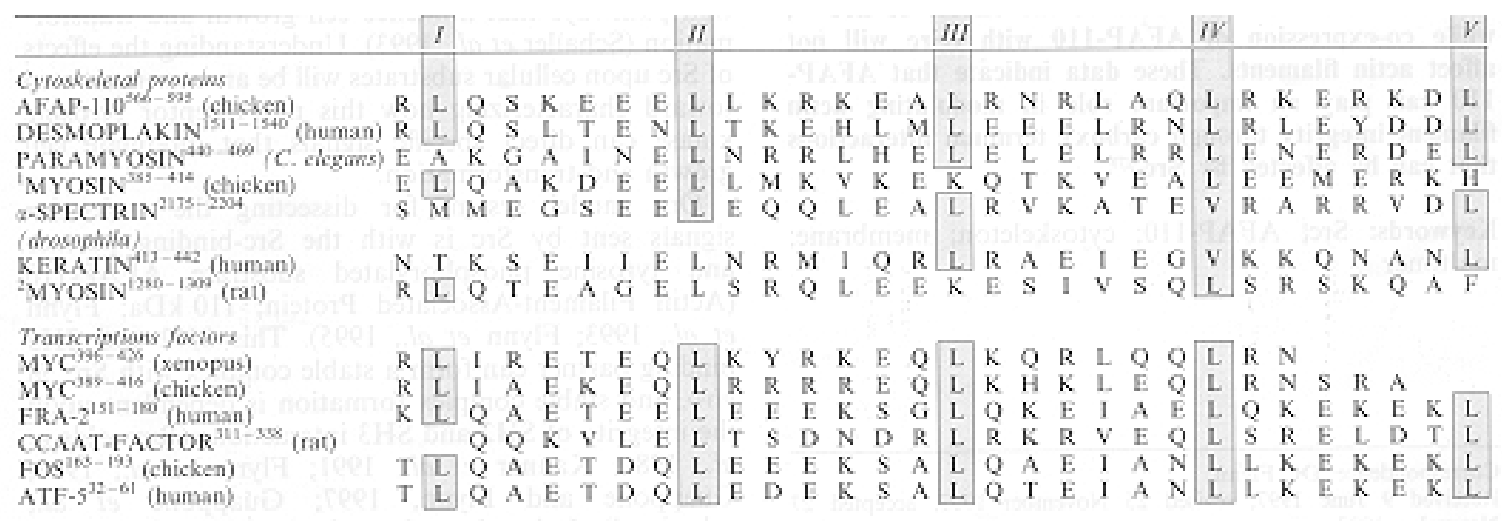

\section{Table 1 Alignment of AFAP-110 carboxy teminus with other know zipper}

containing proteins. 
Figures and Figure Legends

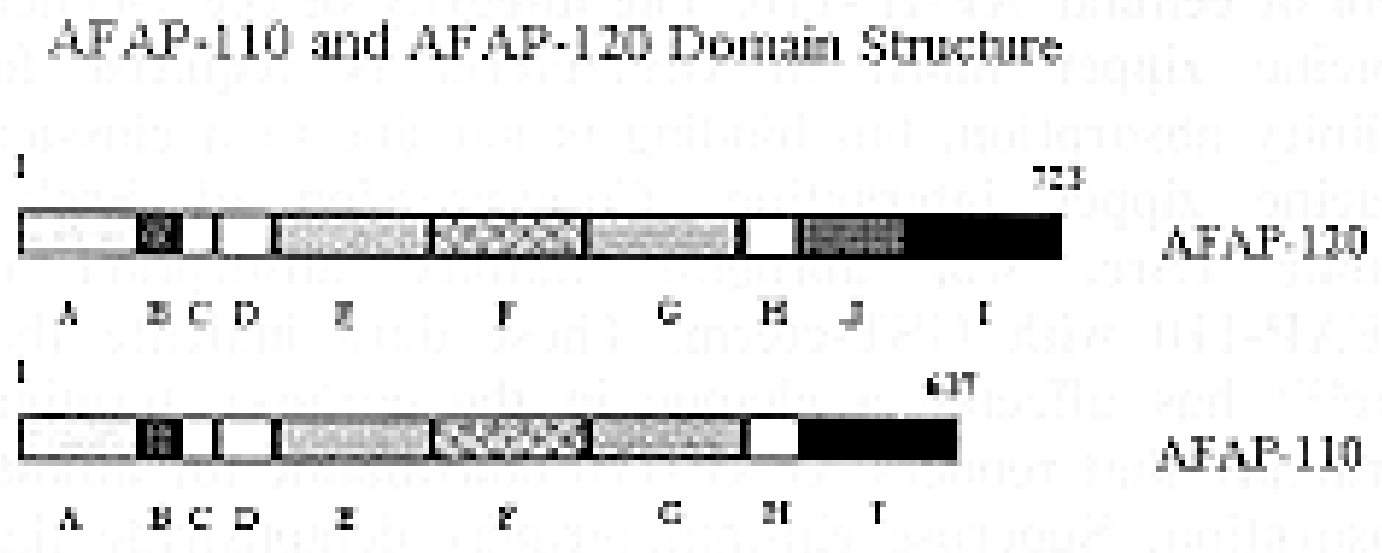

Figure 1 Domain structure of AFAP-120 and AFAP-110. AFAP-110 contains 637 amino acids. AFAP-120 contains 723 amino acids. (a) amino acids 1-61-unknown function, (b) amino acids 62-71-SH3 binding motif I for Src, Fyn and Lyn, (c) amino acids 75-84-SH3 binding motif II, (d) amino acids 85-152- putative $\mathrm{SH} 2$ binding motif, (e) amino acids 153-248-pleckstrin homology domain I, (f) amino acids 210-360-target site for serine/threonine kinases, (g) amino acids 347-450-pleckstrin homology domain II, (h) amino acids 450-510-potential SH2 binding motif, (I) amino acids 511-637 in AFAP110 or amino acids 597-723 in AFAP-120-carboxy terminal leucine zipper motif, (j) amino acids 511-596 in AFAP-120-Novel Insert in AFAP-120. 
a

Carboxy Terminal Fusion Protein Constructs
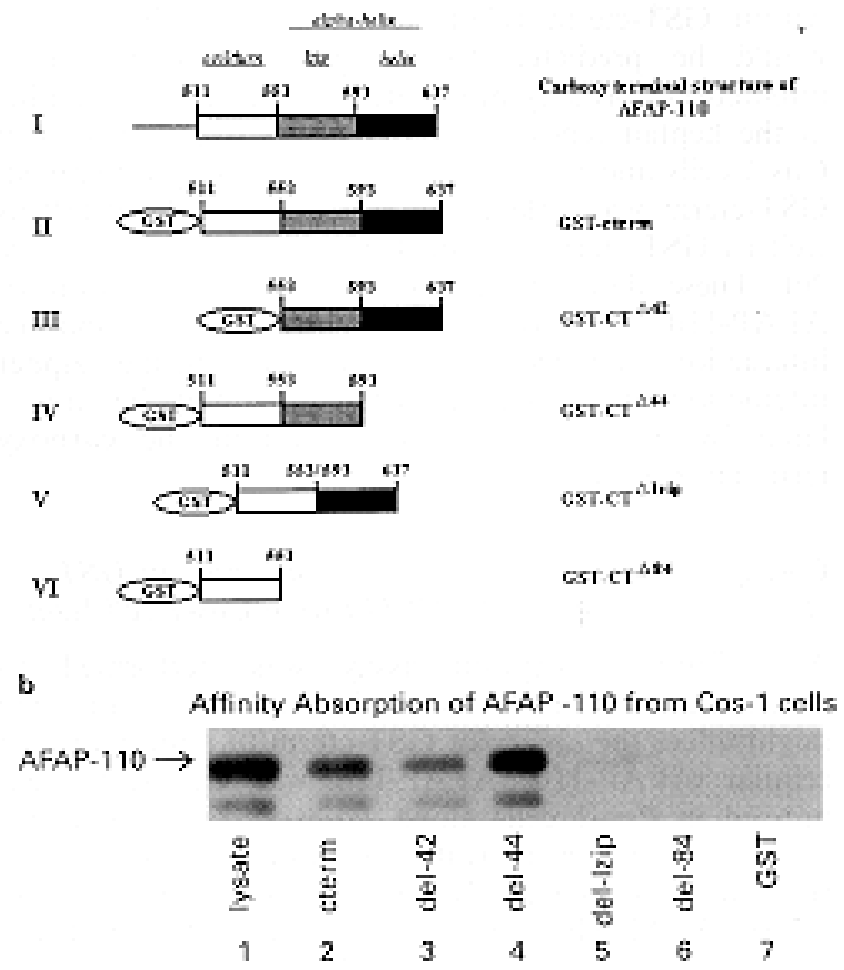

$c$

Affinity Absarption of AFAP-110 from Cos-1 cells:

Mutagene:is of leucines in the leucine zipper motif

AFAP $-110 \rightarrow$

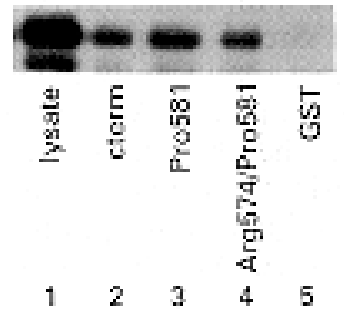


Figure 2 The carboxy terminus of AFAP-110 can modulate dimer formation. (a) The carboxy terminus is comprised of two distinct secondary structures. Amino acids 511-553 predict a region of coils and turns, while amino acids 554-637 predict a $\alpha$-helix (I). Positioned at the amino terminal half of the $\alpha$-helix is the leucine zipper motif (lzip). Fusion proteins used for affinity absorption were designed based upon the secondary structure. Sequences encoding polypeptides represented in the carboxy terminus of AFAP-110 were amplified by PCR and subcloned into pGEX-2T, (II) GST-cterm expresses amino acids 511-637 of AFAP-110, (III) GST-CT ${ }^{\Delta 42}$ expresses amino acids 553-637, (IV) GST-CT ${ }^{\Delta 44}$ expresses amino acids 511-593, (V) GST-CT ${ }^{\Delta \text { lzip }}$ contains a deletion that removes amino acids 554-592, including the majority of leucine zipper motif which is defined by amino acids $564-598$ and (VI) GST-CT ${ }^{\Delta 84}$ expresses amino acids 511-553. (b) Affinity absorption from Cos-1 cell lysates overexpressing AFAP110. AFAP-110 was overexpressed in Cos-1 cells and affinity absorbed with the GSTencoded fusion proteins, as indicated in lanes 2-7. Lane 1, $25 \mu \mathrm{g}$ cell lysate overexpressing AFAP-110 was resolved for comparison. Proteins were resolved by $8 \%$ SDS-PAGE and Western blot analysis was carried out with mAb 4C3. Del refers to $\Delta$ or deletion. (C) Affinity absorption of AFAP-110 does not occur through a classical leucine zipper interaction. Site-directed mutagenesis was employed to mutate one or two leucine residues to an arginine and/or a proline residue within GST-cterm. AFAP-110 was overexpressed in Cos-1 cells and the lysates divided into equal parts for affinity absorption with GST-cterm or the mutated GST-cterm constructs. Absorbed AFAP-110 was analyzed by Western blot with mAb 4C3. 


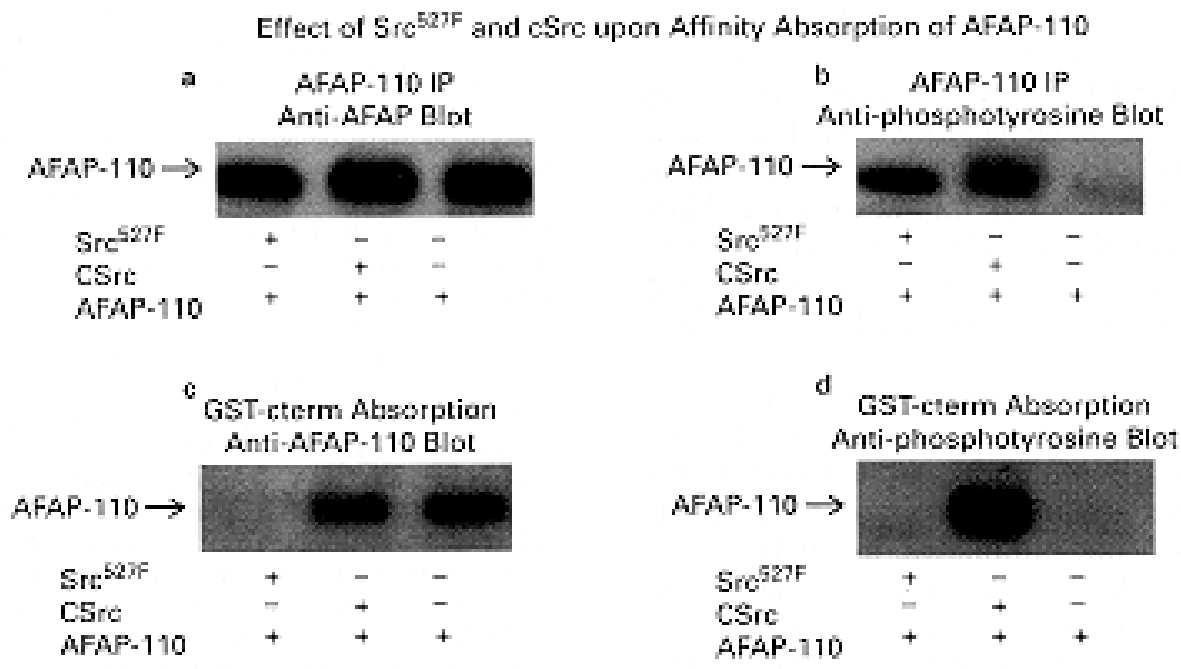

Figure 3 GST-cterm is unable to affinity absorb AFAP-110 co-expressed with $\mathrm{Src}^{527 \mathrm{~F}}$. Protein levels and affinity absorption were done using Cos-1 cell lysates overexpressing AFAP-110. (a) AFAP-110 was immunoprecipitated with mAb 4C3 and quantitated by Western bot analysis with AbF1. (b) Mab 4C3 immunoprecipitation was stripped and reprobed with rabbit anti-phosphotyrosine. (c) Affinity absorption of AFAP-110 with GST-cterm, followed by Western blot analysis with mAb 4C3. (d) Affinity absorption of AFAP-110 with GST-cterm was stripped and reprobed with rabbit anti-phosphotyrosine. 

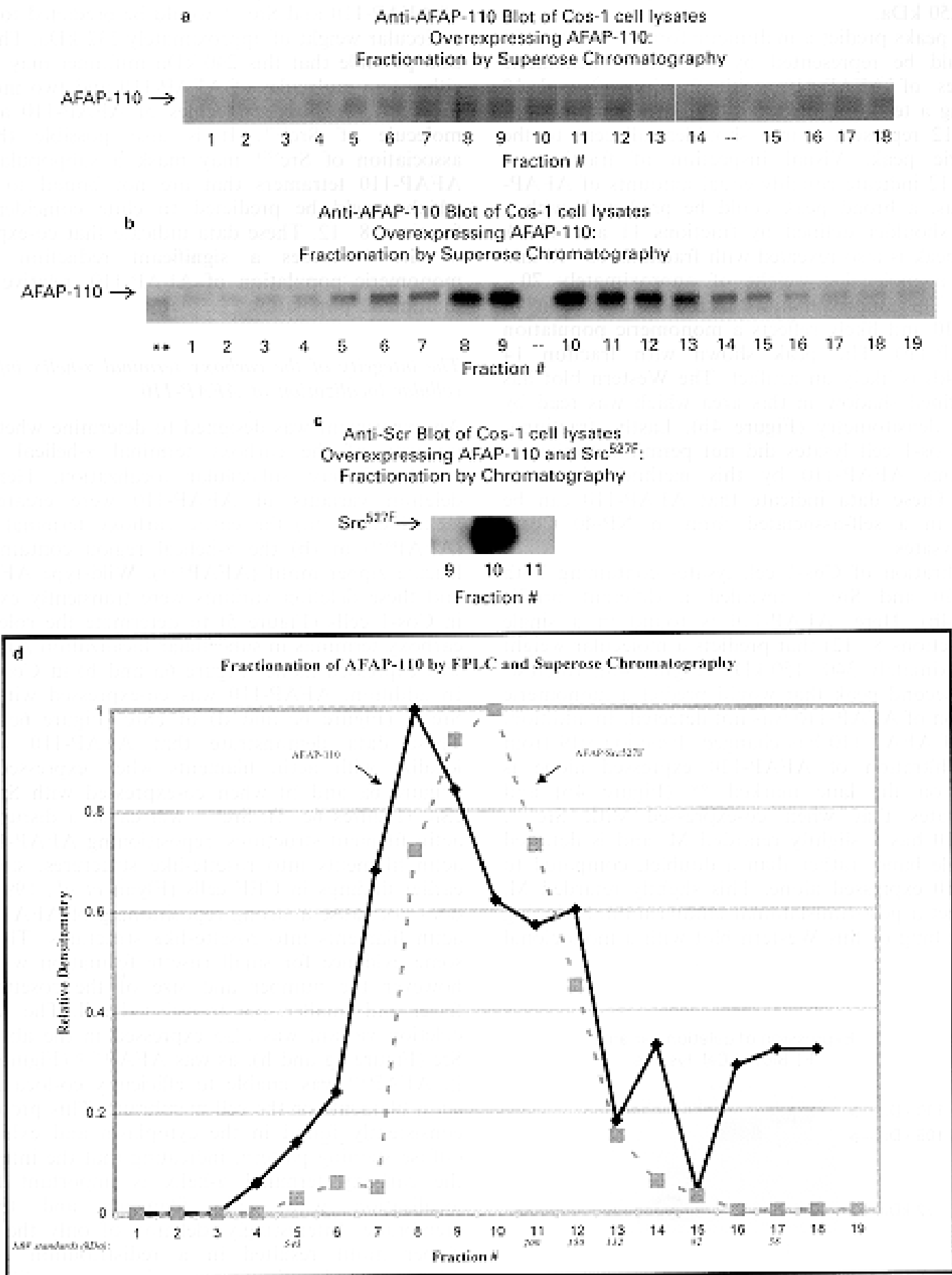
Figure 4 Gel filtration of AFAP-110 from Cos-1 cell lysates. One hundred $\mu \mathrm{g}$ of Cos- 1 cell lysates expressing AFAP-110, AFAP-110 and Src ${ }^{527 \mathrm{~F}}$ or AFAP-110 and cSrc, were resolved by a Supreose chromatography 610/30 column an fractions collected for Western blot analysis. (a) Ab F1 Western blot analysis AFAP-110 from Cos-1 cellular lysate fraction 1-18. (b) Ab F1 Western blot analysis of Cos-1 cellular lysate fraction 119 for $\mathrm{Src}^{527 \mathrm{~F}} / \mathrm{AFAP}-110, * *$ indicates fraction \#19 from AFAP-110 expressed alone, as a marker for an AFAP-110 doublet. (c) Strip and reprobe of fraction \#10-12 by Western blot analysis with mAb EC10, from Cos-1 cell lysates expressing Src ${ }^{527 \mathrm{~F}}$ and AFAP-110. (d) Scanning densitometry of peak fractions for AFAP-110 from fractions 1-18 (solid line with diamonds), and Src ${ }^{527 F} / A F A P-110$ (dashed line with squares) from fractions 1-19. Relative scanning densitometric numbers were normalized to the peak fraction densitometry number (i.e., the darkest band from each analysis). Fractionation of molecular weight (MW) standards are shown in kDa beneath the fraction where eluted. 


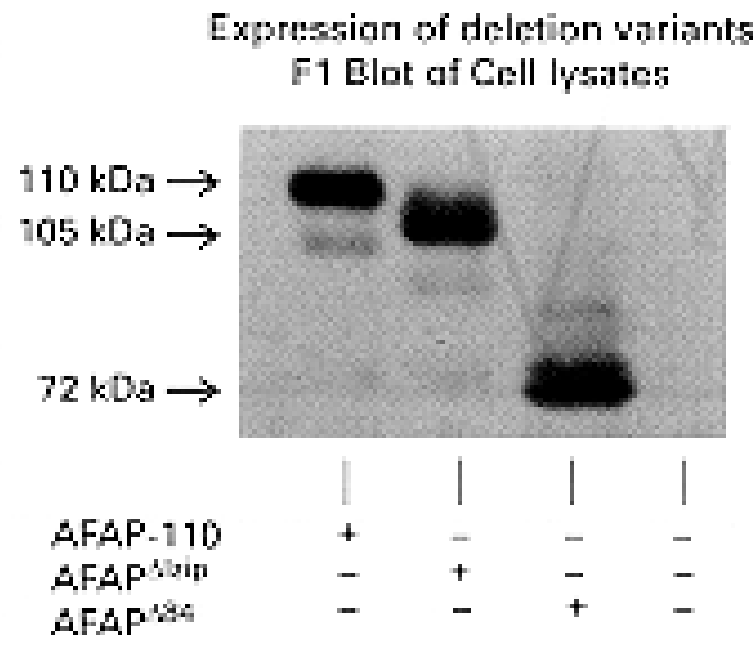

Figure $5 \mathrm{M}_{\mathrm{r}}$ of AFAP-110, AFAP $\mathrm{Alzip}^{\Delta \text { and AFAP }}{ }^{\Delta 84}$. Twenty-five $\mu \mathrm{g}$ of Cos-1 cell lysates overexpressing AFAP-110, AFAP ${ }^{\Delta l z i p}$, AFAP $^{\Delta 84}$ and Cos-1 lysates were resolved as indicated by a (+) symbol beneath the appropriate lane. A (-) symbol indicates that construct is not expressed in that sample. Cell lysates were resolved by $8 \%$ SDS-PAGE and Western blot analysis was done using Ab F1. 


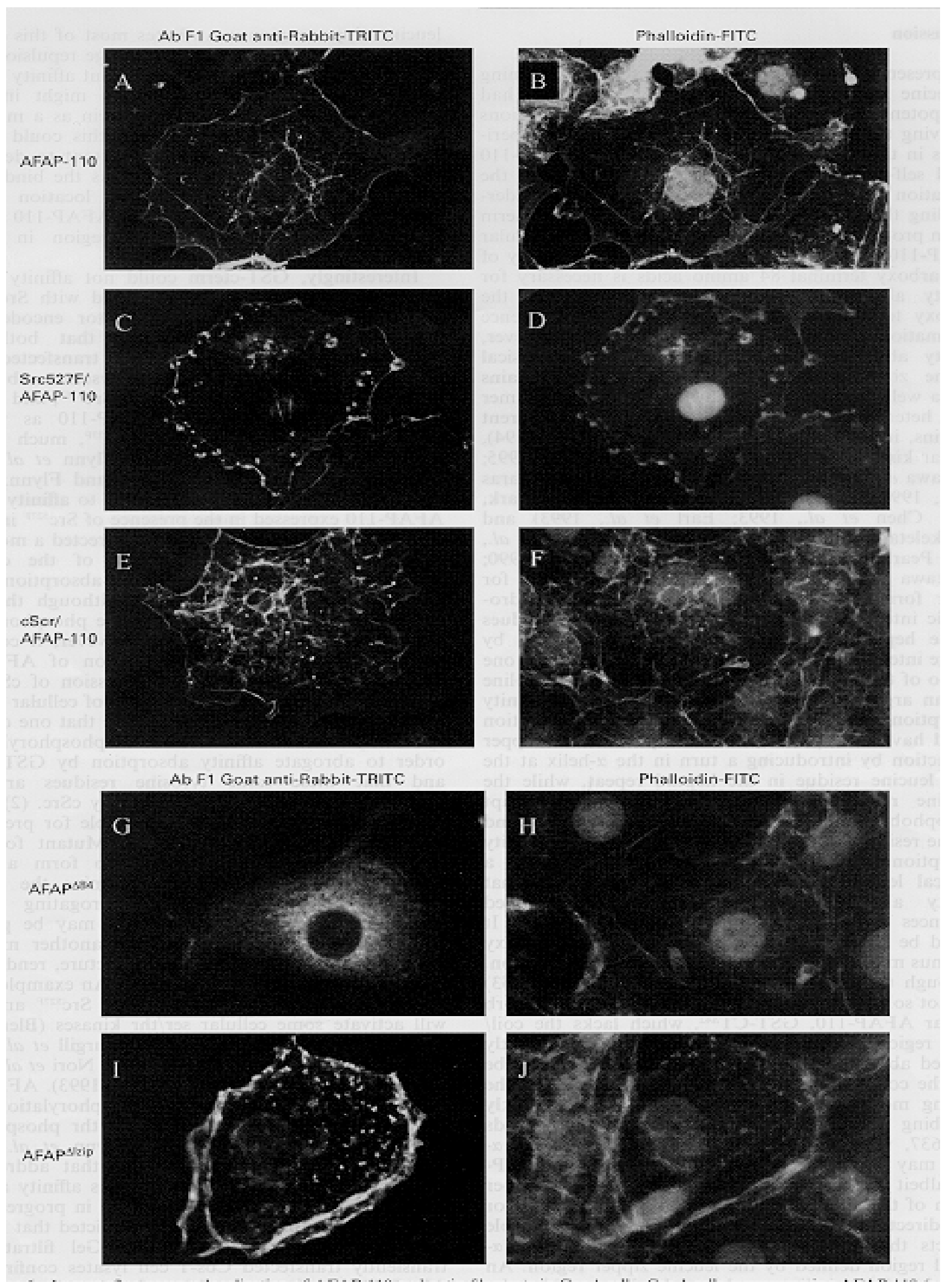


Figure 6 Immunofluorescence localization of AFAP-110 and actin filaments in Coos- 1 cells. Cos- 1 cells overexpressing AFAP-110 (a and b), AFAP-110 and Src ${ }^{527 F}$ (c

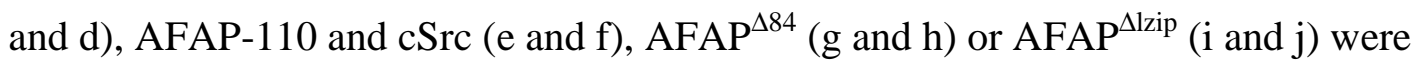
analyzed for localization of AFAP-110 (a, c, e, g, I) or for actin filament integrity (b, d, f, h, j). Overexpressed AFAP-110 was analyzed using Ab F1 and donkey anti-rabbit antibodies conjugated to Texas Red (Sigma). Actin filaments were visualized with FITC-conjugated phalloidin (Sigma). Images were acquired using a Zeiss confocal microscope and represent a single plane of scanning. 


\section{References}

Bikle DD, Munson S and Kornuves L. (1996). Zipper protein, a B-G protein with the ability to regulate actin/myosin 1 interactions in the intestinal brush border. J. Biol. Chem.. 271, 9075 -9083.

Blenis J and Erikson RL. (1985). Regulation of a ribosomal protein S6 kinase activity by the Rous sarcoma virus transforming protein, serum, or phorbol ester. Proc. Nail. Acad. Sci., USA, 82, 7621 -7625.

Blenis J, Kuo CJ and Erikson RL. (1987). Identification of a ribosomal protein S6 kinase regulated by transformation and growth-promoting stimuli. J. Biol. Chem. 262 $14373-14376$.

Bolen JB, Veillette A, Schwartz AM, DeSeau V and Rosen N. (1987). Activation of pp60c-src protein kinase activity in human colon carcinoma. Proc. Nat. Acad. Sci. USA. $84,2251-2255$.

Busch S1 and Sassonc-Corsi P. (1990). Dimers, leucine zippers and DNA-binding domains. TIGS, 6, 36-40.

Cartwright CA, Kamps MP, Meislcr Al, Pipas JM and Ekhart W. (1989). pp60c-src activation in human colon carcinoma. J. Clin. Invest., 83, 2025-2033.

Cartwright CA, Meisler Al, and Eckhart W. (1990). Activation of the pp60c-src protein kinase is an early event in colonic carcinogenesis. Proc Nall. Acad. Sic, USA, 87, $558-562$.

Chen C and Okayama H. (1987). High-efficiency transformation of mammalian cells by plasmid DNA. Mol. Cell. Biol., 7, 2745 -2752. 
Chen SS, Lee CN, Lee WR, McIntosh K and Lee TH. (1993). Mutational analysis of the leucine zipper-like motif of the human immunodeficiency virus type 1 envelope transmembrane glycoprotein. J. Virol.. 67, 3615 - 3619.

Brown MT and Cooper JA. (1996). Regulation, substrates and functions of src. Biochim. Biophys. Acta. Gene. Struct. Exper., 1287, 121-149.

Earl PL. and Moss B. (1993). Mutational analysis of the assembly domain of the HIV-1 envelope glycoprotein. AIDS Res. Hum. Retroviruses. 9,589-594.

Felice GR, Eason P, Nermut MV, and Kellie S. (1990). pp60v-src association with the cytoskeleton induces actin reorganization without affecting polymerization status. Eur. J. Cell. Biol., 52, 47 - 59 .

Flynn, DC, Horne TL, Reynolds AB and Parsons JT. (1993). Identification and sequence analysis of cDNAs encoding a 110-kilodalton actin filament-associated pp60src substrate. Mal. Cell. Biol.. 13, 7892 - 7900.

Flynn DC, Koay TC, Humphries CG and Guappone AC. (1995). AFAP-120. A variant form of the $\mathrm{Src} \mathrm{SH} / \mathrm{SH} 3$-binding partner AFAP-110 is detected in brain and contains a novel internal sequence which binds to a 67-kDa protein. J. Blot. Chem., 270, 3894-3899.

Gamm DM, Francis SH, Angellotti TP, Corbin JD and Uhler MD. (1995). The type II isoform of cGMP-dependent protein kinase is dimeric and possesses regulatory and catalytic properties distinct from the type I isoforms. J. Biol. Chem.. 270, 27380 - 27388. Gibson TJ, Hyvonen M, Birney E. Musacchio A and Saraste M. (1994). PH domain: the first anniversary. TIBS, 19, 349 - 353.- 
Guappone AC, Qian Y, Weimer TG, and Flynn DC. (1996). An in vivo system for analysis of stable complex formation between Src and AFAP-110. Meth. in Cell Sci., 18, $1-11$.

Guappone AC and Flynn DC. (1997). The integrity of the SH3 binding motif of AFAP110 is required to facilitate tyrosine phosphorylation by, and stable complex formation with, Src. Mol. Cell. Bio, 175, 243 - 252

Guappone AC, Weimer T, and Flynn DC. (1998). Formation of a stable src-AFAP-110 complex through either an amino-terminal or a carboxy-terminal SH2-binding motif. Mol Carcinog. 22:110-9.

Hodges RS. (1996). Boehringer Mannheim award lecture 1995. La conference Boehringer Mannheim 1995. De novo design of alpha-helical proteins: basic research to medical applications. Curr. Biol. 2,22-23.

Hurst HC. (1994). Transcription factors. 1: bZIP proteins. In Protein Profile. Academic Press, Inc., San Diego, CA. 1, 123-168.

Jackson P and Bellett AJD. (1989). Relationship between organization of the actin cytoskeleton and the cell cycle in normal and adenovirus-infected rat cells. J. Virol., 63, $311-318$.

Jacobs C, and Rubsarnen H. (1983). Expression of pp60c-src protein kinase in adult and fetal human tissue: high activities in some sarcomas and mammary carcinomas. Cancer Res., 43,16961-702.

Kanner SB, Reynolds AB, Wang HC and Parsons JT. (1991). The SH2 and SH3 domains of pp60src direct stable association with tyrosine phosphorylated proteins p130 and p110. EMBO J., 10, $1689-1698$. 
Kitagawa M, Mukai H, Shibata H and Ono Y. (1995). Purification and characterization of a fatty acid-activated protein kinase $(\mathrm{PKN})$ from rat testis. Biochem. J., $310,657-664$.

Klein NJ, Rigley KP and Cal lard, RE.(1993). IL-4 regulates the morphology, cytoskeleton, and proliferation of human umbilical vein endothelial cells: relationship between vimentin and CD23. Int.1mmunol. 5,293-301.

Maekawa T and Kuriyama R. (1993). Primary structure and microtubule-interacting domain of the SP-H antigen: a mitotic MAP located at the spindle pole and characterized as a homologous protein to NuMA. J. Cell. Sci.. 105,589600. Morrison DK, Kaplan DR, Rapp U and Roberts TM. (1988). Signal transduction from membrane to cytoplasm: growth factors and membrane-bound oncogene products increase Raf-1 phosphorylation and associated protein kinase activity. Proc. Mail. Acad. Sci. USA, 85, 8855-8859.

Nori M, Shawver LK and Weber MJ. (1990). A Swiss 3T3 variant cell line resistant to the effects of tumor promoters cannot be transformed by src. Mol. Cell. Biol.. 10, 4155-4162.

Pearlman JA, Powaser PA, Elledge SJ and Caskey CT. (1994). Troponin T is capable of binding dystrophin via a leucine zipper. FEBS Lett., 354, 183 - 186.

Qureshi SA, Joseph CK, Rim M, Maroney A and Foster DA. (1991). v-Src activates both protein kinase $\mathrm{C}$-dependent and independent signaling pathways in murine fibroblasts. Oncogene, 6, 995-999. 
Reynolds AB, Kanner SB, Wang H-C and Parsons JT. (1989). Stable association of activated pp60src with two tyrosine-phosphorylated cellular proteins. Mal. Cell. Biol., 9, $3951-3958$.

Roche S, Fumagalli S and Courtneidge SA. (1995). Requirement for Src family protein tyrosine kinases in G2 for fibroblast cell division. Science, 269, 1567- 1569.

Rodrigues GA and Park M. (1993). Dimerization mediated through a leucine zipper activates the oncogenic potential of the met receptor tyrosine kinase. Mol. Cell. Biol., 13, 6711-6722.

Rosen N, Bolen JB, Schwartz AM, Cohen P, DeSeau V, and Isreal MA. (1986). Analysis of pp60c-src protein kinase activity in human tumor cell lines and tissues. J. Biol. Chem., 261, 13754-13759.

Ruth P, Pfeifer A, Kamm S, Klatt P, Dostmann WRG and Hofmann F. (1997). Identification of the amino acid sequences responsible for high affinity activation of cGMP kinase Ialpha. J. Biol. Chem.. 272,10522-10528.

Saras J, Claesson-Welsh L, Heldin CH and Gonez: LJ. (1994). Cloning and characterization of PTPL1, a protein tyrosine phosphatase with similarities to cytoskeletal-associated proteins. J. Biol. Chem., 269, 24082 - 24089.

Schaller MD, Bouton AH, Flynn DC and Parsons JT. (1993). Identification and characterization of novel substrates for protein tyrosine kinases. In, Progress in Nucleic Acid Research and Molicular Biology. W.E. Cohn and K. Moldave, editors. Academic Press, Inc., San Diego, CA. 44, 205 - 227. 
Spangler R, Joseph C, Qureshi SA, Berg KL and Foster DA. (1989). Evidence that vsrc and v-fps gene products use a protein kinase C-mediated pathway to induce expression of a transformation-related gene. Proc. Natl. Acad. Sci. USA, 86,7017-7021. Staley CA, Parikh NU and Gallick GE. (1997). Decreased tumorigenicity of a human colon adenocarcinoma cell line by an antisense expression vector specific for c-Src. Cell Growth Differ., 8, 269-274.

Sternberg DW, Scholz G, Fukue Y and Hanafusa H. (1993). Activation of a histone H1 kinase by tyrosine phosphorylation in v-src-transformed fibroblasts. EMBO J, 12, $323-330$.

Sturgill TW, Ray LB, Erikson E and Maller JL. (1988). Insulin-stimulated MAP-2 kinase phosphorylates and activates ribosomal protein S6 kinase II. Nature. 353, 174177.

Taylor SJ and Shalloway D. (1996). Src and the control of cell division. BioEssays, 18, $9-11$.

Ward GE and Kirschner MW. (1990). Identification of cell cycle-regulated phosphorylation sites on nuclear lamin C. Cell, 61, 561-577. 


\title{
CHAPTER 4
}

\section{The carboxy terminus of AFAP-110 modulates interactions} with actin filaments and regulates its ability to alter actin filament integrity and induce lamellipodia formation

\author{
Yong Qian ${ }^{1,2}$, Joseph M. Baisden ${ }^{1,2}$, Henry G. Zot ${ }^{3}$, W. Barry Van Winkle ${ }^{4 \dagger}$ and \\ Daniel C. Flynn ${ }^{1,2 \dagger}$
}

${ }^{1} 2822$ MBR Cancer Center and the ${ }^{2}$ Department of Microbiology and Immunology, West Virginia University, Morgantown, WV 26506-9300, ${ }^{3}$ Department of Biology, Eastern Michigan University, Ypsilanti, MI 48197, ${ }^{4}$ Department of Pathology, University of Texas Health Science Center-Houston, 6431 Fannin Street, Houston, TX 77030.

This manuscript was sent to Experimental Cell Research in Oct. 1999. 


\begin{abstract}
The SH2/SH3 binding partner AFAP-110 is both a Src substrate and an actin binding protein. It contains several protein binding domains, including a $\mathrm{SH} 2$ binding motif, two SH3 binding motifs, two PH domains and a leucine zipper motif. The domain structure indicates AFAP-110 may function as a docking protein to link different signaling proteins to actin filaments. Deletion of the leucine zipper motif within the carboxy terminus of AFAP-110 alters the integrity of actin filaments in Cos- 1 cells, indicating AFAP-110 may have an intrinsic ability to modulate the integrity of actin filaments. In this report, we sought to determine whether AFAP-110 could bind to actin filaments directly. Analysis of the carboxy terminus of AFAP-110 revealed two consensus sequences homologous to known actin binding domains. In vivo and in vitro experiments showed the carboxy terminus of AFAP-110 directly bound actin filaments, and the amino acid sequences that are involved in direct actin filament binding were located between amino acids 593-637, where two homologous actin binding domains identified. Importantly, deletion of the leucine zipper motif within the carboxy terminus of AFAP-110 enables AFAP-110 to alter actin filament integrity and to change cell shape, characterized by the induction of lamellipodia in both C3H10T1/2 cells and NIH 3 T3 cells. These data indicate AFAP-110 may have an intrinsic ability to alter the integrity of actin filaments through carboxy terminal interactions. Thus, we hypothesize that AFAP-110 may directly bind actin filaments and is positioned to affect actin filaments in response to interactions with different cellular signaling proteins.
\end{abstract}




\section{Introduction}

The nonreceptor tyrosine kinase pp60Src $(\mathrm{Src})$ is a prototype member of the Src family and has been used as a model to study cell signal transduction and cell transformation (Cooper and Brown, 1996; Pawsons and Weber, 1989). One of hallmarks of Src transformation is the disruption of actin filaments. The mechanism by which Src affects the integrity of actin filaments is unknown. One candidate effector protein that may mediate the effects of Src upon actin filaments is the Src SH2/SH3 binding partner AFAP-110 (Flynn et al, 1993). The actin filament associated protein AFAP-110 is a

tyrosine phosphorylated substrate of activated $\mathrm{Src}\left(\mathrm{Src}^{527 \mathrm{~F}}\right)$. It forms a stable complex with active Src in primary cultures of chick embryo fibroblast (CE) cells and rat lung embryo fibroblast cells (Flynn et at, 1993; Liu et al, 1996). The formation of stable complex is dependent on both SH2 and SH3 interactions (Reynolds et al, 1989; Kanner et al, 1991; Guappone and Flynn, 1997). AFAP-110 has several protein binding domains, including a $\mathrm{SH} 3$ binding motif, two $\mathrm{SH} 2$ binding motifs, two pleckstrin homology $(\mathrm{PH})$ domains, a serine/threonine substrate region at its amino terminus and a leucine zipper motif at its carboxy terminus (Flynn et al, 1993; Guappone and Flynn, 1997; Guappone et al, 1998; Gibson et al, 1994; Shaw et al, 1996; Qian et al, 1998). The carboxy terminus of AFAP-110 modulates self-association and links AFAP-110 to both actin filaments and cell membrane (Qian et al, 1998). Therefore, AFAP-110 may have the ability to modulate the interaction between Src and actin filaments.

Src transformation increases both AFAP-110's tyrosine phosphorylation level as well as serine/threonine phosphorylation level, and changes AFAP-110's conformation 
(Kanner et al, 1991; Flynn et al, 1993; Qian et al, 1998). Fusion proteins expressing the Src SH3 domain (GST-SH3 ${ }^{\mathrm{Src}}$ ) were able to affinity absorb AFAP-110 from both chick embryo fibroblast (CE) and Cos-1 cell lysates, but was unable to affinity absorb AFAP110 from Src transformed cell lysates (Flynn et al, 1993). In addition, AFAP-110 exists as a tetramer, trimer or monomer in vivo and multermerization is dependent on the integrity of the carboxy terminus and the leucine zipper motif (Qian et al, 1998). Src transformation changes the profile of AFAP-110's self-association. Co-expression of AFAP-110 with transformation competent form of Src $\left(\mathrm{Src}^{527 \mathrm{~F}}\right)$ reduces AFAP-110's self-association through the leucine zipper motif (Qian et al, 1998). These data indicate that Src transformation may induce a conformational change within AFAP-110.

AFAP-110 may have an intrinsic ability to modulate the integrity of actin filaments through the leucine zipper motif. Expression of the leucine zipper motif deletion mutant of AFAP-110 (AFAP $\left.{ }^{\Delta l z i p}\right)$ in Cos-1 cells repositions actin filaments into rosette-like structures, similar to the phenotype of $\mathrm{Src}^{527 \mathrm{~F}}$ transformation (Qian et al, 1998). However, the Cos-1 cells are already SV40 transformed (Gluzman Y., 1981) and their actin filaments are poorly organized, in addition $\mathrm{AFAP}^{\text {Alzip }}$ is expressed at extremely high levels in Cos-1 cells. Thus, it is possible that Cos-1 cells are particular susceptible to the effects of $\mathrm{AFAP}^{\Delta \mathrm{lzip}}$. In this report, we tested a hypothesis to determine whether AFAP-110 bound to actin filaments directly and whether the deletion of leucine zipper motif altered the integrity of actin filaments and changed cell shape. 


\section{Materials and Methods}

\section{Cell culture, in vivo expression and immunofluorescence localization.}

Cos-1 cells were maintained and transfected as previously described (Guappone et, 1996). C3H10T1/2 cells were grown as previously described (Luttrell et al, 1988). Immunofluorescence localization of transiently expressed AFAP-110 was accomplished using mAb 4C3 followed by rabbit anti-mouse conjugated to rhodamine, as previously described (Qian et al, 1998). The mAb 4C3 preferentially recognizes the avian form of AFAP-110 and not the endogenous, murine form of AFAP-110 found in C3H10T1/2 cells (Qian et al, 1999). Both GFP and GFP-fusion proteins were detected as green fluorescence in the targeted cells. Actin filaments were imaged with phalloidin conjugated to BODIPY 650/655 (Molecular Probes). Images were analyzed in the WVU Anatomy department Image Analysis Lab using a Zeiss confocal microscope LSM500 package and scanning different planes of the cell. Images were collected in grayscale.

The pEGFP eukaryotic expression vector was used to express AFAP-110 or the carboxy terminal 127 amino acids (amino acids 511-637), fused to green fluorescent protein (GFP; Clontech). pGFP-AFAP-110 was created by shuttling AFAP-110 from pGEX-6P-1-AFAP-110 to pEGFP-C3 vector using EcoRI(Clontech). pGFP-Cterm was created by shuttling AFAP-Cterm from $\mathrm{pKS}+/$-AFAP-Cterm to pEGFP-C3 vector using EcoRI. pGFP-AFAP-110, pGFP-AFAP-cterm and pGFP were transiently transfected into C3H10T1/2 cells using SuperFect Transfection Reagent (Qiangen).

\section{Polypeptides and eukaryotic expression vectors.}


CT (The carboxy terminal 127 amino acids, amino acids 511-637), d42 (the carboxy terminus 86 amino acids without coil/turn region, 553-637), d44 (the carboxy terminal 84 amino acids without actin bindind domain, 511-593) and dlzip (the carboxy terminus region without the leucine zipper motif, 511-553/593-637) were amplified by PCR using primers that had BamH I and EcoR I restriction sites engineered into the ends. The amplified cDNA product was digested with BamH I and EcoR I and subcloned into pGex-6P-1 (Pharmacia). GST fusion proteins were generated from bacteria as previously described (Flynn et al, 1993; Smith and Johnson, 1988). The purified Glutathione Sepharose Bead bound GST fusion proteins were digested by PreScission ${ }^{\mathrm{TM}}$ Protease (Pharmacia Biotech) in the cleavage buffer (50mM Tis, PH 7.0; $150 \mathrm{mM} \mathrm{NaCl} ; 1 \mathrm{mM}$ EDTA; $1 \mathrm{mM}$ dithiothreitol) to isolate the polypeptides. The polypeptides were separated from the GST portion of the fusion protein and PreScission ${ }^{\mathrm{TM}}$ Protease (which bound to the Glutathione Sepharose Beads) by pelleting in a microfuge and isolating the polypeptides from the supernatant. The polypeptides were dialyzed two times against actin buffer ( $5 \mathrm{mM}$ Tris $\mathrm{pH}$ 8; $0.2 \mathrm{mM} \mathrm{CaCl} ; 50 \mathrm{mM} \mathrm{KCl} ; 2 \mathrm{mM} \mathrm{MgCl}_{2}$ ). pCMV-1 constructs containing pp60 $0^{527 \mathrm{~F}}$ and/or AFAP-110 were generated as previously described and used for transient expression in Cos-1 cells . Constructs containing $\mathrm{AFAP}^{\Delta \mathrm{lzip}}$ and $\mathrm{AFAP}^{\Delta 84}$ were generated as previously described (Qian et al, 1998). $\mathrm{AFAP}^{\Delta 44}$ and $\mathrm{AFAP}^{\Delta 22}$ were created by site-directed mutagenesis. A stop codon was introduced by changing the codon for $\mathrm{Lys}^{593}$ from AAA $\rightarrow$ TAA (for $\mathrm{AFAP}^{\Delta 44}$ ) or Lys $^{616}$ from AAG $\rightarrow$ TAG (for $\mathrm{AFAP}^{\Delta 22}$ ). The newly created stop codon was confirmed by DNA sequence analysis. No second site mutations were identified within the 3 ' region 
of the construct that was subsequently subcloned into pCMV-AFAP-110, generating the

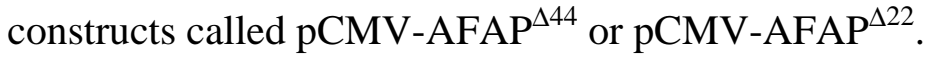

\section{GFP fusion protein constructs}

pGFP-AFAP-110 was created by shuttling AFAP-110 from pGEX-6P-1-AFAP110 to pEGFP-C3 vector using EcoRI(Clontech). pGFP-Cterm was created by shuttling AFAP-Cterm from pKS+/-AFAP-Cterm to pEGFP-C3 vector using EcoRI. pGFPAFAP-110, pGFP-AFAP-cterm and pGFP were transiently transfected into C3H10T1/2 cells using SuperFect Transfection Reagent (Qiangen).

\section{Protein characterization and analysis.}

Protein concentrations and western blot analysis were performed as previously described (Guappone and Flynn, 1997). Bound primary antibody was quantitated using an HRP-conjugated secondary antibody followed by detection using chemiluminescence.

The monoclonal antibody 4C3 (Kanner et al, 1990) was used as previously described and the polyvalent antibody (Ab) F1 was prepared as previously described(Flynn et al, 1993). Isolation of immune complexes and western transfer were done as previously described (Guappone et al, 1996).

\section{Actin filament pelleting assay.}

G-actin (Cytoskeleton Co.) was resuspended in general actin buffer (5 mM Tris $\mathrm{pH} 8.0 ; 0.2 \mathrm{mM} \mathrm{CaCl} 2$ ). The F-actin stock was prepared by adding actin polymerization buffer (final concentration: $50 \mathrm{mM} \mathrm{KCl} ; 2 \mathrm{mM} \mathrm{MgCl}$; $1 \mathrm{mM} \mathrm{ATP}$ ) and incubated at 
$30^{\circ} \mathrm{C}$ for $30 \mathrm{~min}$. The actin pelleting assays were performed by incubating $25 \mu \mathrm{C}$ terminal or NINS polypeptides $(20 \mu \mathrm{M})$ with $100 \mathrm{ul} \mathrm{F}$-actin $(23 \mu \mathrm{M})$ at $30^{\circ} \mathrm{C}$ for $30 \mathrm{~min}$. The reactions were centrifuged at $150,000 \mathrm{x} \mathrm{g}$ for 1.5 hour at $4^{\circ} \mathrm{C}$. Both supernatants and pellets were resolved by $14 \%$ SDS-PAGE gel. Silver staining was used to visualize the polypeptides that co-pelleted with actin filaments.

\section{Results}

\section{There are two actin binding domains and a leucine zipper motif within carboxy terminus of AFAP-110.}

Earlier data showed that AFAP-110 colocalized with actin filaments in vivo and the carboxy terminus of AFAP-110 is important for the colocalization (Qian et al, 1998). Analysis of the carboxy terminal sequence of AFAP-110 revealed that there are two actin binding domains between amino acids 593-637. They have good homology with two types of known actin binding domains identified in other actin filament-associated proteins (Table 1). The sequence defined by amino acids 601-615 demonstrates homology with a consensus actin binding motif termed ABD1 (actin binding domain 1; Taylor et al., 1998). The sequence defined by amino acids 614-617 demonstrates homology with an actin binding motif termed ABD3 (actin binding domain 3; Taylor et al., 1998). There is a leucine zipper motif defined by amino acids 553-595 (Qian et al, 1998). It is a well-characterized protein binding domain existing in both transcription factors as well as some cytoskeletal proteins. One of its main functions is involved in protein dimerization. 


\section{The actin binding domain region (amino acids 593-637) of AFAP-110 is necessary for actin filaments binding in vivo}

Based on the structural analysis of the carboxy terminus of AFAP-110, we constructed different mutant variants of AFAP-110. The AFAP ${ }^{\Delta 84}, \mathrm{AFAP}^{\Delta 44}, \mathrm{AFAP}^{\Delta 22}$, and $\mathrm{AFAP}^{\Delta \mathrm{zip}}$ constructs were generated by deletional mutagenesis and subcloned into the mammalian expression vector pCMV-1 for transient expression in fibroblast cells, as described in materials and methods (Figure 1). $\mathrm{AFAP}^{\Delta 84}$ lacks both actin binding domains and the leucine zipper motif, $\mathrm{AFAP}^{\Delta 44}$ lacks the two actin binding domains, $\mathrm{AFAP}^{\Delta 22}$ lacks actin binding doamin-3 and $\mathrm{AFAF}^{\Delta \text { lzip }}$ lacks the leucine zipper motif. Western blot analysis was used to qualitatively analyze the $\mathrm{M}_{\mathrm{r}}$ of the transiently expressed proteins in Cos-1 cells, as described earlier (Guappone et al., 1996). Protein expression levels and $M_{r}$ of these constructs are shown in Figure 1B. The changes in $M_{r}$ seen with the deletion variants reflect the removal of coding sequence from AFAP-110. The protein band seen at $85 \mathrm{kDa}$ is a proteolytic breakdown product, as previously demonstrated (Flynn et al., 1995; Qian et al, 1999).

Immunofluorescence localization of both overexpressed normal and mutant variants of AFAP-110 constructs in $\mathrm{C} 3 \mathrm{H} 10 \mathrm{~T} 1 / 2$ cells was used to determine whether the actin binding domain region was important for co-localization with actin filaments.

$\mathrm{C} 3 \mathrm{H} 10 \mathrm{~T} 1 / 2$ cells were chosen for these co-localization studies due to the ease in imaging actin filaments in these cells, compared to Cos- 1 cells. In addition, C3H10T1/2 cells are murine derived fibroblasts, while the overexpressed AFAP-110 constructs are of avian origin and an avian-specific monoclonal antibody, mAb 4C3, was used to selectively 
identify the overexpressed avian AFAP-110 constructs from endogenous AFAP-110 (Qian et al, 1999). Figure 2A-C demonstrate that overexpressed AFAP-110 co-localizes well with actin filaments and the cell membrane. However, deletion of the carboxyterminal 84 amino acids (amino acids 553-637) renders $\mathrm{AFAP}^{\triangle 84}$ deficient in actin filament colocalization (Figure 2D-F, black shaded arrow). It is noteworthy that $\mathrm{AFAP}^{\Delta 84}$ was also unable to colocalize with the cell membrane (gray shaded arrow, Figure 2D-F). $\mathrm{AFAP}^{\Delta 44}$ did not efficiently colocalize with actin filaments (Figure 2G-I; black shaded arrows), and was unable to colocalize with the cell membrane (Figure 2G-I; gray shaded arrows). The positioning of $\mathrm{AFAP}^{\Delta 44}$ was "grainy" and diffuse throughout the cytoplasm, indicating that both actin bind domains are important for the colocalization of AFAP-110 with actin filaments. Although $\mathrm{AFAP}^{\Delta 22}$ was unable to align as efficiently with actin filaments as AFAP-110, this deletion mutant did retain some colocalization with actin filaments (Figure 2J-L). These data indicate that amino acids 593-637, which contain both ABD-1 and ABD3 are required for efficient actin filament colocalization, and ABD-1 may be centrally important for efficient actin filament binding (gray shaded arrows). Collectively, these data indicate that AFAP-110 has the potential to directly interact with actin filaments through a putative actin binding motif ABD-1, present between amino acids 601-617.

\section{The carboxy terminus of AFAP-110 is sufficient to bind to actin filaments in vivo.}

To determine whether the carboxy terminus of AFAP-110 itself can colocalize with actin filaments, both AFAP-110 and the carboxy terminal region of AFAP-110 were cloned into the pGFP vector to construct pGFP-cterm and pGFP-110, respectively. Both 
pGFP-cterm and pGFP-110 were transiently transfected into Cos-1 cells and western blot analysis was used to detect GFP-fusion proteins from cell lysates to confirm the expression of GFP-fusion proteins (data not shown). Immunofluorescence localization was applied to determine the cellular localization of overexpressed GFP fusion proteins in C3H10T1/2 cells. The data show that when GFP was expressed alone, it is diffuse throughout the cytoplasm and is unable to colocalize with either actin filaments or cell membrane, indicating that GFP is not an actin binding protein and GFP fusion protein system is applicable for immunofluorescence test (Figure 3D-F). GFP-110 behaves like AFAP-110 in C3H10T1/2 cells, it can be detected both on actin filaments and the cell membrane (Figure 3A-C). GFP-cterm is also located on both actin filaments and cell membrane (Figure 3G-I). These data indicate that the carboxy terminus of AFAP-110 alone can colocalize with actin filaments and cell membrane.

\section{The carboxy terminus of AFAP-110 directly binds to actin filaments in vitro and the actin binding domain region (amino acids 593-637) is necessary for binding}

An actin-filament pelleting assay was attempted to determine whether the carboxy terminus of AFAP-110 had the potential to bind actin filaments, in vitro. Peptide $\mathrm{d} 42$, representing the carboxy terminal 86 amino acids of AFAP-110, has both the leucine zipper motif and actin binding domains. D42 was generated using the pGex-6P vector, affinity purified and proteolytically cleaved away from the GST fusion protein, as described in materials and methods. As a negative control for actin binding, the $66 \mathrm{kDa}$ bovine serum albumen (BSA) protein was used. Recombinant AFAP-cterm and BSA were quantitated by Coomasie staining and BCA protein analysis. The ability of the 
recombinant protein to bind polymerized non-muscle or muscle actin filaments was accomplished by incubating them with polymerized actin filaments, followed by copelleting at $150,000 \mathrm{xg}$, and then analyzing by Coomasie staining the ability of each protein to co-pellet with actin filaments. In this experiment, peptide $\mathrm{d} 42$ co-pelleted with both polymerized muscle and non-muscle actin filaments while BSA was unable to efficiently co-pellet (Figure 4a). The estimated binding affinity of peptide $\mathrm{d} 42$ for nonmuscle actin filaments was $284 \mu \mathrm{M}$ and for skeletal actin filaments was $191 \mu \mathrm{M}$. These data indicate that AFAP-110 does contain the actin filament-binding domains, and can co-pellet with actin filaments through these domains. It should be pointed out that under the conditions used in these experiments, the skeletal muscle actin polymerized much more efficiently than the non-muscle actin, hence, a majority of the resolved muscle actin is in the pellet and a minority is in the supernatant. To further test whether the actin binding domain region (the carboxy terminal 44 amino acids, 593-637) is necessary for actin filament binding, the peptides CT, d44 and dlzip were generated and the actin copelleting assay was performed. CT contains the carboxy terminal 127 amino acids with both the leucine zipper motif and actin binding domains (511-637), d42 contains the carboxy terminus 86 amino acids without coil/turn region (553-637), d44 contains the carboxy terminal 84 amino acids without actin bindind domain (511-593) and dlzip contains the carboxy terminus region without the leucine zipper motif (511-553/593-637) as mentioned in material and methods. The data demonstrate neither BSA nor d44 were able to co-pellet with actin filaments. However, both CT and d42 pelleted with actin filaments while dlzip pelleted with actin filaments less efficiently (Figure 4b). The data are consistent with our in vivo results. Thus, AFAP-110 may bind actin filaments 
directly and the carboxy terminal 44 amino acids are necessary to modulate this interaction.

\section{Deletion of leucine zipper motif alters the integrity of actin filaments and induces the formation of lamellipodia.}

There are some functional implications for the direct binding of AFAP-110 to actin filaments. The leucine zipper motif and the two actin binding domains within the carboxy terminus of AFAP-110 are predicted to form a long $\alpha$-helix structure based on secondary structure analysis (Qian et al, 1998). The deletion variant of AFAP-110, $\mathrm{AFAP}^{\Delta \text { lzip }}$, lacks amino acids 553-593 and has been demonstrated to reposition actin filaments into rosette-like structures in transformed Cos-1 cells (Figure 5A-C) (Qian et al., 1998). However, no effect on morphology of these SV-40 transformed cells was noted. Here, non-transformed cell lines are chosen to test the effects of $\mathrm{AFAP}^{\Delta l z i p}$ on actin filaments and cell morphology. Immunofluorescence analysis revealed that $\mathrm{AFAP}^{\Delta \mathrm{lzip}}$ also repositioned actin filaments cells into rosette-like structures in both C3H10T1/2 and NIH 3T3 cells (Figure 5D-I). In association with changes in actin filament integrity a significant level of lamellipodia formation in both C3H10T1/2 and NIH 3 T3 cells transfected with $\mathrm{AFAP}^{\Delta \mathrm{lzip}}$ was noted and $\mathrm{AFAP}^{\Delta \mathrm{lzip}}$ colocalized with these structures (gray shaded arrows, Figure 5A-I). The lamellipodia appeared as a bright "ridge" at the cell membrane, rich in actin filaments and $\mathrm{AFAP}^{\Delta \mathrm{lzip}}$ was noted in these structures in all transfected cells examined (gray shaded arrows, Figure 5A-I). These data indicate that leucine zipper may have an intrinsic ability to regulate AFAP-110's ability to modulate the integrity of actin filaments and the formation of lamellipodia. 


\section{Discussion}

AFAP-110 has been demonstrated to colocalize with actin filaments and the cell membrane in Cos-1 cells and chick embryo fibroblast (CE) cells (Flynn et al., 1993; Qian et al., 1998). In this report the sequences involved in facilitating interactions between actin filaments and AFAP-110 were identified. Deletion of the carboxy terminal 84 or 44 amino acids were sufficient to prevent efficient co-localization with actin filaments, based on immunofluorescence co-localization studies. However, removal of the carboxy terminal 22 amino acids exerted a less drastic effect on colocalization with the cell membrane and actin filaments while permitting some association with the cell membrane. Thus, amino acids 593-615 are hypothesized to contain sequences that may be necessary for actin filament co-localization, and amino acids 616-637 contain sequences that may stabilize the actin filament binding. Within this sequence, between amino acids 593-637, two putative actin-binding motifs were identified based on a homology search: amino acids 601-615 and amino acids 614-617. Amino acids 601-615 demonstrate homology with the known actin binding motifs of Dystrophin, $\alpha$-actinin, Spectrin, and others (Matsudaira 1994; Taylor et al., 1998) and are referred to as Actin Binding Domain 1 (ABD1) in agreement with previously described nomenclature (Taylor et al., 1998). ABD-1 usually has 26 conserved amino acids existing in many actin cross-link proteins such as spectrin, dystrophin, fimbrin, and tensin. In vitro studying found the polypeptide representing this conserved sequence is sufficient to bind to actin filaments. Amino acids 
614-617 (KLKK) demonstrate homology with the known actin-binding motifs of Thymosin $\beta 4$, Vilin and Vasp and are referred to as Actin Binding Domain 3 (ABD 3) (Taylor et al., 1998). ABD 3 has a consensus sequence of KLKK. Deletion of both putative actin binding motifs resulted in abrogation of actin-filament binding, in vivo, as shown by images of $\mathrm{AFAP}^{\Delta 44}$ or $\mathrm{AFAP}^{\Delta 84}$. These mutants also failed to colocalize with the cell membrane. AFAP ${ }^{\Delta 22}$ retains the ABD1 motif (amino acids 601-615) but lacks the second half of the ABD3 motif (amino acids 614-617). This was accomplished by the introduction of a stop codon in place of residue 616, causing protein translation to prematurely end after amino acid Leu ${ }^{615}$. When expressed in cells, $\mathrm{AFAP}^{\Delta 22}$ is somewhat deficient in actin colocalization; however, some actin colocalization was noted, especially with the cell membrane. Therefore, it is likely that both ABD1 and ABD3, and possibly additional sequences in the carboxy-terminus, are required for efficient colocalization of the protein with actin filaments. However, the presence of $\mathrm{AFAP}^{\Delta 22}$ on the cell membrane and with lamellipodia structures suggests a role for the first of the ABD1 motif (amino acids 601-615) in association of AFAP-110 with these structures. It is likely that membrane association reflects an interaction with the cortical actin matrix, although this has not been demonstrated definitively. These data indicate that in vivo, actin filament colocalization is modulated by sequences in the carboxy-terminal 44 amino acids of AFAP-110.

The strong homology with known actin binding motifs indicated that AFAP-110 could associate with actin filaments directly. Peptides representative of the carboxy terminal 86 amino acids of AFAP-110 were able to co-precipitate with polymerized nonmuscle actin filaments, in vitro. Similarly, peptides CT and d42 were able to co-pellet 
with polymerized skeletal muscle actin filaments, indicating an ability to associate with either non-muscle or skeletal muscle actin filaments, in vitro. Peptide d44 was unable to co-pellet with actin filaments, indicating the actin binding domain region is necessary for actin binding activity in vitro. The data are totally consistent with the in vivo results that demonstrate $\mathrm{AFAP}^{\Delta 44}$ is deficient for colocalizing with actin filaments, indicating that the actin binding domain region is necessary for actin filament binding. In vivo data demonstrate the carboxy terminus of AFAP-110 colocalized with both actin filaments and the cell membrane when it was expressed alone. The data are consistent with the results that both $\mathrm{AFAP}^{\Delta 84}$ and $\mathrm{AFAP}^{\Delta 44}$ are unable to colocalize with either actin filaments, cell membrane or lamellipodia structures. Taken together, the data imply the carboxy terminus of AFAP-110 may be both necessary and sufficient to bind actin filaments directly in vivo and the last 44 amino acids, where the actin binding domains are located, are critical. Earlier data showed that AFAP-110 has the ability to multimerize, ranging from monomers to tetramer in vivo. We predicted that AFAP-110 may cross-link and bundle actin filaments through its ability to multimerize in vivo.

It was previously reported that a deletion in the carboxy terminus of AFAP-110 $\left(\mathrm{AFAP}^{\Delta l z i p}\right.$ ) was sufficient to reposition actin filament structures in Cos-1 cells (Qian et al., 1998). However, the Cos-1 cells are already transformed by SV-40 virus, their actin filaments are not well organized and relatively thin and AFAP ${ }^{\Delta l z i p}$ are extremely overexpressed in the Cos-1 cells. Those properties may have made Cos-1 cells more susceptible to AFAP ${ }^{\Delta l z i p}$. Thus, both C3H10T1/2 and NIH3T3 cells were used to test the effects of $\mathrm{AFAP}^{\Delta \mathrm{lzip}}$ on actin filaments. Neither C3H10T1/2 nor NIH3T3 cells are oncogenically transformed cells and their actin filaments are well organized. Expression 
of $\mathrm{AFAP}^{\mathrm{\Delta lzip}}$ in both $\mathrm{C} 3 \mathrm{H} 10 \mathrm{~T} 1 / 2$ cells and NIH3T3 cells also repositions the actin filament into rosette like structure, similar to what was seen in cells expressing $\mathrm{Src}^{527 \mathrm{~F}}$. The AFAP ${ }^{\Delta l z i p}$ transfected cells also demonstrated changes in cell morphology characterized by the increased levels of lamellipodia formation, unlike the cells transfected with wild-type AFAP-110 or any of the other deletion variants used in this study. The lamellipodia is full of meshwork of actin filaments that are in constant rearrangements and $\mathrm{Src}^{527 \mathrm{~F}}$ transformation can induce the formation of lamellipodia within minutes (Thomas SM and Brugge JS, 1997). These data indicate that AFAP-110 may have an intrinsic capability to alter actin filament integrity through its leucine zipper motif, in vivo.

Expression of $\mathrm{AFAP}^{\Delta \mathrm{lzip}}$ in Cos-1 cells, followed by separation by gel filtration demonstrate that $\mathrm{AFAP}^{\Delta \mathrm{zip}}$ is detected only in the dimeric form and not in the tetrameric or trimeric forms as AFAP-110 is (Qian and Flynn, unpublished data). Therefore, the leucine zipper motif may play a functional role in both regulating the ability of AFAP110 to multimerize and the capability of AFAP-110 to alter actin filament integrity. These two functions could also be linked. In addition, Src transformation alters actin filaments and induces the formation of lamellipodia, similar to the phenotype of the expression of $\mathrm{AFAP}^{\Delta \mathrm{lzi}}$, and coexpreesion of AFAP-110 with $\mathrm{Src}^{527 \mathrm{~F}}$ reduces the multimerization of AFAP-110 into dimeric form, which could result from changes in conformation of the leucine zipper motif. Those data indicate that Src transformation may induce a conformational change in the leucine zipper motif and thus enable AFAP110 to modulate the integrity of actin filaments. 


\section{Acknowledgements}

This work was supported by a grant from the National Cancer Institute, CA 60731

from the National Institutes of Health (to DCF and HGZ), and a grant from the National Science Foundation, MCB-9514248 (to HGZ). JMB is supported by the West Virginia University Medical Scientist Training Program. Special thanks to Dr. J. T. Parsons, J. Summy and A.C. Koay for helpful comments. 


\section{Tables}

Homology to ABD-1

\begin{tabular}{|l|c|c|c|c|c|c|c|c|c|c|c|c|c|c|c|}
\hline & & & & & & & & & & & & & & & \\
\hline AFAP-110 (avian, 601-615) & V & N & A & G & R & K & T & Q & V & I & L & E & D & K & L \\
\hline Dystrophin (human, 92-106) & V & N & I & G & S & T & D & I & V & D & G & N & H & K & L \\
\hline Dystrophin (avian, 96-110) & V & N & I & G & S & S & D & I & V & D & G & N & H & K & L \\
\hline$\alpha$-Actnin (dicty, 101-115) & V & G & I & G & A & E & E & L & V & D & K & N & L & K & M \\
\hline$\alpha$-actinin (avian, 120-134) & V & S & I & G & A & E & E & L & V & D & G & N & A & K & M \\
\hline Spectrin (drosophila,127-141) & E & N & I & G & S & H & K & I & V & D & G & N & A & S & L \\
\hline Spectrin (human, 131-145) & E & N & M & G & S & H & D & I & V & D & G & N & H & R & L \\
\hline ABP-120 (dicty, 90-104) & V & G & I & G & A & E & D & I & V & D & S & Q & L & K & L \\
\hline ABP & V & S & I & D & S & D & A & I & V & D & G & N & L & K & L \\
\hline Filamin (122-136) & V & S & I & D & S & K & A & I & V & D & G & N & L & K & L \\
\hline Tensin (avian, 372-385) & E & N & G & P & S & V & S & V & - & D & Y & N & T & S & D \\
\hline Fimbrin (avian, 211-225) & V & N & I & G & S & Q & D & L & Q & E & G & K & P & H & L \\
\hline T-plastin (human, 209-223) & V & N & I & G & A & E & D & L & R & A & G & K & P & H & L \\
\hline & & & & & & & & & & & & & & & \\
\hline
\end{tabular}

Homology to ABD-3

\begin{tabular}{|l|l|l|l|l|}
\hline AFAP-110 (614-617) & K & L & K & K \\
\hline Thymosin $\beta 4(17-20)$ & K & L & K & K \\
\hline Villin (818-821) & N & L & K & K \\
\hline Vasp (234-237) & K & L & R & K \\
\hline
\end{tabular}

Table 1. Alignment of the carboxy terminus of AFAP-110 with known actin binding motifs termed actin binding domain 1 (ABD1) and actin binding domain 3 (ABD3). Species from which these proteins were cloned are shown in parentheses as well as the amino acids. Shaded areas indicate regions of identity or homology. 
Figures and Figure Legends 
A

Deletion constructs of AFAP-110

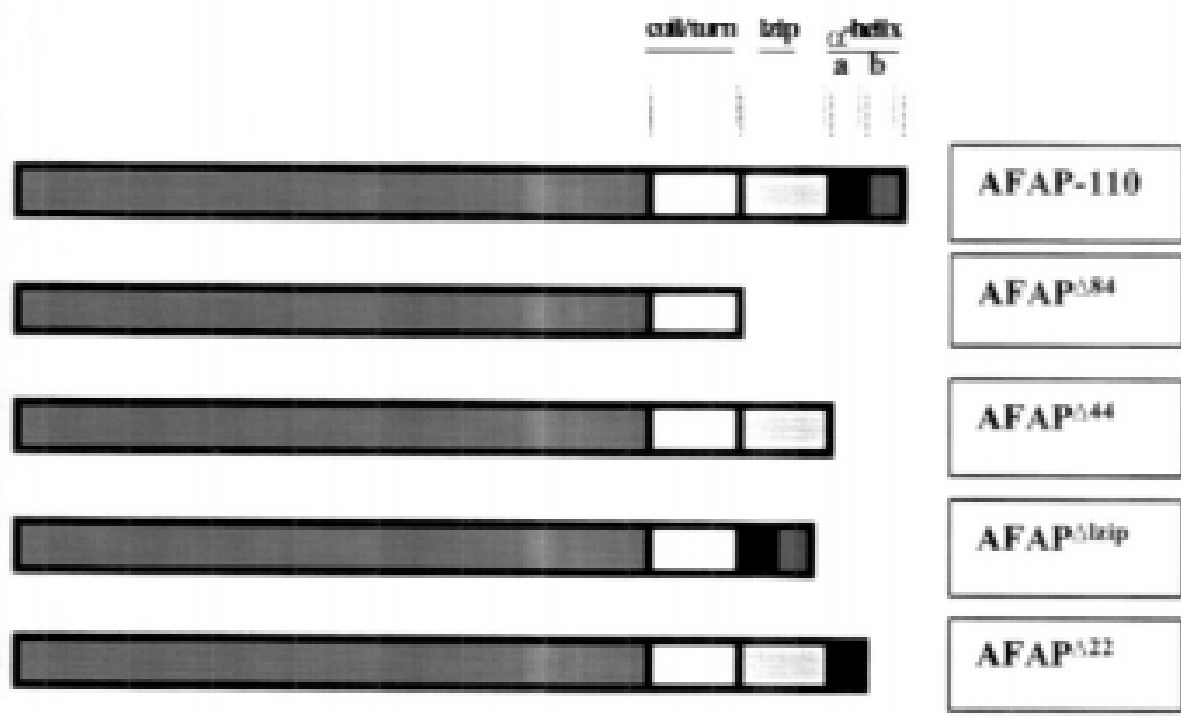

B

\section{Expression of AFAP-110 Deletion Constructs}

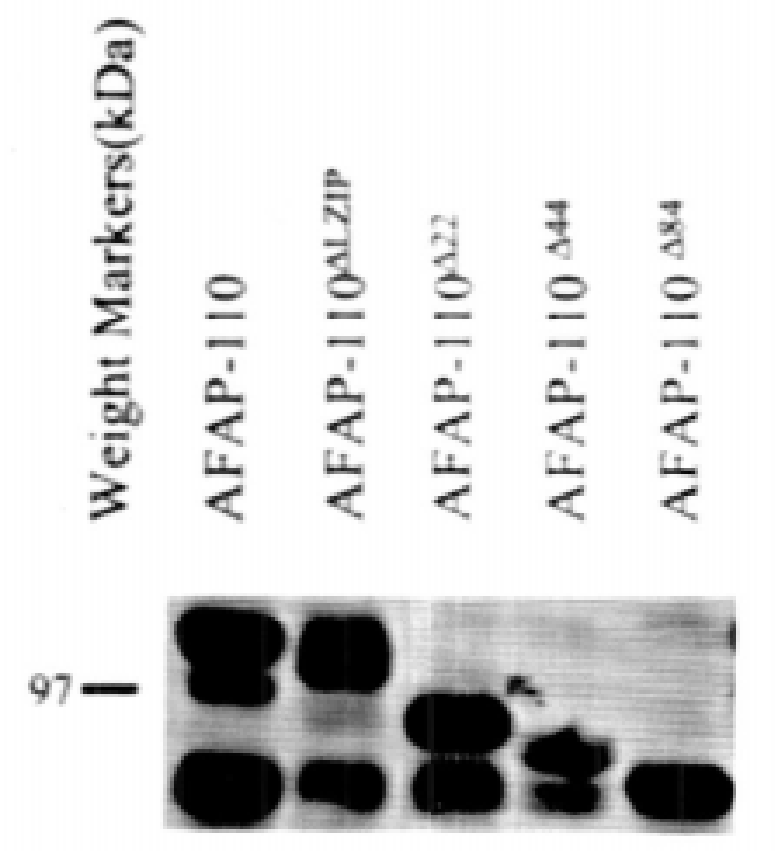


Figure 1. (A) The AFAP-110, $\mathrm{AFAP}^{\Delta 84}$, and $\mathrm{AFAP}^{\Delta \text { lzip }}$ constructs were generated as previously described [26]. $\mathrm{AFAP}^{\Delta 44}$ was generated by engineering a stop codon in place of Lys ${ }^{593}$ and $\mathrm{AFAP}^{\Delta 22}$ was generated by engineering a stop codon in place of Lys ${ }^{616}$, thus removing the carboxy-terminal 44 or 22 amino acids from the AFAP-110 open reading frame. (B) Expression of AFAP-110 constructs in Cos-1 cells. Each AFAP110 construct was transiently expressed in Cos-1 cells and protein expression levels measured from cell lysates 66 hours post transfection. Twenty-five $\mu \mathrm{g}$ of cell lysate was resolved by $8 \%$ SDS-PAGE, transferred to PVDF by western transfer and probed with mAb 4C3, followed by quantitation with sheep anti-mouse conjugated to HRP and chemiluminescence. 

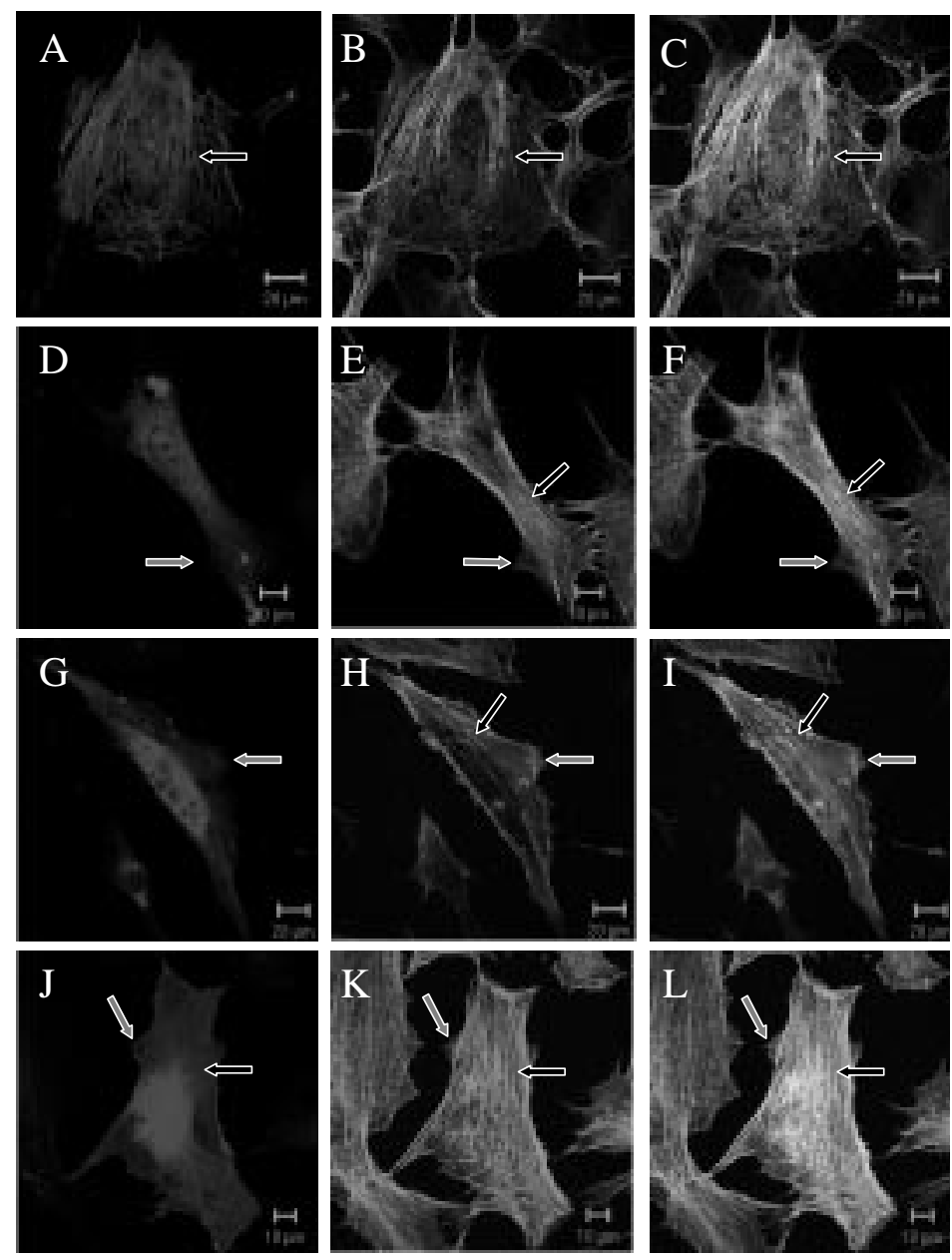
Figure 2. Immunofluorescence labeling patterns of AFAP-110 deletion constructs in C3H10T1/2 cells. C3H10T1/2 cells were transiently transfected and probed for AFAP-110 overexpression as described in materials and methods. To differentiate transfected avian AFAP-110 mutants from endogenous AFAP-110, the avian specific mAb 4C3 antibody was used. Panels A, D, G and J show emission of rhodamineconjugated rabbit anti-mouse, which recognizes the monoclonal 4C3 antibody, demonstrating the localization of transiently over-expressed AFAP-110 in C3H10T1/2 cells. Panels B, E, H and K show emission of BODIPY 650/655-conjugated phalloidin, which demonstrates the sub-cellular localization of actin. Panels C, F, I and L represent a composite emission pattern for AFAP-110 (and deletion variants) with actin filaments. Yellow indicates co-localization. Cells transfected with AFAP-110 and mutants are as follows: Panels A-C, AFAP-110; Panels D-F, AFAP ${ }^{\Delta 84}$; Panels G-I, AFAP ${ }^{\Delta 44}$; and Panels J-L, AFAP ${ }^{\Delta 22}$. Gray shaded arrows indicate membrane. Black shaded arrows indicate actin filaments. 


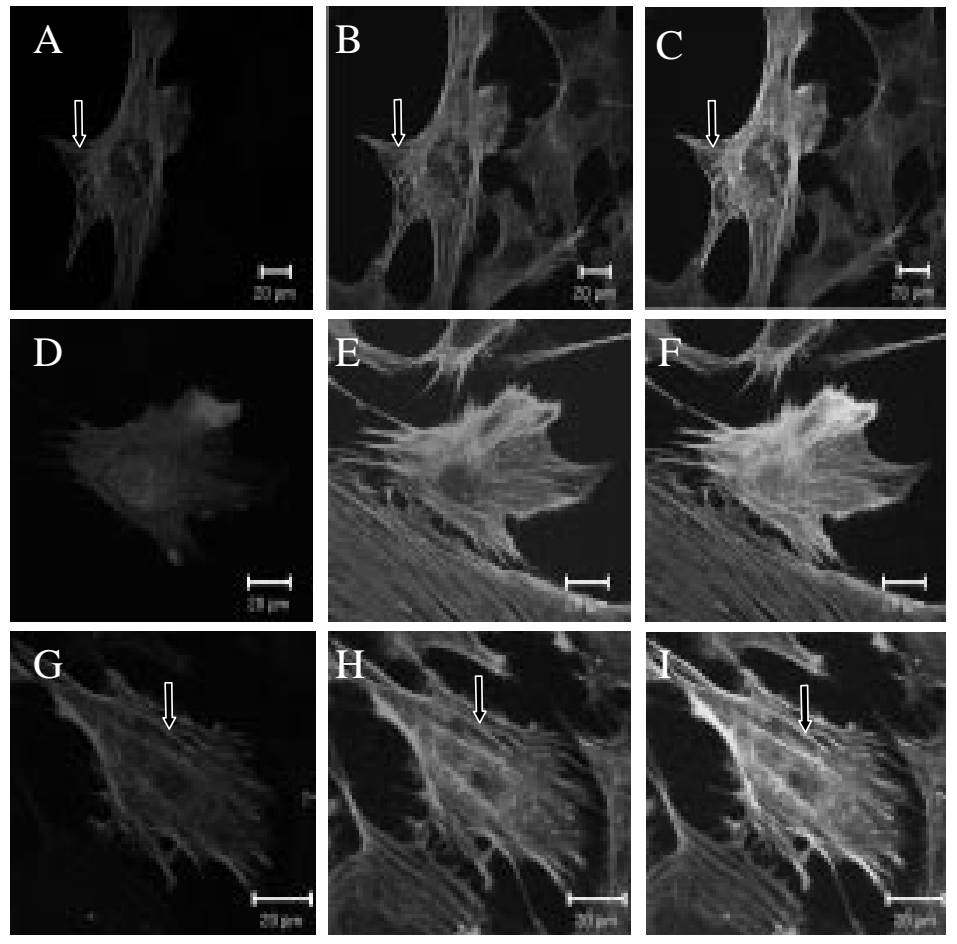


Figure 3. Immunofluorescence labeling patterns of both GFP and GFP-fusion protein in C3H10T1/2 cells. C3H10T1/2 cells were transiently transfected and probed for both GFP and GFP fusion protein overexpression as described. Panel A, D, and G show emission of green fluorescence (which were false colored red), demonstrating the localization of transiently over-expressed both GFP and GFP fusion proteins. Panel B, E, and $\mathrm{H}$ show emission of BIODIPY 650/655-conjugated phalloidin, which demonstrates the sub-cellular localization of actin filaments, which were false colored green.Panel C, F, and I represent a composite emission patter for GFP fusion proteins with actin filaments. Yellow indicates co-localization. The order of cell transfection is follows: Panel A-C, GFP-AFAP-110; Panel D-F, GFP; Panel G-I, GFP-Cterminal. 


\section{Actin Filament Co-pelleting Assay}

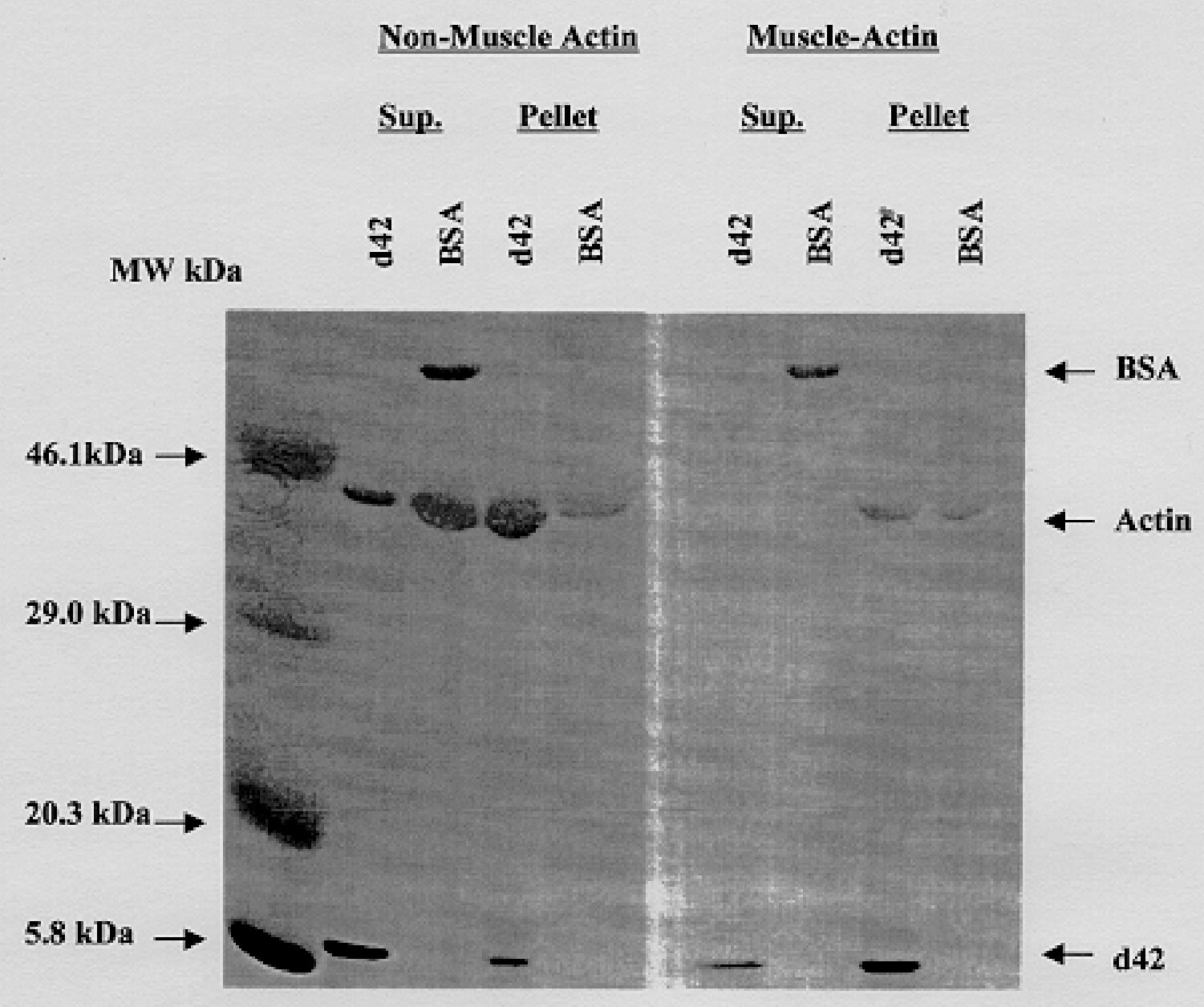


Figure 4. Actin filament co-pelleting assay. The purified carboxy terminal 86 amino acids (Cterminal) co-pelleted with both purified muscle and non-muscle actin filaments in vitro. Silver stain demonstrates the co-pellets of the C-terminal or BSA polypeptides with the actin filaments pellet (Pellet) or supernatant (Sup.). MW markers are noted. BSA has a $\mathrm{M}_{\mathrm{r}}$ of $66 \mathrm{kDa}$ while the $\mathrm{C}$-terminal polypeptide has a $\mathrm{M}_{\mathrm{r}}$ of $10 \mathrm{kDa}$. 

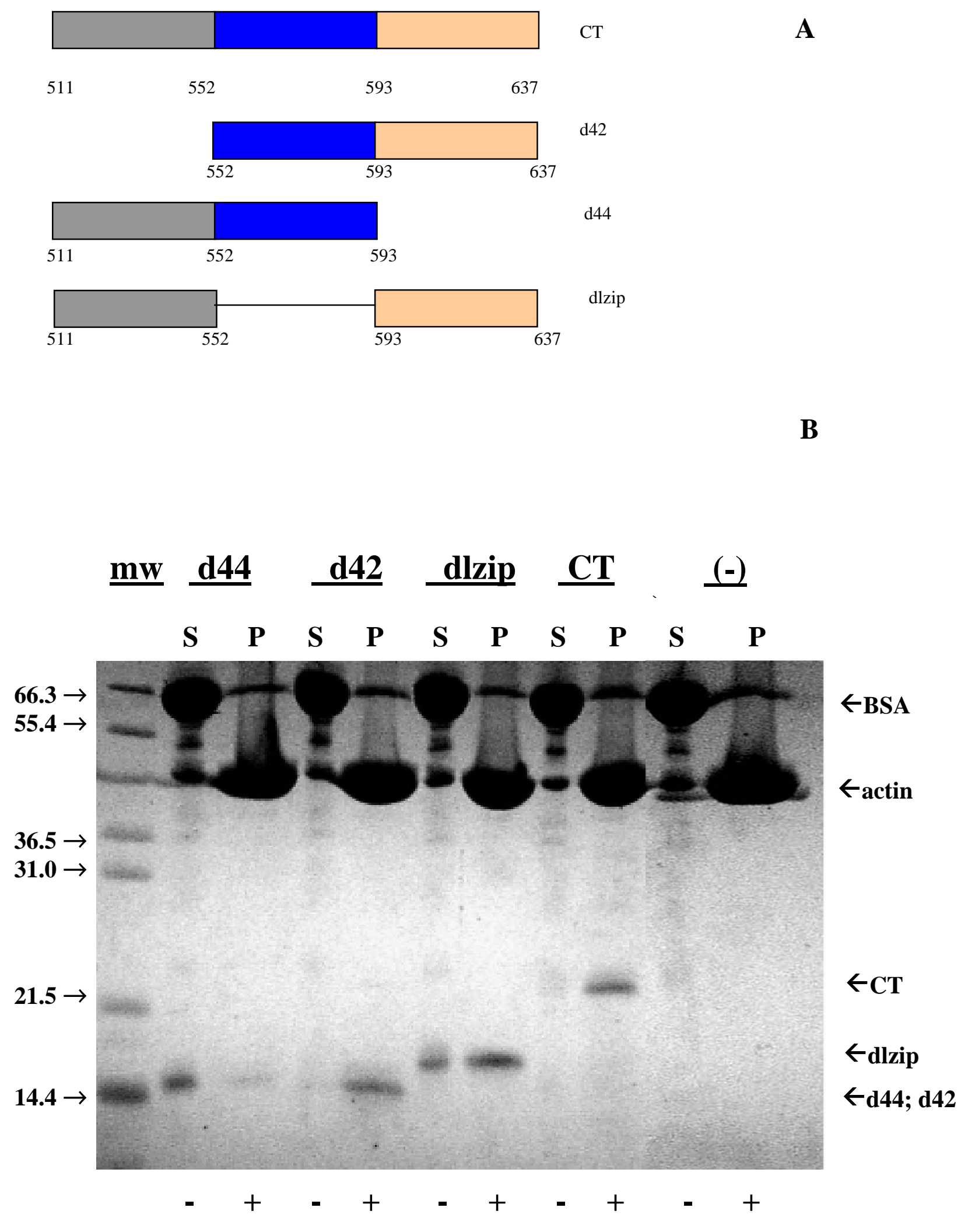
Figure 5. AFAP-110 binds to actin filaments in vitro via amino acids 594-637. (A) polypeptides representative of amino acids 511-637 (the carboxy terminus; CT), amino acids 552-637 (d42, which lacks the coil/turn region shown in Figure 1); amino acids 511-593 (d44, which lacks the actin binding domains), or amino acids 511-552/593637 (dlzip, which lacks the leucine zipper motif) were generated as described in materials and methods. (B) The polypeptides were mixed with polymerized actin filaments and BSA and pelleted, followed by resolution of the S and $\mathrm{P}$ fractions using $12 \%$ SDS-PAGE and silver staining. The $\mathrm{S}$ fraction is the supernatant fraction and contains proteins not bound to actin filaments while the $\mathrm{P}$ fraction contains the pelleted actin filaments. The $\mathrm{M}_{\mathrm{r}}$ of the CT, dlzip, $\mathrm{d} 44$ and $\mathrm{d} 42$ polypeptides are noted and were confirmed by running a separate gel resolving the purified polypeptides and silver stain. 

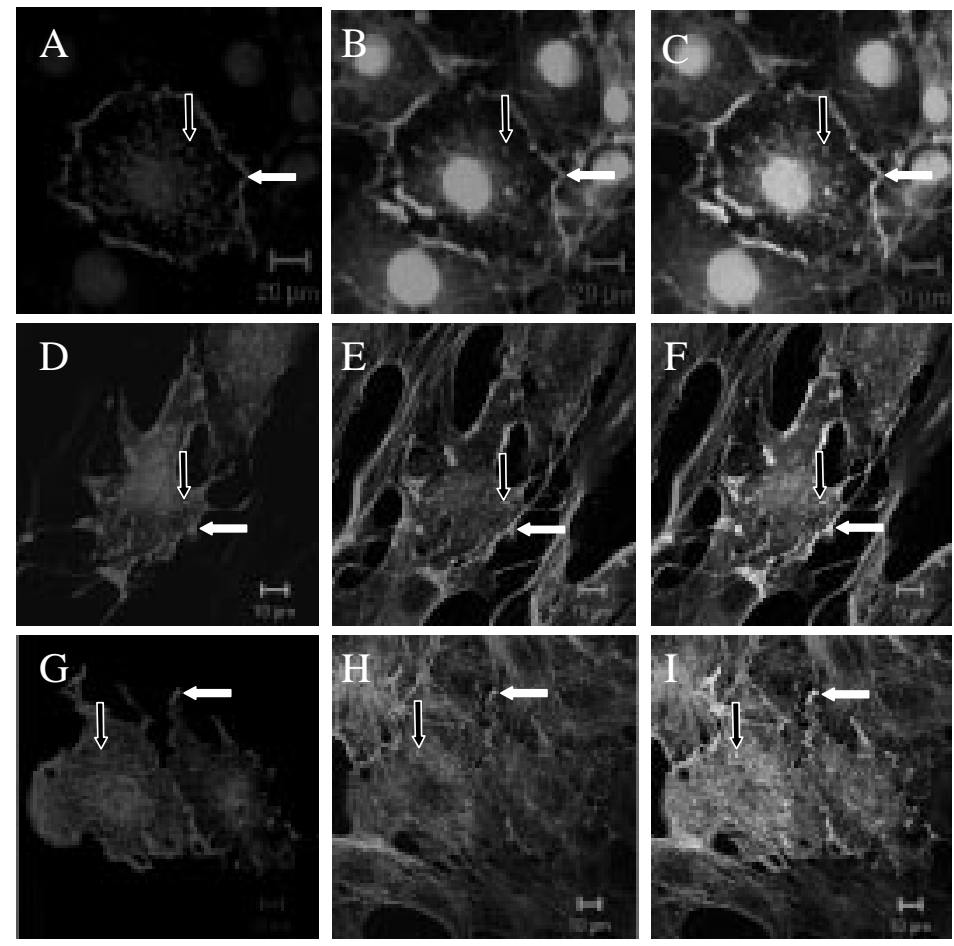
Figure 6. Immunofluorescence labeling patterns of $\mathrm{AFAP}^{\Delta \text { lzip }}$ deletion construct in Cos-1 cells, C3H10T1/2 cells and NIH 3T3 cells. The cells were transiently transfected and probed for AFAP $\mathrm{Alzip}^{\mathrm{Alz}}$ overexpression as described in materials and methods. To differentiate transfected avian $\mathrm{AFAP}^{\text {Llzip }}$ from endogenous AFAP-110, the avian specific mAB 4C3 antibody was used. Panels A, D, and G show emission of rhodamineconjugated rabbit anti-mouse, which recognizes the monoclonal 4C3 antibody, demonstrating the localization of transiently over-expressed $\mathrm{AFAP}^{\Delta \mathrm{lzip}}$ in the cells. Panels B, E, and H show emission of BODIPY 650/655-conjugated phalloidin, which demonstrates the sub-cellular localization of actin filaments. Panels C, F, and I represent a composite emission pattern for $\mathrm{AFAP}^{\Delta \mathrm{lzip}}$ with actin filaments. Yellow indicates colocalization. The order of cells is follows: Panels A-C, Cos-1 cells; Panels D-F, C3H10T1/2 cells; Panels G-I, NIH 3T3 cells. 


\section{Reference}

Ayscough, KA (1998) : In vivo functions of actin-binding proteins. Cur Opin Cell Biol. 10: $102-111$

Boyce, B.F., Yoneda, T., Lowe ,C., Soriano, P., and Mundy, G.R.. (1992):

Requirement of pp60c-src expression for osteoclasts to form ruffled borders and resorb bone in mice. J. Clin. Invest. 90:1622-1627.

Boyce, G. F., Chen, H., Soriano, P., and Mundy, G. R. (1993): Histomorphometric and immunocytochemical studies of src-related osteopetrosis. Bone 14:335-340.

Cooper, J.A., and Brown, M.T. (1996): Regulation, substrates and functions of src. Biochim. Biophys. Acta, Gene Struct. Exper. 1287:121-149.

Cox D, Condeelis J, Wessels D, Soll D, Kern H and Knecht DA (1992): Targeted disruption of the ABP-120 gene leads to cells with altered motility. J Cell Biol 116:943955

Faix J, Seinmetz M, Boves H, Kammerer RA, Lettspeich F, Mintert U, Murphy J, Stock A, Aebi U and Gerisch G (1996): Cortexillins, major determinants of cll-shape and size, are actin-bundling proteins with a parallel coiled-coil tail. Cell 86:631-642 Felice, G.R., Eason, P., Nermut, M.V., and Kellie, S. (1990): pp60v-src association with the cytoskeleton induces actin reorganization without affecting polymerization status. Eur J Cell Biol 52:47-59.

Flynn, D.C., Koay, T.C., Humphries, C.G., and Guappone, A.C. (1995): AFAP-120. A variant form of the Src SH2/SH3-binding partner AFAP-110 is detected in brain and 
contains a novel internal sequence which binds to a $67-\mathrm{kDa}$ protein. J. Biol. Chem. 270:3894-3899.

Flynn, D.C., Horne, T.L., Reynolds, A.B., and Parsons, J.T. (1993): Identification and sequence analysis of cDNAs encoding a 110-kilodalton actin filament-associated pp60src substrate. Mol. Cell. Biol. 13:7892-7900.

Gibson, T.J., Hyvonen, M., Birney, E., Musacchio, A., and Saraste, M. (1994): PH domain: the first anniversary. TIBS 19:349-353.

Glyzman Y. (1981): SV40-transformed simian cells support the replication of early SV40 mutants. Cell 23: 17-182

Guappone, A.C., and Flynn, D.C. (1997): The integrity of the SH3 binding motif of AFAP-110 is required to facilitate tyrosine phosphorylation by, and stable complex formation with, Src. Mol. and Cell. Bioch. 175:243-252

Guappone, A.C., Qian, Y., Weimer, T.G., and Flynn, D.C. (1996): An in vivo system for analysis of stable complex formation between Src and AFAP-110. Meth. in Cell Sci. 18:1-11.

Guappone, A.C., Weimer, T., and Flynn, D.C. (1998): Formation of a stable srcAFAP-110 complex through either an amino-terminal or a carboxy-terminal SH2-binding motif. Mol. Carcinogenesis 22:110-119.

Holme, T.C., Kellie, S., Wyke, J.A., and Crawford, N. (1986): Effect of transformation by Rous sarcoma virus on the character and distribution of actin in Rat-1 fibroblasts: A biochemical and microscopical study. Brit. J. Cancer 53:465-476. 
Horne, W. C., L. Neff, D. Chatterjee, A. Lomri, J. B. Levy, and R. Baron. (1992):

Osteoclasts express high levels of pp60c-src in association with intracellular membranes.

J. Cell Biol. 119:1003-1013.

Jackson, P., and Bellett, A.J.D. (1989): Relationship between organization of the actin cytoskeleton and the cell cycle in normal and adenovirus-infected rat cells. J. Virol.

63:311-318.

Kanner, S.B., Reynolds, A.B., Wang, H.C., and Parsons, J.T. (1991): The SH2 and SH3 domains of pp60src direct stable association with tyrosine phosphorylated proteins p130 and p110. EMBO J. 10:1689-1698.

Kanner, S.B., Reynolds, A.B., Vines, R.R., and Parsons, J.T. (1990): Monoclonal antibodies to individual tyrosine-phosphorylated protein substrates of oncogene-encoded tyrosine kinases. Proc Natl Acad Sci, USA 87:3328-3332.

Kaplan, K.B., Swedlow, J.R., Morgan, D.O., and Varmus, H.E. (1995): c-Src enhances the spreading of src-/- fibroblasts on fibronectin by a kinase-independent mechanism. Genes and Devel. 9:1505-1517.

Liu, M., Qin, Y., Liu, J., Tanswell, A. K., and Post, M. (1996): Mechanical strain induces pp60src activation and translocation to cytoskeleton in fetal rat lung cells. J. Biol. Chem. 271:7066-7071.

Lowe, C., Yoneda, T., Boyce, B.F., Chen, H., Mundy, G.R., and Soriano, P. (1993):

Osteopetrosis in Src-deficient mice is due to an autonomous defect of osteoclasts. Proc. Natl. Acad. Sci., USA 90:4485-4489. 
Luttrell, D.K., Luttrell, L.M., and Parsons, S.J. (1988): Augmented mitogenic responsiveness to epidermal growth factor in murine fibroblasts that overexpress pp60csrc. Mol. Cell. Biol. 8:497-501

Maidment, S.L. (1997): The Cytoskeleton and Brain Tumour Cell Migration. Antican. Res. 17:4145-4150.

Matsudaira, P. (1994): Actin crosslinking proteins at the leading edge. Sem. Cell Biol. $5: 165-174$.

Parsons, J.T., and Weber, M.J. (1989): Genetics of src: structure and functional organization of a protein tyrosine kinase. Curr. Top. Microbiol. Immunol. 147:79-127. Qian, Y., Baisden, J.M., Westin, E.H., Guappone, A.C., Koay, T.C., and Flynn, D.C. (1998): Src can regulate carboxy terminal interactions with AFAP-110, which influence self-association, cell localization and actin filament integrity. Oncogene 16:2185-2195. Reynolds, A.B., Roussell, D.J., Kanner, S.B., and Parsons, J.T. (1989a): Transformation-specific tyrosine phosphorylation of a novel cellular protein in chicken cells expressing oncogenic variants of the avian cellular src gene. Mol Cell Biol 9:629638.

Reynolds, A.B., Kanner, S.B., Wang, H.-C., and Parsons, J.T. (1989b): Stable association of activated pp60src with two tyrosine-phosphorylated cellular proteins. Mol. Cell. Biol. 9:3951-3958.

Rivero F, Furukawa R, Noegel AA and Fechheimer (1996): Dictyostelium discoideum cells lacking the 34,000-delton actin-binding protein can grow, locomote, and develop, but exhibit defects in regulation of cell structure and movement- a case of partial redundancy. J Cell Biol 135:965-980 
Roche, S., Fumagalli, S., and Courtneidge, S.A. (1995): Requirement for Src family protein tyrosine kinases in G2 for fibroblast cell division. Science 269:1567-1569. Schaller, M.D., Bouton, A.H., Flynn, D.C., and Parsons, J.T. (1993): Identification and characterization of novel substrates for protein tyrosine kinases. Prog. in Nucleic Acid Res. and Molec. Biol. 44:205-227.

Schwartzberg, P.L., Xing, L., Hoffmann, O., Lowell, C.A., Garrett, L., Boyce, B.F., and Varmus, H.E.. (1997): Rescue of osteoclast function by transgenic expression of kinase-deficient Src in src-/- mutant mice. Genes Dev. 11:2835-2844.

Shaw, G. (1996): The pleckstrin homology domain: an intriguing multifunctional protein module. Bioessays 18:35-46

Small, J. V. (1994): Lamellipodia architecture: actin filament turnover and the lateral flow of actin filaments during motility. Semin. Cell Biol. 5:157-163.

Soriano, P., Montgomery, C., Geske, R., and Bradley, A. (1991): Targeted disruption of the c-src proto-oncogene leads to osteopetrosis in mice. Cell 64:693-702.

Tanaka, S., Takahashi, N., Udagawa, N., Sasaki, T., Fukui, Y., Kurokawa, T., and Suda, T. (1992): Osteoclasts express high levels of p60c-src, preferentially on ruffled border membranes. FEBS Letters 313:85-89.

Taylor, J.M., Richardson, A., and Parsons, J.T. (1998): Modular domains of focal adhesion-associated proteins. Curr. Top. Microbiol. Immunol. 228:135-163.

Taylor, S. J., and Shalloway, D. (1996): Src and the control of cell division. BioEssays 18:9-11.

Thomas SM and Brugge JS (1997): Cellular functions regulated by Src family kinases. Annu Rev Cell Dev Biol 13:513-609 
Van Troys, M., Dewitte, D., Goethals, M., Carlier, M.F., Vandekeerckhove, J., and Ampe, C. (1996): The actin binding site of thymosin beta 4 mapped by mutational analysis. EMBO J. 15:201-210.

Wang, E. A., and Goldberg, R. (1976): Changes in microfilament organtization and surface topography upon transformation of chick embryo fibroblasts with Rous sarcoma virus. Proc. Natl. Acad. Sci. 73:4065-4069. 


\section{CHAPTER 5}

\section{General Discussion}


Src is one of the earliest identified oncogenes (Brugge and Erikson, 1977). Src transformation changes cell morphology, which is linked to the changes of actin filament based cytoskeleton. The mechanisms by which Src affects the integrity of actin filaments are unknown. One candidate protein that may serve as a model system to study the effects of Src upon the integrity of actin filaments is AFAP-110. AFAP-110 is both an actin filament binding protein and a Src substrate. Its' domain structure indicates that AFAP-110 may facilitate the interactions between Src (and other signal proteins) with actin filaments. Ultimately, this may lead to a change in cell shape.

There are three isoforms of AFAP-110: AFAP-110, AFAP-120 and AFAP-82. AFAP-120 encodes an additional 86 amino acids compared to AFAP-110, which are inserted just amino terminal to the carboxy terminal 127 amino acids of AFAP-110. The carboxy terminus of AFAP-120 is identical to that of AFAP-110. AFAP-82 conserves all the protein motifs of AFAP-110, except it lacks the carboxy terminus. Those data indicate that the carboxy terminus of AFAP-110 may be important for the function of AFAP-110. The overall goal of my dissertation was to determine the functional roles of the carboxy terminus of AFAP-110.

In chapter two, two monoclonal antibodies to AFAP-110 were mapped. Mab 4C3 recognizes an epitope that is part of SH3 binding motif. Importantly, Mab 4C3 is unable to efficiently react with mammalian homologous AFAP-110 due to one amino acid difference of Mab 4C3's epitope between avian AFAP-110 and mammalian AFAP-110. This property is unique for Mab 4C3, as we can use its epitope as an internal epitope-tag to localize avian AFAP-110 expressed in mammalian cells. Mab anti-AFAP-110 recognizes an epitope, including and around the $5^{\text {th }}$ leucine zipper motif heptad repeat 
within the carboxy terminus of AFAP-110. The leucine zipper motif may mediate the function of AFAP-110. Thus, mab anti-AFAP-110 is a useful monoclonal antibody to study the function of AFAP-110.

There is an $82 \mathrm{kDa}$ proteolytic breakdown product of AFAP-110 in both endogenous and overexpressed AFAP-110. This $82 \mathrm{kDa}$ band can be detected by both F1 and $4 \mathrm{C} 3$ antibodies, but is not detected by Mab anti-AFAP-110, and its $\mathrm{M}_{\mathrm{r}}$ is slightly decreased compared to that of $\mathrm{AFAP}^{\triangle 84}$, indicating this proteolytic breakdown product lacks carboxy terminal sequence. AFAP-110 associates with actin filaments through the carboxy terminus. This implies that removal of the carboxy terminus by proteolysis may provide a mechanism by which AFAP-1100/actin filament interactions could be regulated. Similar results have been identified with other signaling proteins (Yao et al, 1993; Shuster et al, 1995). This indicates that the carboxy terminus of AFAP-110 may be important for the function of AFAP-110.

The very carboxy terminal end 84 amino acids form a long $\alpha$ helical structure and the leucine zipper motif is located at the $\mathrm{N}$-terminus of this long $\alpha$ helix. The existence of leucine zipper motif implies AFAP-110 may have the ability to self-association. In chapter 3, both the affinity absorption data and FPLC data demonstrate AFAP-110 does have the ability to self-associate in vivo and the carboxy terminal $\alpha$ helix region may mediate this self-association. AFAP-110 is an actin binding protein, the ability to selfassociate indicates that AFAP-110 may behave as an actin bundling protein, facilitating actin filament bundling in vivo. Future experiments will be needed to address this issue. We still don't know the mechanism by which AFAP-110 self-associates in vivo. Our data indicate that the self-association may not be mediated by the classic leucine zipper 
interactions. It may be mediated by an interaction between leucine zipper motif and its upper stream region. Identification of the mechanism (s) by which AFAP-110 associate (s) with each other in vivo is important. As Src transformation changes the profile of AFAP-110's self-association through the leucine zipper motif in vivo, and the changes of self-association pattern in vivo may provide some mechanisms as for how AFAP-110 mediates the effects of Src upon actin filaments. In the future, we will detect the leucine zipper motif binding partner in the amino terminus and determine whether the deletion of this binding partner will have the same effects upon the cells as AFAP ${ }^{\Delta l z i p}$.

In both chapter 3 and 4, we demonstrate that the last 44 amino acids (593-637) of the carboxy terminus are necessary for actin filament association both in vivo and in vitro, and the carboxy terminus of AFAP-110 is sufficient to bind actin filaments both in vivo and vitro. In vitro actin filament co-pelleting assays indicate AFAP-110 may bind to actin filaments directly. Analysis of the last 44 amino acids revealed two homologous actin binding domains. The structural analysis data are consistent with early research data and indicate a mechanism by which AFAP-110 directly associates with actin filament. To further test the importance of the two actin binding domains for AFAP-110's cellular localization, we could do point mutations to mutate crucial amino acids within the two actin binding domains, and transfect mammalian cells to see whether these mutated AFAP-110s co-localize with actin filaments or not. We might put these point mutations into $\mathrm{AFAP}^{\Delta l z i p}$ to see whether the mutants could abrogate the effects of $\mathrm{AFAP}^{\Delta \mathrm{\Delta zip}}$ on actin filaments. We might further challenge these transfected cells with $\mathrm{Src}^{527 \mathrm{~F}}$ to test whether the mutation within actin binding domains will change the effects of $\mathrm{Src}^{527 \mathrm{~F}}$ on actin filaments. The mutant(s) that could block changes in actin filaments will be served as the 
dominant negative AFAP-110 for future research. Therefore, these experiments might tell us the importance of the association of AFAP-110 with actin filaments in mediating the effects of $\mathrm{Src}^{527 \mathrm{~F}}$ transformation upon actin filaments.

The leucine zipper motif may have a significant role in regulating AFAP-110's ability to modulate the integrity of actin filaments. Transient transfection of cells with $\mathrm{AFAP}^{\Delta l z i p}$ disrupts the integrity of actin filaments, and redistrubutes actin filaments into rosette-like structure similar as the phenotype of $\operatorname{Src}^{527 \mathrm{~F}}$ transformation. We also mutated the third leucine residue into a proline within the leucine zipper motif $\left(\mathrm{AFAP}^{\mathrm{L581P}}\right)$. The $\mathrm{AFAP}^{\mathrm{L} 581 \mathrm{P}}$ was transfected into the cells and the similar phenotypic changes were observed as with $\mathrm{AFAP}^{\Delta \mathrm{Azip}}$ (data is not shown). The data imply that $\mathrm{Src}^{527 \mathrm{~F}}$ may affect the integrity of actin filaments by changing the conformation at the leucine zipper motif. It also suggests that AFAP-110 may have intrinsic ability to modulate the integrity of actin filaments, which is regulated by the leucine zipper motif. One question raised is how does the leucine zipper motif regulate AFAP-110's ability to modulate the effects of $\mathrm{Src}^{527 \mathrm{~F}}$ upon actin filaments. There are two possible mechanisms by which the leucine zipper motif may regulate AFAP-110 to modulate the integrity of actin filaments. The first possible mechanism is that protein interactions, mediated by the leucine zipper motif, are changed upon either deletion and point mutation of the leucine zipper motif or $\mathrm{Src}^{527 \mathrm{~F}}$ transformation, which enables AFAP-110 to affect the integrity of actin filaments. The second mechanism is that the structure of leucine zipper motif itself, which is part of the long $\alpha$-helix at the carboxy terminus, is changed upon either mutation within the leucine zipper motif or transformation by $\mathrm{Src}^{527 F}$. Dr. C. Vinson indicated to us that the point mutation at leucine 581 to proline placed a kink structure within $\alpha$-helix and 
disrupted the structural integrity of leucine zipper motif. $\mathrm{Src}^{527 \mathrm{~F}}$ transformation could have the same effects on leucine zipper motifs as AFAP ${ }^{\mathrm{L} 581 \mathrm{P}}$ does. Src $^{527 \mathrm{~F}}$ can activate serine/threonine phosphorylation in vivo (Pawsons and Weber, 1989) and serine/threonine phosphorylation may disrupt the structural integrity of leucine zipper motif. Protein lamin is an example. It has a leucine zipper motif involved in dimerization. The phosphorylation of serine/threonine residues near the leucine zipper motif creates a perturbation within the leucine zipper motif, which disables lamin to form homodimer (Heald and Mckeon, 1990). It is possible that phosphorylation of Ser/Thr residues near the leucine zipper motif of AFAP-110 may place a perturbation or a kink structure within the leucine zipper motif, which disrupts the structural integrity of $\alpha-$ helix, similar to the effects of deletion or point mutation of the leucine zipper motif. Currently, these two possible mechanisms are being tested in this lab. We screened the Gene-bank database and found cFos had a homologous leucine zipper motif compared to that of AFAP-110. This homologous leucine zipper motif was cloned into AFAP- $110^{\Delta \text { lzip }}$ to create a chimeric AFAP ${ }^{\text {cfos/lzip }}$ construct. The chimeric AFAP ${ }^{\text {cfos/lzip }}$ was predicted to restore the integrity of carboxy terminal $\alpha$-helix structure, but would mediate different protein interactions. The chimeric protein (AFAP-cfos/lzip) was transfected into C3H10T1/2 cells. The immunofluroscence data showed the integrity of actin filaments was restored, and AFAP-cfos/lzip was colocalized with actin filaments (data not shown). The results indicate the structural integrity of leucine zipper motif may be essential for modulating the integrity of actin filaments and protein interactions may be less important. Further experiments will be needed to verify the importance of structural integrity of leucine zipper motif by substituting the $3^{\text {rd }}$ leucine of the chimeric heptad 
repeats with Proline (similar as AFAP ${ }^{\mathrm{L} 581 \mathrm{P}}$ ). This mutated chimeric AFAP-cfos/lzip will be transfected into mammalian cells to see whether this mutant will also affect the integrity of actin filaments same as $\mathrm{AFAP}^{\mathrm{L} 581 \mathrm{P}}$ does. Additional experiments are needed to test whether cfos' leucine zipper motif is functionally active i.e. whether this leucine zipper motif permits affinity absorption of AFAP-110, in vitro.

The mechanisms by which AFAP-110 affects the integrity of actin filaments are still unclear. Our data strongly suggest that AFAP-110 may have an intrinsic ability to alter actin filaments directly and the region that mediates this activity may be located to carboxy terminal 44 amino acids. To test this hypothesis, we performed an actin filament viscosity assay (MacLean-Fletcher and Pollard, 1980). We mixed purified GST-cterm, GST-cterm $^{\Delta \text { lzip }}$, GST-cterm ${ }^{\Delta 84}$ and GST fusion proteins with G-actin, and polymerized Gactin to F-actin in the presence of these fusion proteins. The fusion protein/actin mixtures were applied into the capillary tubes and the time for a steel ball to fall in the tubes was measured. The theory of this experiment is the polymerized actin filaments have high viscosity while proteins that alter the integrity of actin filaments decrease the viscosity. The relative viscosity can be measured by calculating the falling speed of steel balls. Our unpublished data showed that only GST-cterm ${ }^{\Delta l z i p}$, among the four fusion proteins, decreased the viscosity of actin filaments, which indicates that GST-cterm ${ }^{\Delta l z i p}$ may have an intrinsic ability to directly alter the integrity of actin filaments and the leucine zipper motif may play a regulatory role as GST-cterm has no effect on the viscosity (figure 1). The sequence region that has the ability to directly alter the integrity of actin filaments may exist within last 44 amino acids of the carboxy terminus, as GST-cterm ${ }^{\Delta 84}$ is unable to decrease the viscosity. There are four possible ways for proteins to inhibit the 
polymerization of actin filaments i.e. decrease the viscosity of actin filaments here. They include (a) sequestering monomeric actin, (b) severing, (c) capping or (d) destabilizing the filaments. Further experiments are needed to address these mechanisms. The novel data in this thesis are that deletion of the leucine zipper motif within AFAP110 can induce the formation of lamellipodia and changes in cell shape. The data indicate that AFAP-110 has an intrinsic ability to remodel actin filaments, regulate the formation of lamellipodia and the leucine zipper motif may play a regulatory role, which are consistent with our earlier data that AFAP-110 has the intrinsic ability to alter the integrity of actin filaments. Src transformation induces the formation of lamellipodia within minutes, which is concomitant with the increase of cell migration (Thomas and Brugge, 1997). This implies that AFAP-110 may have the ability to mediate the effects of $\mathrm{Src}^{527 \mathrm{~F}}$ upon actin filaments, through the leucine zipper motif. As I discussed in chapter one, the lamellipodia is the cell membrane protrusion at the leading edge of migrating cells, and is full of actin filament meshwork. The actin filaments within lamellipodia are highly dynamic and actively remodel (Welch et al, 1997). The formation of lamellipodia correlates with cell migration (Bearer et al, 1993). Therefore, our data indicate that AFAP-110 may effect cell motility. Modified Boyden chamber assays indicated that $\mathrm{AFAP}^{\Delta \mathrm{Izip}}$ expression increases cell motility 4-times above wild type AFAP-110 expression (Baisden and Flynn, unpublished data).

In chapter 3, the data indicate that $\mathrm{Src}^{527 \mathrm{~F}}$ can affect AFAP-110's self-association, cell localization and actin filament integrity, and these effects may be achieved through regulating the carboxy terminal interactions of AFAP-110. We still don't know whether $\mathrm{Src}^{527 \mathrm{~F}}$ interacts with AFAP-110 directly or indirectly. Our lab's earlier data showed 
$\mathrm{Src}^{527 \mathrm{~F}}$ could bind to AFAP-110 directly, in vitro. But in vivo experiments showed that $\mathrm{Src}^{527 \mathrm{~F}}$ could still disrupt actin filaments when it was coexpressed with mutant AFAP-110 that was deficient for binding to $\operatorname{Src}^{527 F}$ (Guappone and Flynn, unpublished data). This in vivo data indicate the direct interaction between $\mathrm{Src}^{527 \mathrm{~F}}$ and AFAP-110 may not be necessary for the effects of $\mathrm{Src}^{527 \mathrm{~F}}$ upon actin filaments. In chapter 3, we also found that the disruption of affinity absorption of AFAP-110 by GST-cterm is independent of tyrosine phosphorylation by $\mathrm{Src}^{527 \mathrm{~F}}$. Therefore, it is possible that AFAP-110 could indirectly mediate the effects of $\mathrm{Src}^{527 \mathrm{~F}}$ upon actin filaments through serine/threonine phosphorylation. Indeed, Kanner (1991) found $\mathrm{Src}^{527 \mathrm{~F}}$ could increase the serine/threonine phosphorylation level of AFAP-110. One candidate protein that could mediate the effects of Src ${ }^{527 F}$ upon AFAP-110's serine/threonine phosphorylation is PKC or Rho-GTPase protein Rac. The active Rac kinase, which is one of main stimulators that induce the formation of lamellipodia and membrane ruffles (Tapon and Hall, 1997). We hypothesize that $\mathrm{Src}^{527 \mathrm{~F}}$ and other kinases may activate Ras, and the activated Ras may activate Rac. The activated Rac may interact with AFAP-110, which alters the integrity of actin filaments and remodulates actin filaments to induce the formation of lamellipodia directly. Currently, our lab is actively doing research to address this issue. Indeed, Baisden and Flynn demonstrated that PKC will bind to AFAP-110 (unpublished data).

In summary, we demonstrated in this thesis that 1) Mab anti-AFAP-110 recognizes an epitope within the carboxy terminal region of AFAP-110; 2) Mab 4C3 recognizes an epitope within SH3 binding motif of AFAP-110, which is avian specific; 3) the carboxy terminus of AFAP-110 has a leucine zipper motif and two actin binding 
domains; 4) AFAP-110 may have the ability to self-association in vivo and the selfassociation may be mediated through the carboxy terminus of AFAP-110; 5) AFAP-110 can bind to actin filaments directly through its carboxy terminal 44 amino acids; 6) AFAP-110 has the intrinsic ability to alter the integrity of actin filaments and remodulate actin filaments to induce formation of lamellipodia and changes of cell shape, which are regulated through its leucine zipper motif; 7) $\mathrm{Src}^{527 \mathrm{~F}}$ has the ability to influence AFAP110's self-association, cell localization and actin filament integrity through the leucine zipper motif.

Here is our working model as for how AFAP-110 affects the integrity of actin filaments. AFAP-110 binds to actin filaments directly through the carboxy terminal 44 amino acids. Src ${ }^{527 F}$ and other cell signals interact with AFAP-110 and change the integrity of AFAP-110's leucine zipper motif. The altered leucine zipper motif enables AFAP-110 to rearrange and remodel actin filaments to induce the formation of lamellipodia and membrane ruffle through the carboxy terminal 44 amino acids. 
Figures and Legends 


\section{Actin filament viscosity assay}

Actin was prepared from rabbit fast skeletal muscle acetone powder (MacleanFletcher and Pollard, 1980). Crude G-actin and filtered with Sephacryl S-300 in G-buffer (2 mM imidazole, pH 7.5, $0.2 \mathrm{mM}$ ATP, $0.2 \mathrm{mM} \mathrm{CaCl}$, $0.5 \mathrm{mM}$ DTT, 3 mM NaN3). Apparent low shear viscosity was measured by falling ball viscometry (Maclean-Fletcher and Pollard, 1980). Samples of $180 \mu$ were prepared with G-buffer containing $10 \mu \mathrm{M} \mathrm{G}$ -

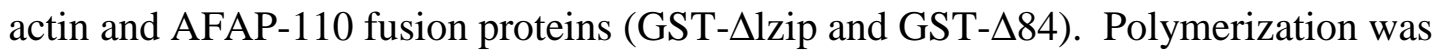
induced with the addition of $20 \mu \mathrm{l}$ of a solution containing $500 \mathrm{mM} \mathrm{KCl}, 10 \mathrm{mM} \mathrm{MgCl} 2$, $10 \mathrm{mM}$ EGTA, $100 \mathrm{mM}$ imidazole, $\mathrm{pH}$ 7.5. The mixed sample was immediately drawn into a cappilary tube $(100 \mu \mathrm{l})$. The tube was incubated vertically at least $2 \mathrm{hr}$ at $25^{\circ} \mathrm{C}$ before measuring the time for a steel ball to fall $8 \mathrm{~cm}$ in the tube. 

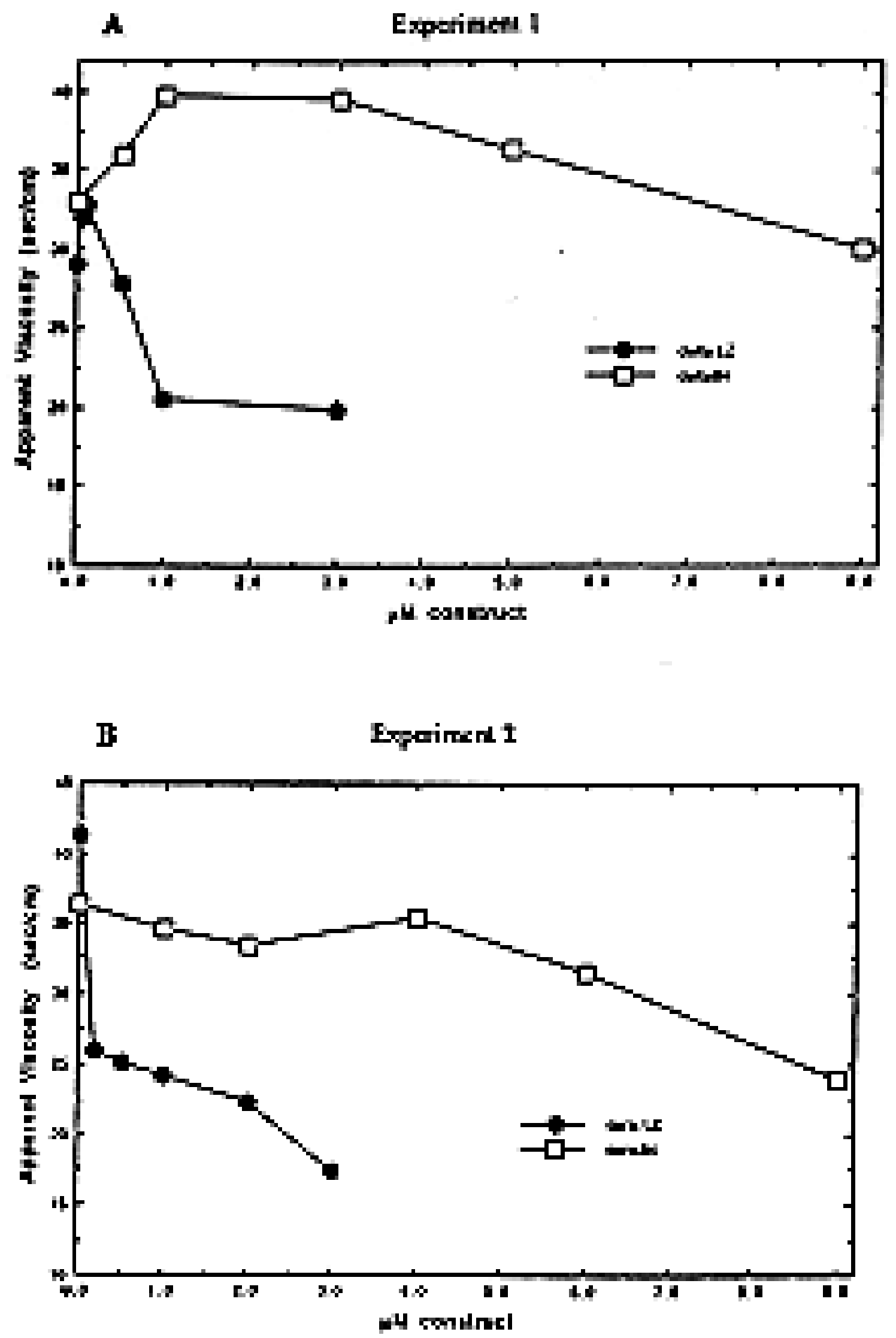
Figure 1. Fusion proteins expressing the carboxy terminus of $\mathrm{AFAP}^{\Delta \mathrm{lzi}}$ can reduce actin filament viscosity, in vitro. Polymerization of actin filaments into a viscous solution was performed in the presence of different concentrations of purified GST- $\Delta$ lzip or GST- $\Delta 84$. Relative viscosity was plotted as described in materials and methods. Panels A and B represent two independent experiments. 


\section{Reference}

Bearer EL (1993): Role of actin polymerization in cell locomotion: molecules and models. Am J Respir Cell Mol Biol 8:582-91

Brugge JS and Erikson RL (1977) Identification of a transformation-specific antigen induced by an avian sarcoma virus. Nature 269:346-8

Kanner SB, Reynolds AB, Wang R and Parsons JT (1991) The SH2 and SH3 domains of p60src direct stable association with tyrosine phosphorylated proteins p130 and p110. EMBO J 10:1689-1698

MacLean-Fletcher S, Pollard TD (1980): Mechanism of action of cytochalasin B on actin. Cell 20:329-41

Parsons JT and Weber MJ (1989) Genetics of src: structure and functional organization of a protein tyrosine kinase. Curr Topics Micro Immunol 147:79-127

Shuster, C.B., and Herman, I.M. (1995) Indirect association of ezrin with F-actin: isoform specificity and calsium sensitivity. J. Cell Biol. 128,837-848.

Thomas SM, Brugge JS (1997): Cellular functions regulated by Src family kinases. Annu Rev Cell Dev Biol 13:513-609

Tapon N, Hall A (1997): Rho, Rac and Cdc42 GTPases regulate the organization of the actin cytoskeleton. Curr Opin Cell Biol. 9:86-92

Welch MD, Mallavarapu A, Rosenblatt J, Mitchison TJ (1997): Actin dynamics in vivo. Curr Opin Cell Biol 9:54-61

Yao, X., Thibodeau, A., and Forte, J.G. (1993). Exrin-calpain I interactions in gastric parietal cells. Am. J. Physiol. 265,C36-46. 


\title{
Curriculum Vitae
}

\author{
Yong Qian \\ The Mary Babb Randolph Cancer Center and the Department of Microbiology and \\ Immunology, School of Medicine, P.O. Box 9177, West Virginia University, \\ Morgantown, WV 26506 \\ Telephone: 304-293-0501, Email: Yqian26@ Yahoo.com
}

\section{Education:}

1993-1999 Ph.D. The Mary Babb Randolph Cancer Center (MBRCC) and the Department of Microbiology and Immunology, School of Medicine, West Virginia University (WVU), Morgantown, WV 26506

1985-1988 Master of Medicine. Research Pediatrics. Shanghai Institute for Pediatric Research (SIPR), Department of Pediatrics, Shanghai Second Medicine University (SSMU), Shanghai, China

1980-1985 Bachelor of Medicine. Pediatrics. Department of Pediatrics, SSMU, Shanghai, China

\section{Research}

1995-1999 Research Assistant. MBRCC and the Department of Microbiology and Immunology, WVU.

1994-1995 Research Assistant. Department of Microbiology and Immunology, WVU 
1991-1993 Lecturer. Department of Pediatrics, SIPR, SSMU, Shanghai, China

1988-1991 Assistant Professor. Department of Pediatrics, SIPR, SSMU, Shanghai, China

1985-1988 Research Assistant. Department of Pediatrics, SIPR, SSMU, Shanghai, China

\section{Teaching}

1996-1993 Teaching assistant. Department of Microbiology and Immunology, WVU

1991-1993 Lecturer. Department of Pediatrics, SIPR, SSMU, Shanghai, China

1988-1991 Assistant Professor. Department of Pediatrics, SIPR, SSMU, Shanghai, China

\section{Clinical practices}

1988-1993 Pediatrician. Shanghai Xin Hua Children's Hospital, SSMU, Shanghai, China

\section{Bibliography}

\section{Full papers:}

1. Qian, Y., Baisden, J.M., Zot, H.G. and Flynn, D.C. The carboxy terminus of AFAP110 modulates interactions with actin filaments and regulates its ability to alter actin filament integrity and induce lamellipodia formation. (Submitted.)

2. Qian, Y., Guappone, A.C., Baisden, J.M., Hill, W., Summy J.M. and Flynn, D.C. Monoclonal Antibodies Directed Against AFAP-110 Recognize Species-Specific and Conserved Epitopes. Hybridoma 18:167-175 (1999) 
3.Qian, Y., Baisden, J.M., Westin E.H., Guappone A.C., Koay T.C. and Flynn, D.C. Src can regulate carboxy terminal interactions with AFAP-110, which influence selfassociation, cell localization and actin filament integrity. Oncogene 16:2185-2195 (1998) 4. Guappone, A.C., Qian, Y., Weimer, T. and Flynn, D.C. An in vivo system for analysis of stable complex formation between Src and AFAP-110 Methods in Cell Science 18:1$11(1996)$

5. Qian, Y., Li, S. and Qi, J. Relationship between hypersensitivity Type I and wheezing with respiratory syncytial virus (RSV) infection. J. Shanghai Sec. Med. University 1990 4(2) 26-31 (English)

6. Qian, Y., and Li, S. The role of basophilous cell in Respiratory syncytial virus infectious asthma. J. Clinical Pediatrics 1990 (Chinese)

7. Qian, Y. and Li S. The role of specific Ig-E in respiratory syncytial virus infectious asthma. J Shanghai Immunology 1990 (Chinese)

\section{Memberships}

Associate Member of American Association for Cancer Research

\section{Honors}

American Association for Cancer Research, Young Investigator Award Recipient 1998 American Association for Cancer Research, Young Investigator Award Recipient 1997 